NATIONAL LABORATORY

MANAGED BY UT-BATTELLE

FOR THE DEPARTMENT OF ENERGY

\title{
Magnetic Field Processing - A Heat Free Heat Treating Method
}

\section{August 8, 2012}

\section{Prepared by}

Gerard (Gerry) M. Ludtka

Distinguished R\&D Staff

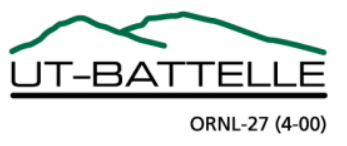




\title{
DOCUMENT AVAILABILITY
}

Reports produced after January 1, 1996, are generally available free via the U.S. Department of Energy (DOE) Information Bridge.

Web site http://www.osti.gov/bridge

Reports produced before January 1, 1996, may be purchased by members of the public from the following source.

\author{
National Technical Information Service \\ 5285 Port Royal Road \\ Springfield, VA 22161 \\ Telephone 703-605-6000 (1-800-553-6847) \\ TDD 703-487-4639 \\ Fax 703-605-6900 \\ E-mail info@ntis.gov \\ Web site http://www.ntis.gov/support/ordernowabout.htm
}

Reports are available to DOE employees, DOE contractors, Energy Technology Data Exchange (ETDE) representatives, and International Nuclear Information System (INIS) representatives from the following source.

Office of Scientific and Technical Information

P.O. Box 62

Oak Ridge, TN 37831

Telephone 865-576-8401

Fax 865-576-5728

E-mail reports@osti.gov

Web site http://www.osti.gov/contact.html

This report was prepared as an account of work sponsored by an agency of the United States Government. Neither the United States Government nor any agency thereof, nor any of their employees, makes any warranty, express or implied, or assumes any legal liability or responsibility for the accuracy, completeness, or usefulness of any information, apparatus, product, or process disclosed, or represents that its use would not infringe privately owned rights. Reference herein to any specific commercial product, process, or service by trade name, trademark, manufacturer, or otherwise, does not necessarily constitute or imply its endorsement, recommendation, or favoring by the United States Government or any agency thereof. The views and opinions of authors expressed herein do not necessarily state or reflect those of the United States Government or any agency thereof. 


\section{Acknowledgements}

This research utilized ORNL's unique and world-class Thermomagnetic Processing Facilities supported by the Office of Energy Efficiency and Renewable Energy, U.S. Department of Energy. Research supported by ORNL's Shared Research Equipment (SHaRE) User Facility, which is sponsored by the Office of Basic Energy Sciences, U.S. Department of Energy. The authors also wish to thank Drs. Thomas Muth and Ryan Dehoff for providing their technical review of this report. 
DOE EERE Advanced Manufacturing Office (Formerly Industrial Technologies Program) CPS Agreement No. 17875

June 30, 2008 to September 30, 2011

\title{
FINAL TECHNICAL REPORT:
}

\section{Magnetic Field Processing - A Heat Free Heat Treating Method}

\author{
Authors \\ Gerard (Gerry) M. Ludtka \\ (865-574-5098, ludtkagm1@ornl.gov) \\ Gail Mackiewicz Ludtka \\ John B. Wilgen \\ Edward A. Kenik \\ Chad M. Parish \\ Orlando Rios \\ J. Hiram Rogers \\ Michelle Manuel (University of Florida) \\ Roger A. Kisner \\ Thomas R. Watkins \\ Bart L. Murphy
}

Date Published: August, 2012

Prepared by

OAK RIDGE NATIONAL LABORATORY

Oak Ridge, Tennessee 37831-6283

managed by

UT-BATTELLE, LLC

for the

U.S. DEPARTMENT OF ENERGY

under contract DE-AC05-00OR22725 



\section{Table of Contents}

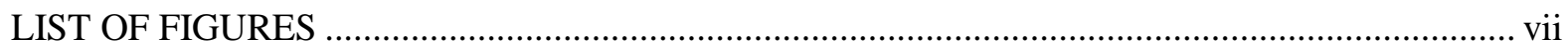

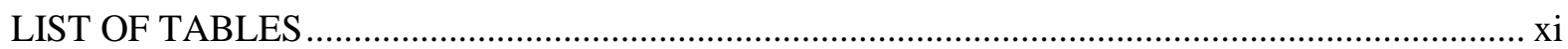

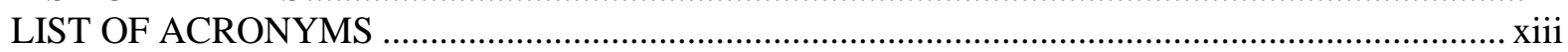

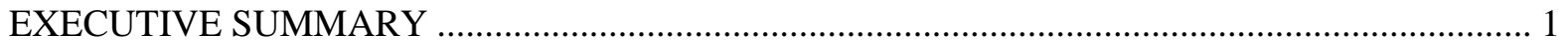

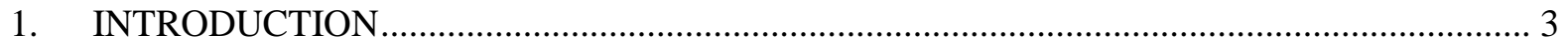

$1.1 \quad$ Description of the Technology ……………………………………………………... 3

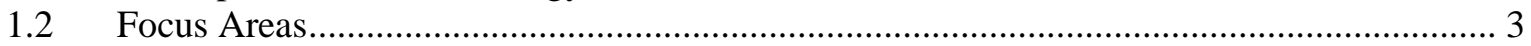

1.3 Broad Potential Applications, Energy Savings, Environmental and Economic Benefits ...... 4

1.4 Commercialization Status .............................................................................................. 5

2. TECHNOLOGY BACKGROUND ……………………………………………………. 7

$2.1 \quad$ High- and Thermomagnetic Processing (HTMP) Technology …………………………… 7

2.2 Electromagnetic Acoustical Transducer (EMAT) Technology ............................................ 8

2.3 Qualifications and Relevant Expertise of Project Team …………………………………. 10

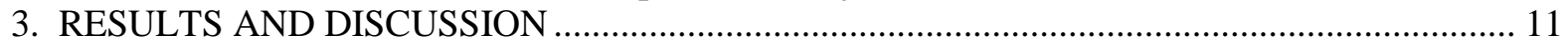

3.1 Heat- And Cryo-Free, Retained Austenite Conversion...................................................... 12

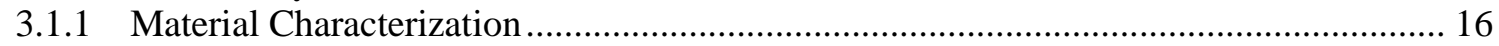

3.2 Superior Strength and Ductility in Steels Via HTMP ....................................................... 18

3.2.1 High Strength Bainitic Alloy...................................................................................... 18

3.3 IMPROVED CASTING HOMOGENEITY AND PROPERTIES VIA EMAT ……………... 29

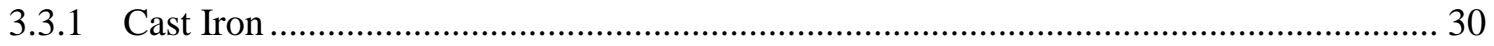

3.3.2 Magnesium with Dysprosia $\left(\mathrm{Dy}_{2} \mathrm{O}_{3}\right)$ Nanoparticle Dispersion EMAT Evaluation ......... 36

3.3.3 EMAT Technology for Developing Wrought Properties in Additional Mg As-cast Alloys

3.4 FACILITATION OF HTMP/EMAT TECHNOLOGY COMMERCIALIZATION ............45

3.4.1 Magnet Design Considerations ……………………………………………………... 45

3.4.2 Commercial Prototype System Designed, Fabricated, Installed, and Operational at ORNL 51

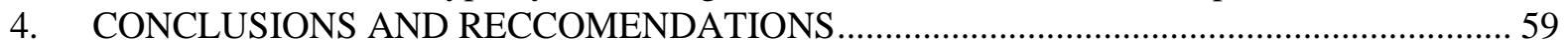

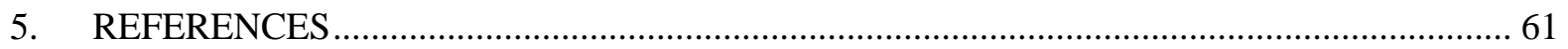




\section{LIST OF FIGURES}

Figure 1. The HTMP innovation will enable major energy savings and material performance breakthroughs for the myriad of markets and applications.

Figure 2. The shift (blues lines) in the phase boundaries (solvus lines) for a 52100 steel under the influence of a 9 Tesla magnetic field as predicted using ThermoCalc after this software was modified to factor in the magnetic free energy term. 8

Figure 3. Induction heating in a high-field magnet, showing the applied $\mathrm{H}$-field of the induction coil, the induced surface current in the sample $(\mathrm{J})$, the static field of the magnet (B), and the resulting $\mathrm{JxB}$ force.

Figure 4. Schematic of the original ASR process showing the various processing conditions and subsequent microstructural constituent volume fractions at each stage. ........................................... 13 Figure 5. Caterpillar's application for the RA conversion thrust of this project was their fuel injector tip advanced design thrust.

Figure 6. Several induction coil designs that were used in initial experiments to develop uniform temperatures across the entire face of the safety razor strip.

Figure 7. A novel spring holding design was employed to keep the razor strip in tension while applying the HTMP process for the thermal transient shown in Fig. 4.....

Figure 8. A quartz environmental tube was employed to surround the razor strip so an inert gas could be blown across the sample while at elevated temperature to prevent oxidation.

Figure 9. An example of the heating uniformity using an elliptical-turn induction coil for the razor strip.

Figure 10. Two parallel flat induction heating coils could not achieve temperature uniformity and so the design in Fig. 9 was used in the batch processing experiments.

Figure 11. (a) SEM image of polished sample - box indicates $30 \square 30 \square \mathrm{m}$ EBSD scan area, (b) EBSD phase map not including chemical information, and (c) Confidence Index map not including chemical information.

Figure 12. (a) Image quality map, (b) Fe X-ray map,(c) Cr X-ray map, and (d) automated partitioning

of the IQ+Fe+Cr maps into four regions for re-indexing.

Figure 13. (a) Re-indexed phase map using chemical information. (b) Confidence index map using chemical information.

Figure 14. Plot depicting the experimentally determined martensite start (Ms) phase transition temperature $\left(238^{\circ} \mathrm{C}\right)$ for a baseline steel composition using high speed quenching dilatometry techniques during high speed helium gas quenching $\left(>200^{\circ} \mathrm{C} / \mathrm{s}\right)$ from the austenite single phase field.

Figure 15. Preliminary metallographic micrographs of a high strength bainitic alloy austenitized and aged for 8 hrs without (Fig. 15 a \& c), the No Field (NF) condition and with (Fig. 15 b \& d) a magnetic field (9T) indicate that magnetic field processing appears to refine the microstructure ((Fig. 15 a vs. b: transverse view) and significantly reduce the banded structure ((Fig $15 \mathrm{c}$ vs. d: longitudinal view) when compared to the no-field conditions.

Figure 16. Charpy V-notch property results for this high strength bainitic alloy out-perform maraging 250 steel.

Figure 17. Scanning Electron Microscopy (SEM) micrographs of the NF (no-field) longitudinal section exhibiting very fine microstructural features (possibly a fine carbide dispersion) for a region that appears bright in the SEM (opposite to perspective in optical micrographs).....

Figure 18. Scanning Electron Microscopy (SEM) micrographs of the alternating contrast region to Figure17 for the NF (no-field) longitudinal section exhibits very fine microstructural features (possibly a fine carbide dispersion) for a region that appears bright in the SEM (opposite to perspective in optical micrographs).....

Figure 19. Scanning Electron Microscopy (SEM) micrographs of the alternating contrast regions in 
the 9T longitudinal section exhibits very fine microstructural features for the bright region that contrasts with a mixture of fine and coarse in the darker regions that were visible in the optical micrographs.

Figure 20. EBSD analyses determination of the grain size distribution in the longitudinal direction for the NF case.

Figure 21. EBSD analyses determination of the grain size distribution in the longitudinal direction for

the $9 \mathrm{~T}$ TMP case.

Figure 22. Scanning transmission BF and HAADF micrographs reveal a dual population of fine carbides in the TMP sample consisting of elongated carbides and very fine and copious spherical carbides.

Figure 23. Elemental spectra obtained in the SEM for the light versus dark contrast regions in the non-TMP sample ID 28.9A (These data were further processed in Fig. 24.) …............................... 27 Figure 24. The elemental spectra data shown in Fig. 23 were analyzed to show the local chemistry differences of the various elements which indicates that the dark areas appear to be enriched in $\mathrm{Si}, \mathrm{V}$, $\mathrm{Cr}$, and $\mathrm{Ni}$.

Figure 25. Microstructural evaluation of the fine microstructure in thermomagnetically processed Carpenter bainitic alloy has discovered a very fine and copious nano-carbide cluster dispersion throughout the microstructure that does not appear in non-thermomagnetically processed samples. . 29 Figure 26. Thermodynamic software calculation predicting phase stabilities and weight fraction of each phase for the GMC010 alloy as a function of temperature to define optimum EMAT processing conditions in the mushy, two-phase liquid plus solid field.....

Figure 27. Experimental setup for inducing radial pulsating forces using a combination of a large axial magnetic field and induction coil to produce the EMAT effect.....

Figure 28. The EMAT processing dramatically altered the appearance of the final solidified microstructures in the cast iron samples as well as significantly improved the hardness of the casting.

Figure 29. BSE images of cast iron as-received and processed under 0, 4.5 and 18 tesla fields,

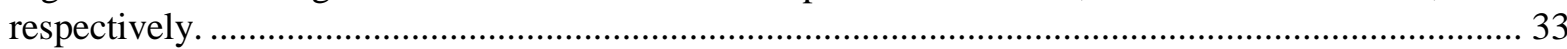

Figure 30. (a) Higher magnification BSE image of cast iron re-cast under 18 tesla field................. 33 Figure 31. Different carbide types (1 and 2) and morphologies (I and II) were observed in the various conditions processed in these EMAT experiments.

Figure 32. . The elongated Carbide 2 phase (darker elongated phase shown in the TEM Bright Field image on left) is shown to be face-centered cubic from these multiple zone axis electron diffraction patterns.

Figure 33. The complex nature of the microstructure that evolved in the cast iron during the $18 \mathrm{~T}$ EMATsolidification experiment is clearly evident (in the TEM bright field image to the left) by the multiple phases (indicated as M [matrix], G, H, I, J, K) clustered in this small region...................... 35 Figure 34. Schematic representing the experimental set-up for EMAT processing of pure Mg with nanoparticles incorporated into the set-up to achieve nano-particle dispersion.................................. 37 Figure 35. Photo of the Mg sample stainless steel crucible after thermo-magnetic processing........... 37 Figure 36. A pure $\mathrm{Mg}$ samples is shown initially in the stainless steel crucible it was prepared in prior tothe EMAT experiments with (a) showing the sample prior to placement of the loose nanoparticles in the assembly and (b) showing the final assembly with a containment lid on top of the crucible in the

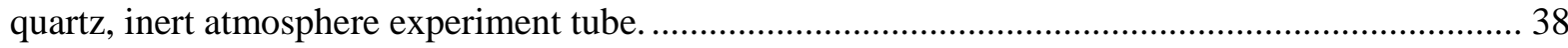
Figure 37. Transmission electron microscopy micrographs of the uniformly dispersed dysprosium

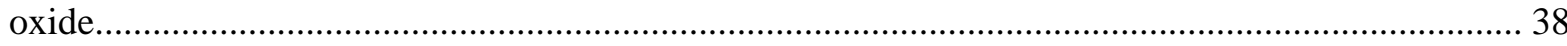
Figure 38. BF (middle two images) and DF (two right hand side images) images of one location of the EMAT processed $\mathrm{Mg}$ ingot clearly showing the uniformly distributed dysprosia nanoparticles

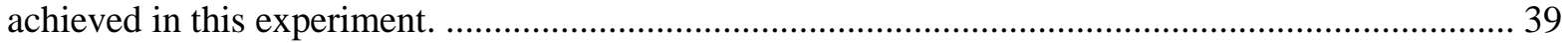
Figure 39. A second location in this cross section showed more evidence of the finely dispersed

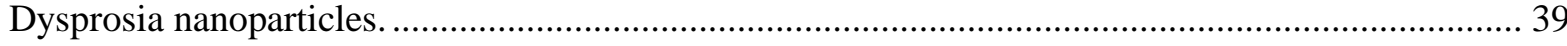


Figure 40. Energy Dispersive X-ray Spectroscopy (EDS) characterization clearly identified these agglomerated nanoparticles as dysprosia.

Figure 41. The HAADF (high angle annular dark field) STEM technique (which is atomic number, $\mathrm{Z}$,sensitive) clearly shows the contrast between the lower $\mathrm{Z} \mathrm{Mg}$ matrix material and the higher Zbased Dysprosia nanoparticles.

Figure 42. One series of EMAT experiments stopped the EMAT effect by turning off the induction power.

Figure 43. The second series of EMAT experiments continued the EMAT at a reduced induction power supply setting until solidification was completed.

Figure 44. The recent EMAT experiments defined in Tables 10 and 11 after being EDM cut in half. 44 Figure 45. A typical example of a Mg ingot after it had been EMAT processed and EDM cut in half.

Figure 46. Top view and cross-section view of a single-layer helically wound induction heating coil showing the axial alignment of the 9 Tesla magnetic (B) field.

Figure 47. Total radial strain as a function of frequency for a 2.75" diameter coil, with 2000 amp peak coil current (1410 A(rms)), and a 9T magnetic field

Figure 48. Resonant magnification as a function of frequency for various normalized damping factors.

Figure 49. Image of the induction coil extracted from a design drawing of the induction insert for the 8 " vertical magnet.

Figure 50. The inner main coil of the new commercial prototype 9-T, 8-inch diameter warm bore superconducting magnet system was fabricated and tested by American Magnetics, Inc. in Oak Ridge, TN.

Figure 51. Views (a), (b), \& (c) show the vessel for the 8-inch diameter warm-bore, 9-T superconducting magnet system containing (d) the main superconducting solenoid coil with the quenching resistors exposed.

Figure 52. Photos (a) \& (b) show the delivery and placement of the commercial scale frame that will beintegrated with ORNL's 8-inch diameter bore, 9T superconducting magnet, shown here in (c) an artist's rendition (d) completed magnet.

Figure 53. The world's first commercial prototype TMP/EMAT processing system is operational now at ORNL and has been used for experimental trials on industrial-scale components.

Figure 54. The ORNL commercial prototype HTMP/EMAT system with working platform installed.

Figure 55. ORNL's multiple HTMP/EMAT systems represent the world's most advanced systems for conducting high magnetic field experiments from small prototype to large scale commercial samples. 



\section{LIST OF TABLES}

Table 1. Projected (by 2025) annual energy savings, CO2 reduction, and cost savings of HMFP applications

Table 2. Chemistry of super bainitic alloy (Heat 010964)

Table 3. Mechanical property results for this high strength bainitic alloy demonstrate that HTMP processing produces unprecedented, and simultaneous improvements in both yield strength and ductility

Table 4 SEM-EDS characterization of the composition of the various phases present in the 18-T

EMAT processed sample

Table 5. SEM/BSE quantitative determination of phase volume fractions for several experimental conditions.

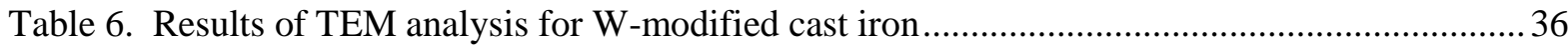

Table 7. Definition of Mg EMAT experiment sample identification and goal. ................................. 41

Table 8. Summary of Mg EMAT experiment control parameters for each condition.......................... 42 



\section{LIST OF ACRONYMS}

\begin{tabular}{|c|c|}
\hline AMO & Advanced Manufacturing Office \\
\hline AMI & American Magnetics Inc. \\
\hline ASR & American Safety Razor \\
\hline ATM & Ajax-Tocco Magnethermic \\
\hline $\mathrm{B}$ & Magnetic Flux Density \\
\hline $\mathrm{BCC}$ & Body Centered Cubic \\
\hline $\mathrm{BCT}$ & Body Centered Tetragonal \\
\hline $\mathrm{BF}$ & Bright Field \\
\hline BSE & Backscattered Electron \\
\hline BTU & British Thermal Unit \\
\hline $\mathrm{CC}$ & Cubic Centimeter \\
\hline CCT & Continuous Cooling Transformation \\
\hline $\mathrm{CI}$ & Confidence Interval \\
\hline DOE & Department Of Energy \\
\hline EBSD & Electron Backscatter Diffraction \\
\hline EDM & Electro Discharge Machining \\
\hline EDS & Electron Dispersion Spectroscopy \\
\hline EIP & Energy Intensive Processes \\
\hline EERE & Office of Energy Efficiency and Renewable Energy \\
\hline EMAT & Electro-magnetic Acoustic Transducer \\
\hline EMPA-WDS & Electron Microprobe Analysis-Wavelength Dispersive Spectroscopy \\
\hline FCC & Face Centered Cubic \\
\hline FIB & Focused Ion Beam \\
\hline FOLZ & First Order Laue Zone \\
\hline GHG & Greenhouse Gasses \\
\hline GM & Gram \\
\hline GPA & Gigapascal \\
\hline GPM & Gallons per Minute \\
\hline GPRA & Government Performance and Results Act \\
\hline $\mathrm{H}$ & Magnetic Intensity \\
\hline HAADF & High Angle Annular Dark Field \\
\hline HMFP & High Magnetic Field Processing \\
\hline HTMP & High and Thermal Magnetic Processing \\
\hline ID & Inner Diameter \\
\hline IPF & Inverse Pole Figure \\
\hline ITP & Industrial Technologies Program \\
\hline IQ & Image Quality \\
\hline $\mathrm{J}$ & Surface Current \\
\hline $\mathrm{KHz}$ & Kilohertz \\
\hline $\mathrm{kW}$ & Kilowatt \\
\hline M & Magnetization \\
\hline MM & Million metric tonnes \\
\hline n.d. & Not Detected \\
\hline NDI & Nodular Ductile Iron \\
\hline NF & No Field \\
\hline NHMFL & National High Magnetic Field Laboratory \\
\hline OD & Outer Diameter \\
\hline ORNL & Oak Ridge National Laboratory \\
\hline PSI & Pounds per Square Inch \\
\hline
\end{tabular}




$\begin{array}{ll}\text { Q\&T } & \text { Quench and Temper } \\ \text { QUAD } & \text { Quadrillion }\left(1 \text { Quad }=10^{15}\right) \text { Btus } \\ \text { RA } & \text { Retained Austenite } \\ \text { SC } & \text { Superconducting } \\ \text { SEM } & \text { Scanning Electron Microscope } \\ \text { STEM } & \text { Scanning Transmission Electron Microscope } \\ \text { T } & \text { Temperature } \\ \text { T } & \text { Tesla } \\ \text { TEM } & \text { Transmission Electron Microscope } \\ \text { UTS } & \text { Ultimate Tensile Strength } \\ \text { VHN } & \text { Vickers Hardness Number } \\ \text { XRD } & \text { X-Ray Diffraction } \\ \text { YS } & \text { Yield Strength }\end{array}$




\section{EXECUTIVE SUMMARY}

The High and Thermal Magnetic Processing/Electro-magnetic Acoustic Transducer (HTMP/EMAT) technology has been shown to be an enabling disruptive materials processing technology, that can achieve significant improvements in microstructure and consequently material performance beyond that achievable through conventional processing, and will lead to the next generation of advanced performance structural and functional materials.

HTMP exposure increased the reaction kinetics enabling refinement of microstructural features such as finer martensite lath size, and finer, more copious, homogeneous dispersions of strengthening carbides leading to combined strength and toughness improvements in bainitic steels.

When induction heating is applied in a high magnetic field environment, the induction heating coil is configured so that high intensity acoustic/ultrasonic treatment occurs naturally. The configuration results in a highly effective electromagnetic acoustical transducer (EMAT). HTMP combined with applying high-field EMAT, produce a non-contact ultrasonic treatment that can be used to process metal alloys in either the liquid state resulting in significant microstructural changes over conventional processing. Proof-of-principle experiments on cast irons resulted in homogeneous microstructures in small castings along with improved casting surface appearance. The experiment showed that by exposing liquid metal to the non-contact acoustic/ultrasonic processing technology developed using HMFP/EMAT wrought-like microstructures were developed in cast components.

This Energy Intensive Processes (EIP) project sponsored by the DOE EERE Advanced Manufacturing Office (AMO) demonstrated the following:

- The reduction of retained austenite in high carbon/high alloy steels with an ambient temperature HTMP process, replacing either a cryogenic or double tempering thermal process normally employed to accomplish retained austenite transformation. HTMP can be described as a "heat-free", heat treating technology. Lower residual stresses in HTMP treated materials are anticipated since no thermal strains are involved in inducing the transformation of retained austenite to martensite in high alloy steel.

- The simultaneous increase of $12 \%$ in yield strength and $22 \%$ in impact energy in a bainitic alloy using HTMP processing. This is a major breakthrough in materials processing for the next generation of structural materials since conventionally processed materials show a reduction in impact toughness with an increase in yield strength. HTMP is a new paradigm to beneficially increase both yield strength and impact energy absorption simultaneously.

- HTMP processing refined both the martensite lath population and the carbide dispersion in a bainitic steel alloy during Gausstempering ${ }^{\mathrm{TM}, 1}$. The refinement was believed to be responsible for the simultaneous increase in strength and toughness. Hence, HTMP significantly impacts nucleation and growth phenomenon.

- HTMP processing developed comparable ultimate tensile strength and twice the impact energy in a lower cost, lower alloy content ( $\sim 8 \%$ alloy content) steel, compared to highly alloyed, (31\% alloy elements involving $\mathrm{Ni}, \mathrm{Co}$, and Mo) 250-grade margining steel. Future low-cost HTMP alloys appear viable that will exceed the structural performance of highly alloyed materials that are conventionally processed. This economic benefit will enable U.S. industry to reduce cost (better more competitive worldwide) while maintaining or exceeding current performance.

1 Gausstemper ${ }^{\mathrm{TM}}$ is an ORNL trademark for the process of magnetically processing a material in a magnetic field. 
- EMAT processed cast iron exhibits significantly higher hardness (by $51 \%$ for a $9 \mathrm{~T}$ condition) than a no-field processed sample.

- EMAT produced microstructures in cast iron resulted in an unique graphite nodule morphology, a modified pearlite content, and unique carbide types, that formed during solidification and cooling.

- EMAT processed nanoparticle dispersions in Mg resulted in a very fine, unagglomerated distribution of the nanoparticles in the magnesium matrix. This provides a breakthrough technology to make the next generation of nanocomposite reinforced metal matrix composites which can be tailored to exhibit higher strength and ductility combinations not only at ambient temperature but at elevated temperatures where enhanced creep resistance is observed. This technology can be extended to non-metallic systems as long as a conductive containment vessel is utilized that will convey the EMAT signal into the material of interest during processing.

- Facilitation of HTMP/EMAT technology commercialization, throughout the course of the project. Two technology limitations were overcome that led to the first generation commercial prototype HTMP/EMAT system which was initially installed at ORNL.

$\circ$ The effort, downtime and expense of regularly replacing liquid cryogens were identified as a major barrier to commercialization. A recondensing cryocooler system for liquid helium was designed, built and installed on an operating system.

- A second barrier to commercialization was identified relating to the EMAT effect. When lower frequency was employed at relatively modest $(>2 \mathrm{KW})$ induction power levels, the EMAT effect caused the superconducting magnet to quench, lose cryogens and no longer be superconducting. Industrial partner AMI implemented several proprietary internal system design changes to make the superconducting magnet immune to EMAT-induced quenches.

- During this project, a production-scale equipment design to enable commercialization of HMFP technology was conceptualized, designed, fabricated, and installed at ORNL as a commercial-scale prototype system. The commercial-scale prototype was comprised of an 8inch diameter, warm-bore superconducting magnet and a $220 \mathrm{KW}$, dual-frequency $(10 \mathrm{KHz}$ and $30 \mathrm{KHz}$ ) induction power supply with 75 gallon per minute (gpm) polymer quenching capability. The material handling through the magnet bore included a sample handling system capable of an extraction force of 2,000 pounds and the integrated quench assembly that allowed rotation of the industrial component at $30 \mathrm{~Hz}$. The rotation during quenching promotes uniform heat transfer. Currently, negotiations are underway for the technology commercialization licensing of the HTMP/EMAT equipment. 


\section{INTRODUCTION}

\subsection{Description of the Technology}

High Magnetic Field Processing (HMFP) is a pivotal and transformational materials processing technology that can be applied across a broad and diverse spectrum of materials to achieve comparable and/or superior materials properties at significantly reduced energy- and processing-costs for high-energy consuming industries. HMFP is superior to conventional thermal processing methods, and has the potential to achieve or surpass conventionally achieved properties by eliminating and/or minimizing conventional thermal processing steps. In some cases room temperature treatment, can be performed resulting in enhanced properties. Energy savings from implementation of HMFP comes from three facets of magnetic processing: (1) magnetic processing is a non-thermal process, (2) thermal processes can either be eliminated or process times dramatically reduced due to enhanced transformation kinetics, and (3) superconducting (SC) magnets are employed. (SC magnets require no energy once they achieve full field and operate in persistent mode.)

ORNL prior proof-of-principle efforts on HMFP have demonstrated and documented the following properties and advantages of ultrahigh magnetic field processing of ferromagnetic materials in the solid-state:

- Dramatic shifts in phase equilibria and enhanced phase solubilities. New (3-D) phase diagrams which include magnetic fields, opening up new avenues for major alloy development activities. Additional "new" phases can now exist in "equilibrium".

- Increased phase transformation kinetics. Benefits include major energy savings, enhanced process flexibility, and improved efficiency.

- The production of novel microstructures with enhanced performance. The development of currently "impossible" microstructures with unique properties is now possible and is applicable to bulk nanomaterial design efforts (magnetically cycling about a transformation temperature for grain refinement while still being isothermal).

- A totally new and unique processing (HMFP) methodology to design and engineer new materials and processing approaches. The technology enables enhanced "Materials by Design" flexibility and allows residual stress relief for component life extension and improved manufacturability.

\subsection{Focus Areas}

The primary objectives identified for this project were to:

$\checkmark$ Demonstrate batch HMFP continuous cooling treatment of ferrous materials with industrial significance to reduce costs associated with the conventional, high temperature (thermal) processing treatments that use extended hold-times, and cryogenic processing. The objective is to develop microstructures that meet specified mechanical properties using a lower cost treatment.

$\checkmark$ Investigate the application of HMFP processing in a non-conventional heat treatment process (meaning not quenched and tempered [Q\&T] for a high-performance ferrous alloy such as a bainite-forming steel and,

$\checkmark$ Extend HMFP from solid state applications to solidification processes (casting, welding) via ORNL Electro-magnetic Acoustic Transducer (EMAT) -HMFP technology. 


\subsection{Broad Potential Applications, Energy Savings, Environmental and Economic Benefits}

Many industrial and manufacturing sectors of the U.S. domestic market (Fig.1) can be impacted by the materials and manufacturing advances enabled by HMFP.

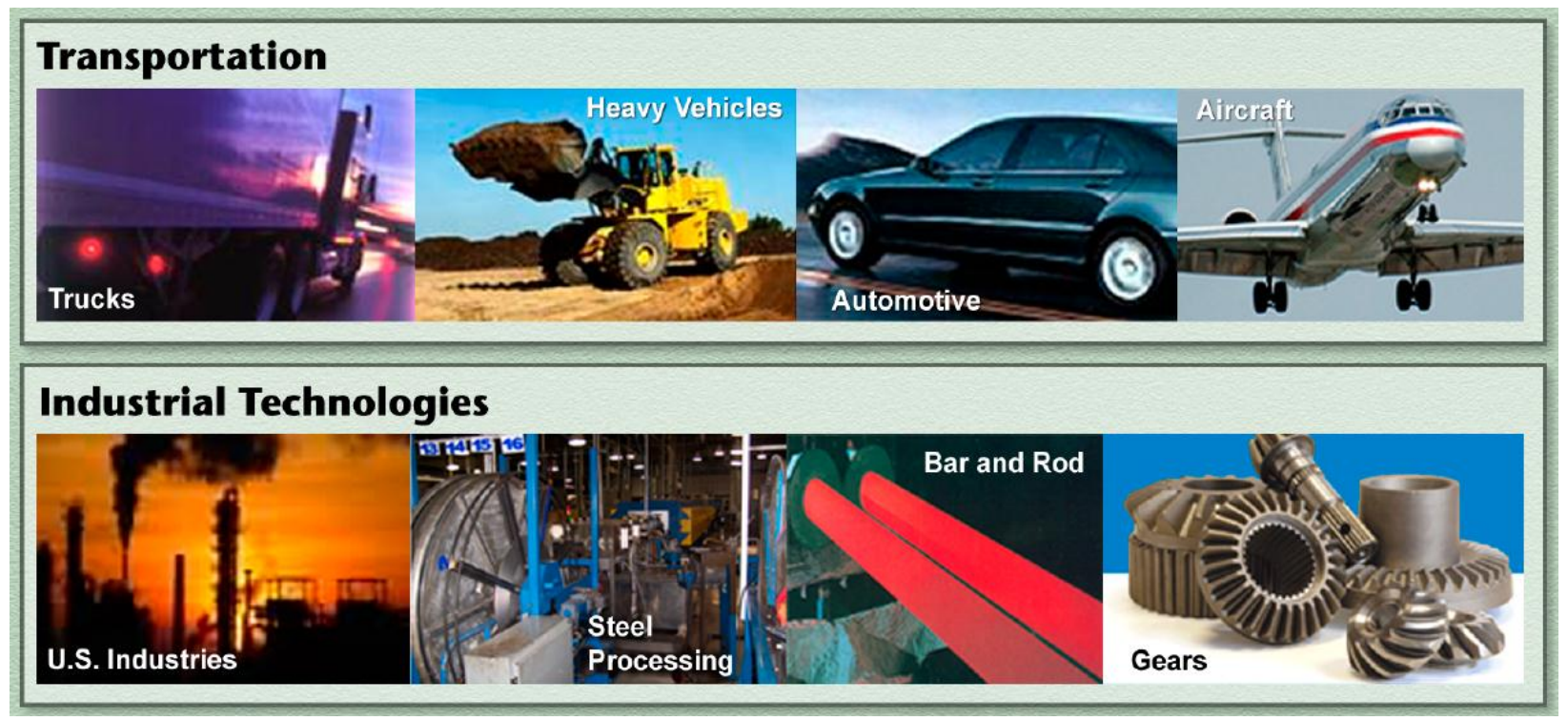

Figure 1. The HTMP innovation will enable major energy savings and material performance breakthroughs for the myriad of markets and applications.

The US industrial sector consumes approximately one-third of US energy (110.3 quadrillion Btu(Quads)) (2004 data), representing 37\% of the US natural gas demand, 29\% of US electricity demand, and is responsible for $30 \%$ of US greenhouse gas (GHG) emissions. US process heattreating consumes 5,780T Btu/year (based on 2002 data) and has a carbon footprint of >311Million Metric Tons of Carbon Equivalent (MMTCE) associated with fossil fuel consumption/year. In addition, US Manufacturing Industry consumes approximately 16.2 quadrillion Btu per year. Therefore, a transformational process technology such as high magnetic field processing can be pivotal in achieving the energy efficiencies and cost savings for the US heat treating and secondary tier manufacturing industries. For example, if HMFP only eliminated one normalization heat treatment step of steels for bar and rod product, the annual cost savings would be approximately $\$ 945$ million/yr., with an energy savings of approximately 70 trillion Btu per year based on the total tonnage of US bar product of 7 million tons/year. These cost savings are rather significant since costs for natural gas (used in heat treat processing) have escalated $400 \%$ over the past six years for the US Steel Industry, rising from \$50B/yr. to \$200B/yr (AISI 2006 Annual Report). Consequently, for just this one heat treat operation, magnetic processing has the potential for reducing energy consumption by $70 \mathrm{~T}$ BTU/year and $\mathrm{CO}_{2}$ by $\sim 0.3 \mathrm{MM} /$ year. As this technology matures, there will be increased energy savings from other applications.

Table 1 summarizes the energy and environmental savings that were estimated for three possible industrial processing applications that could be impacted with the commercialization and implementation of HMFP technology (calculated using DOE's GRPRA analysis software program along with other estimates). In some other applications where ambient temperature processing could be used to replace some current high temperature processing, energy savings could be even more 
significant. Additional and comparable energy and cost savings would be expected for implementing HMFP for the time-consuming spheroidization process used on some steels.

Table 1. Projected (by 2025) annual energy savings, CO2 reduction, and cost savings of HMFP applications.

\begin{tabular}{|c|c|c|c|}
\hline Impact area & $\begin{array}{c}\text { Energy savings } \\
\text { (trillion } \\
\text { BTU/yr.) }\end{array}$ & $\begin{array}{c}\mathrm{CO}_{2} \text { reduction } \\
\text { (million metric } \\
\text { tonnes/yr. }\end{array}$ & $\begin{array}{c}\text { Cost savings } \\
(\$ M / y r .)\end{array}$ \\
\hline $\begin{array}{l}\text { Normalization Heat Treatment } \\
\text { (Bar \& Rod) }\end{array}$ & 70 & $\sim 0.33$ & 945 \\
\hline $\begin{array}{ll}\text { Spheroidization } & \text { Heat } \\
\text { Treatment (Bar \& Rod) } & \end{array}$ & 70 & $\sim 0.33$ & 945 \\
\hline Casting & 231.5 & $\sim 1.0$ & 3,100 \\
\hline Total Impact & 371.5 & $\sim 1.66$ & 4,990 \\
\hline
\end{tabular}

The project focused on energy intensive industries such as the U.S. heat treating industry, and its associated manufacturing industries (heavy equipment and heavy transportation, castings, forgings, joining industries, etc.). However, this technology is also applicable to the aluminum, steel, pulp and paper, and light transportation manufacturing industries, and will enable a more competitive edge by reducing thermal processing costs and energy consumption, while providing environmental benefits.

One project activity also focused on the use of HMFP for casting/solidification applications whereby a non-contact acoustic/ultrasonic processing (electromagnetic acoustic transducer (EMAT)) approach incorporating HMFP was pursued to develop homogeneous, non-dendritic cast microstructures in a ferrous alloy. The treatment achieved wrought alloy performance in a casting. Conceptually this EMAT technology could be implemented for all casting industries including the aluminum, steel, and broader metal casting industries. The major energy savings would be for near-net shape casting/fabrication, whereby the elimination or significant reduction of high-temperature homogenization, deformation processing, and post process thermal treatments could be realized.

The basis for these calculations began with the complete energy consumption values for the aluminum, steel, and metal casting industries that are 0.4, 1.8, and 2.43 Quads per year, respectively ( 1 Quad $=10^{15}$ BTUs), considering all primary and secondary processing operations that include casting and forming operations. Assuming this EMAT technology will impact all of these industries and the total energy consumption for these three sectors is 4.63 Quads, conservatively, implementation of the EMAT HMFP technology could conceivably reduce the total energy consumption during primary and secondary processing by $5 \%$ or 231.5 trillion Btu annually. Energy savings of this magnitude would be a major driving force for EMAT technology to become pervasive in the primary metal casting industries by the year 2025. These energy savings would be reflected in annual cost savings of $\$ 3.1 \mathrm{~B}$ and a reduction of $\mathrm{CO}_{2}$ emissions by $1.0 \mathrm{MMT} / \mathrm{year}$.

\subsection{COMMERCIALIZATION STATUS}

During this project, a production-scale equipment design to enable commercialization of HMFP technology was conceptualized, designed, fabricated, and installed at ORNL as a commercial-scale prototype system. This milestone was accomplished through the collaboration of the industrial partners Ajax TOCCO Magnethermic (ATM) and American Magnetics Inc. (AMI) who are induction heating system and superconducting magnet manufacturers respectively. This acceleration of commercialization status was enhanced by having these equipment manufacturers as part of this project team throughout the entire effort in evaluating end-user application end needs and suggesting 
potential commercial H\&TMP system designs for their specific applications for possible procurement after this investigation.

The commercial-scale prototype was comprised of an 8-inch diameter, warm-bore superconducting magnet and a $220 \mathrm{KW}$, dual-frequency $(10 \mathrm{KHz}$ and $30 \mathrm{KHz})$ induction power supply with a $75 \mathrm{gpm}$ polymer quenching unit. The system included a sample handling system, capable of an extraction force of 2,000 pounds. The integrated quench assembly could rotate the industrial component at 30 $\mathrm{Hz}$ during the quenching operation to promote uniform heat transfer conditions. The inner bore of the superconducting magnet had an internal, water-cooled jacket to prevent accidental heating by the induction heating coil which might result in a magnet quench (loss of superconducting operating state). In addition, the superconducting magnet had several unique, proprietary internal modifications made to mitigate the oscillatory forces from the EMAT effect that might otherwise induce a magnet quench. Of significant relevance for economical commercial implementation of this technology was the integration of a cryogen recondensing system to the superconducting magnet assembly which eliminated the need to periodically replace cryogens. This system is described and shown in great detail later in this report along with several of the design calculations that were conducted to optimize the performance of the magnet and the induction heating system.

Currently, negotiations are underway for the technology commercialization licensing of the HTMP/EMAT equipment. As of this report, several companies have approached the equipment manufacturers for design and procurement quotes for production-rate capable, commercial systems for incorporation into their industrial facilities. Of particular relevance is a next generation, production-rate-capable (up to 300 six-pound gears per hour) HTMP commercial system being designed by Ajax TOCCO and AMI to be flexible in handling multiple component types for a large, international company. 


\section{TECHNOLOGY BACKGROUND}

\subsection{HIGH- AND THERMOMAGNETIC PROCESSING (HTMP) TECHNOLOGY}

An applied magnetic field has a direct thermodynamic influence on the chemical potential (Gibbs Free Energy) of the various phases in a material. This is clearly shown in the following equation for calculating the Gibbs Free Energy change for the ferrite $(\alpha)$, to austenite $(\gamma)$, phase transformation in a Fe-C binary alloy, in the presence of an applied magnetic field:

$$
\Delta \mathrm{GFe}_{\mathrm{Fe}} \gamma \rightarrow \alpha=\mathrm{RT}\left[\ln \left(\mathrm{aFe}^{\gamma}\right)-\ln \left(\mathrm{aFe}^{\alpha}\right)\right]+\int_{0} \mathrm{H}\left(\mathrm{MFe}^{\gamma}-\mathrm{MFe}^{\alpha}\right) \mathrm{dH} \quad \text { (Equation 1) }
$$

$\mathrm{M}$ and $\mathrm{H}$ are defined as the magnetization and magnetic intensity, respectively. The magnetic effect will be manifested in the Fe-C binary equilibrium phase diagram as a shift in the transformation temperatures of the various phases as well as changes in the solubility limits (solvus lines) of the various phases.

Thermodynamic calculations based on Gibbs Free Energy in the M-H-T (Magnetization-Magnetic Intensity-Temperature) magnetic equation of state space ( $[\mathrm{M}, \mathrm{H}, \mathrm{T}]=0$ rather than the conventional P-V-T [pressure-volume-temperature] space to calculate "conventional" phase diagrams) demonstrate that significantly different phase equilibria may result for material systems where the product and parent phases exhibit different magnetization responses. The calculations (based on equation 1) show that the Gibbs Free Energy is changed by a factor equal to $-\mathrm{MdH}$ where $\mathrm{M}$ and $\mathrm{H}$ (for $\mathrm{B}=\mu_{0}[\mathrm{H}+\mathrm{M}]$ where $\mathrm{B}$ and $\mu_{0}$ are the magnetic flux density and magnetic permeability respectively) are the magnetization and applied field strength, respectively. Since all materials have some form of ferromagnetism or paramagnetism, magnetic field processing is directly applicable to a broad range of materials by influencing phase stability and phase transformations in an alloy or compound. The ability to selectively control microstructural stability and alter transformation kinetics through appropriate selection of the magnetic field strength promises to provide a very robust mechanism to develop and tailor enhanced microstructures (even nanostructures through accelerated kinetics) with superior properties for a broad spectrum of materials.

An example of the shift in phase equilibria for a standard 52100 steel alloy under the influence of a 9 Tesla magnetic field is shown in Figure 2 (the predicted phase diagram using ThermoCalc) where the "invariant" eutectoid temperature and composition are shown to shift to a higher temperature and higher carbon solubility under the influence of the magnetic field. Because Equation 1 shows a linear response to magnetic field strength (due to the integral over "dH"), magnetic fields can continuously vary these "invariants" with increasing magnetic field strength. Although not shown in the phase diagram below, the Fe-C system also exhibits a Curie temperature for all of the known carbides that can form in steels. Carbide formation will also be dramatically impacted relative to carbide's Curie temperature. Predicted phase diagrams were developed for all of the various alloys to be pursued in this endeavor to guide the experimentation, reducing the need for costly Edisonian approaches. 


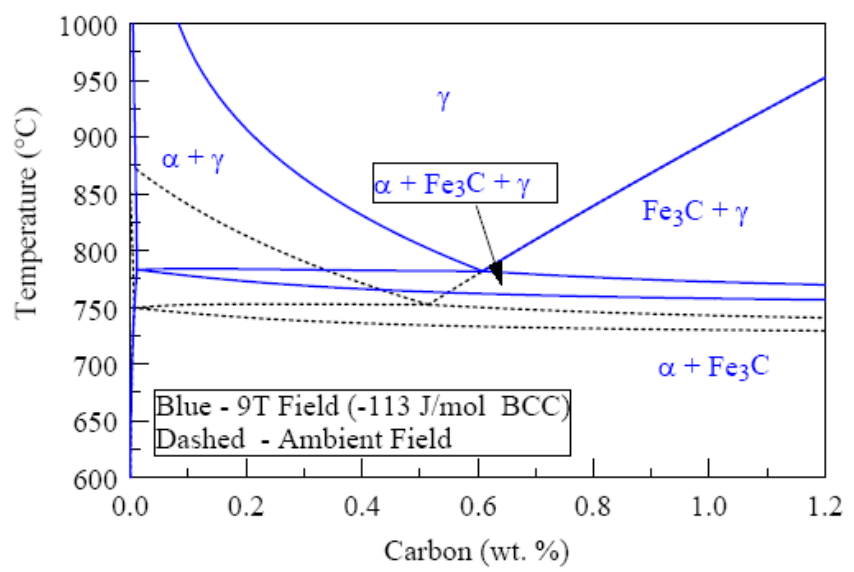

Figure 2. The shift (blues lines) in the phase boundaries (solvus lines) for a 52100 steel under the influence of a 9 Tesla magnetic field as predicted using ThermoCalc after this software was modified to factor in the magnetic free energy term.

This innovative technology results in large process energy savings in three ways: (1) magnetic processing by itself is a non-thermal process, (2) thermal processes, if needed, can either be eliminated or process times and temperatures dramatically reduced, and (3) use of energy-efficient superconducting magnet technology requires no energy to maintain a magnetic field once the magnet is in persistent mode.

Further reduction in energy use with this technology is achieved by coupling induction heating as the thermal source when needed. The energy saving occurs through: (1) significantly shorter processing times (minutes rather than hours) than required for conventional processing methods, (2) equipment energy consumption is significantly less with operational efficiencies on the order of $80 \%$, and (3) induction heating coupled with HTMP provides the opportunity to uniquely optimize performance of both the surface and core microstructures in a component, resulting in higher power density.

\subsection{ELECTROMAGNETIC ACOUSTICAL TRANSDUCER (EMAT) TECHNOLOGY}

When induction heating is applied in a high magnetic field environment, the induction heating coil is configured in such a way that high intensity acoustic/ultrasonic treatment occurs naturally. The resulting configuration is a highly effective electromagnetic acoustical transducer (EMAT). This approach is unique because the magnetic field strength of the high-field magnet can greatly exceed that used in a typical EMAT device. As a consequence, the interaction of a high surface current density (induced via induction heating) with the steady-state high magnet field, results in an especially effective method for creating a high energy density acoustic environment. The exceptionally high energy efficiency of the resulting electromagnetic transducer is due to the use of the high magnetic field, which greatly reduces the current needed to achieve the same acoustic pressure. EMAT produced in this way provides an efficient non-contact method for applying highintensity acoustic/ultrasonic energy to molten and solidified metals. Furthermore, the applied ultrasonic excitation can be uniformly distributed over most of the surface of the metal sample.

If the axis of a helical induction heating coil is aligned with the static magnetic field of a high-field magnet, the azimuthally-directed surface current induced in the process metal interacts with the static field of the magnet. The result is a large oscillatory electromagnetic force, or pressure, that acts directly on the metal surface, at the induction heating frequency. In cylindrical coordinates, the force is in the radial direction. Figure 3 shows the applied H-field of the induction coil, the induced 
azimuthally-directed surface current (J), the static externally applied magnetic field (B), and the resulting radially-directed electromagnetic force $(\mathrm{J} \times \mathrm{B})$. The acoustic driving force is bi-directional, alternately compressing and stretching (tensioning) the sample in the radial direction. In liquids, the later leads to cavitation that can be very beneficial for ultrasonic processing of the melt phase. The acoustic pressure can be quite substantial since both the induced surface current and the static magnetic field are quite large.

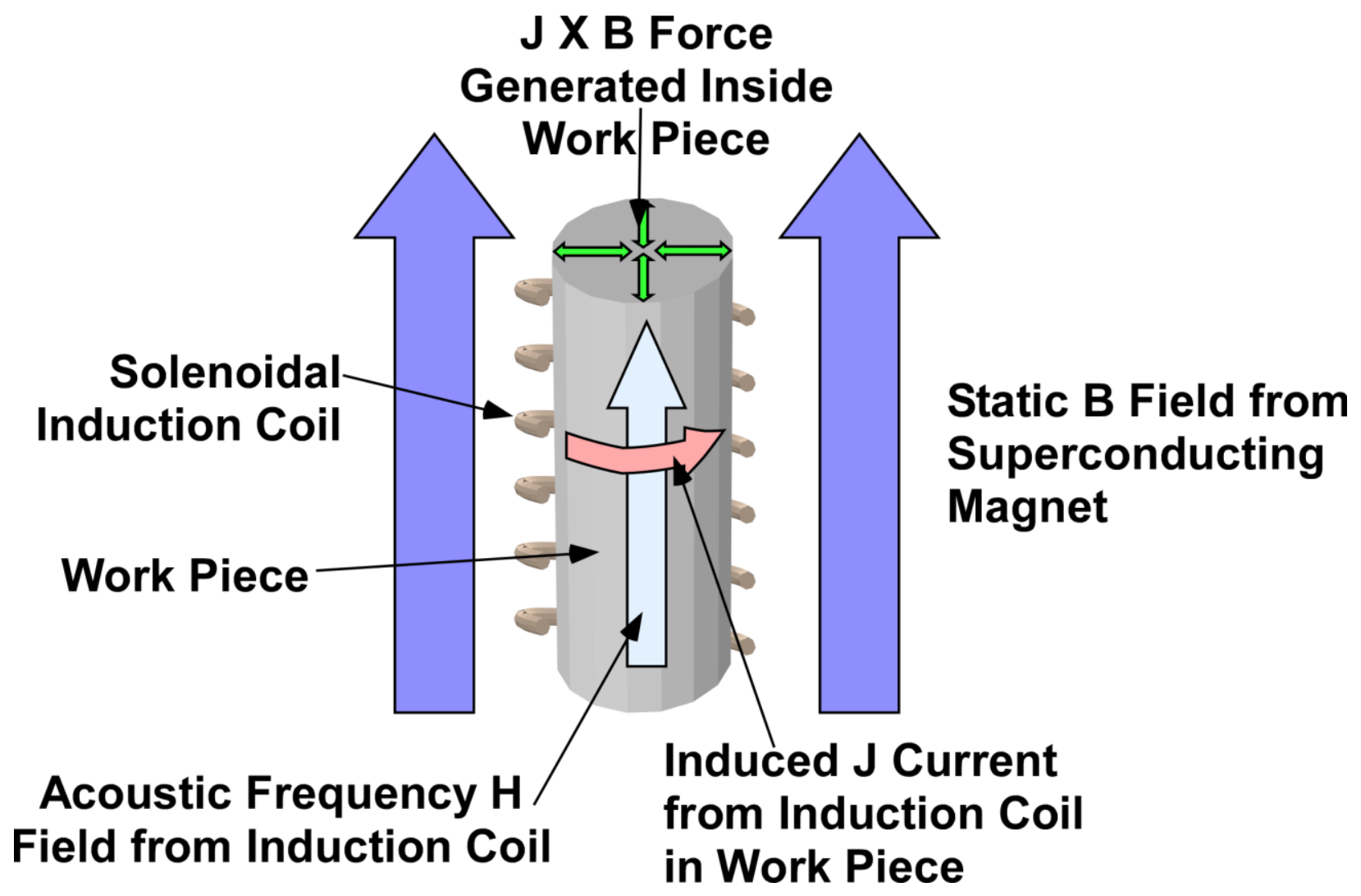

Figure 3. Induction heating in a high-field magnet, showing the applied $\mathrm{H}$-field of the induction coil, the induced surface current in the sample $(\mathrm{J})$, the static field of the magnet $(\mathrm{B})$, and the resulting $\mathrm{JxB}$ force.

The $\mathrm{H}$-field of the induction heating coil is insignificant $(\mathrm{H} \ll \mathrm{B})$ by comparison with the static Bfield of the high-field magnet.

The effectiveness of acoustical excitation can be enhanced if the frequency happens to coincide with a natural resonant frequency of the sample. Because of the large mismatch in the acoustic impedance at a material-air interface, most of the acoustic energy can be trapped within the sample and the sample container, forming an acoustical resonator. If the acoustic drive frequency is chosen to match a natural resonant frequency of the sample, then the peak acoustic pressure in the resonator can be enhanced by a factor that is equal to the quality factor of the resonator. Quality factors for liquid metal columns with large length-to-diameter ratios are expected to be in the range of 10-100, ${ }^{1}$ although a somewhat smaller quality factor might be anticipated for a typical experimental configuration. Due consideration should be given to the potentially advantageous use of acoustical resonances.

Using this high-field EMAT method, non-contacting ultrasonic treatment can be applied to the processing of metal alloys in either the solid or liquid phase. Molten metals can be contained in non- 
metallic ceramic crucibles that are readily penetrated by the electromagnetic induction fields. Proofof-principle experiments have resulted in more homogeneous microstructures in small castings along with improved casting surface appearance. Therefore, our pioneering experiments show that this noncontact acoustic/ultrasonic processing technology developed using a high magnetic field in conjunction with induction heating has significant promise in impacting commercial casting applications with the potential to develop wrought-like microstructures in as-cast components.

\subsection{QUALIFICATIONS AND RELEVANT EXPERTISE OF THE PROJECT TEAM}

The success-focused project team for this project integrated the technology and original equipment pioneer/innovator staff from ORNL with four major innovative-technology end-user organizations; Carpenter Technologies, DuraBar, Caterpillar, and American Safety Razor. The team was further enhanced by equipment manufacturers, Ajax TOCCO and AMI, who were involved throughout the entire effort in evaluating end-user applications and potential commercial HTMP system designs. This has been a proven teaming concept for successful HTMP technology evaluation and commercialization pursuits, as demonstrated in the recent EERE Advanced Manufacturing Office EIP Eaton-led project (CPS Agreement Number: 18300) involving ORNL, Ajax TOCCO, and AMI that has resulted in the initial design concepts being formulated for a HTMP system rated for 300 sixpound gears per hour. The EIP team led by ORNL won an R\&D 100 Award in 2009 for advancing HTMP from a research curiosity to a commercially-viable technology demonstrated on real industrial components and protected by multiple U.S. patents.

ORNL has significant experience developing and commercializing innovative technologies as it has won over 160 R\&D 100 awards. The awards are indicative of the focus the organization has taken in moving innovative concepts in materials and technologies through the proof-of-principle and demonstration phases, to implementation in the marketplace. Similarly, Ajax TOCCO and AMI build and deliver their unique and revolutionary systems throughout the worldwide marketplace as they are world-class technology leaders in their specific markets. 


\section{RESULTS AND DISCUSSION}

Four activities were pursued in this project; three high-impact, industrially-relevant technical applications and one technology commercialization thrust areas.

\section{A. HEAT-AND CRYO-FREE, RETAINED AUSTENITE CONVERSION}

Application of HMFP to high energy consumption and high impact heat treatment operations involving: - The reduction/elimination of retained austenite (RA) through ambient temperature HMFP thereby replacing cryogenic cooling or double temper heat treatments.

-Commercial manufacturing and heat-treating operations must be tailored to eliminate both residual stresses and RA. To do this additional processing steps are necessary, such as cryogenic treatments immediately upon quenching from the austenitizing temperature $\left(\sim 830^{\circ} \mathrm{C}\right)$, or a double temper cycle. Alternately, to reduce the amount of RA, more expensive, higher hardenability grades of the same alloy must be specified to prevent the deleterious effects of RA on product performance. The elimination of these additional heat treatment steps and/or the use of higher cost alloys will result in energy savings, materials savings and reduced greenhouse gas emissions. In addition, component life and performance will be enhanced through the elimination of undesirable microstructures and their deleterious effects on product performance. Also, material and fabrication savings and reduced scrap and product liability will result for many industrial applications if residual stresses and RA could be eliminated. Previous research (on laboratory size samples) had demonstrated that magnet field processing reduces residual stress, and also can destabilize and eliminate retained austenite.

- Heat- and cryo-free, retained austenite conversion was demonstrated on static (batch) processing of American Safety Razor material to replace their cryogenic treatment operation with ambient temperature high magnetic field processing after the initial austenitization and quenching process.

- The replacement of conventional quench and tempering (Q\&T) processing with HMFP promoted phase transformation of austenite below the Curie temperatures of both the ferrite and $\mathrm{Fe}_{3} \mathrm{C}$ phases to nucleate and develop a fine carbide dispersion in a fine ferritic microstructure similar (or better) in performance to conventional Q\&T microstructures.

\section{B. SUPERIOR STRENGTH AND DUCTILITY IN STEELS VIA H\&TMP}

Investigate the application of HMF processing in a non-conventional heat treatment process (not quenched and tempered $[Q \& T])$ for a high-performance ferrous alloy such as a bainite-forming steel:

- Previous results (in a proprietary Work for Others project) on a paramagnetic, age-hardening nonferrous alloy during the early stages of precipitation hardening have shown a $10 \%$ improvement in yield strength when compared to the no-field case. Therefore, an austempering process where ferrite and carbide precipitate directly from austenite during an isothermal hold above (or just slightly below) the martensite start temperature were expected to yield excellent combinations of strength and ductility without significant residual stress and distortion normally associated with conventional Q\&T processes.

\section{IMPROVED CASTING HOMOGENEITY \& PROPERTIES VIA EMAT}

Demonstration of the non-contact electromagnetic acoustic transducer (EMAT) process for casting of a ferrous alloy under a HMF to improve microstructural homogeneity and properties over conventionally cast product.

- Our prior limited EMAT results on an aluminum alloy showed an improved microstructural homogeneity and casting surface appearance.

D. FACILITATION OF HTMP/EMAT TECHNOLOGY COMMERCIALIZATION

Project team interactions and collaborations during the course of this project through periodic meetings, conference calls, and interim reports defined the technology transfer path most appropriate for commercialization of improved HMFP concepts and enhanced performance materials developed during 
the course of this project.

- $\quad$ During the course of this project the current technology limitations of the superconducting magnet and induction heating systems were identified. New HTMP systems were designed that overcome those issues leading to the design of the first generation commercial prototype HTMP/EMAT capable system. The commercial prototype was initially installed at ORNL.

\subsection{HEAT- AND CRYO-FREE, RETAINED AUSTENITE CONVERSION}

Retained austenite is deleterious in many materials applications because under external stress this phase can transform to high carbon martensite, which is very brittle and can lead to catastrophic failure in service. In applications such as high-speed bearings, which are machined to very high tolerances, the transformation of RA under load leads to a large, positive volume strain $(\sim 4 \%)$ that can result in bearing seizure.

The presence of retained austenite upon quenching to room temperature is a major heat treatment concern requiring rapid transfer of the quenched components to an alternate quench facility where cryogenic treatments are performed to drive the transformation of austenite to completion. Generally, this additional processing step still leaves a residual amount of retained austenite. Alternately, multiple tempering heat treatments are employed to successively temper the initial martensite and form additional martensite from the residual retained austenite. The secondarily transformed austenite must be re-tempered to the desired ferrite and carbide microstructure. The elimination of these additional heat treatment steps will result in huge energy savings and reduced greenhouse gases.

American Safety Razor (ASR) uses a martensitic Fe-10\%Cr steel strip for the manufacture of safety razor blades. For the blades to perform to maximize the user's experience, steel strip has to be optimally heat treated to yield a maximum amount of martensite and minimum amount of retained austenite. This is currently accomplished by very tight control inside the austenitizing furnace, followed by a rapid quench and a subsequent liquid nitrogen treatment (Fig. 4). The liquid nitrogen quench requires a constant feed of liquid nitrogen. Although the liquid nitrogen quench is adequate, it is highly desirable to further reduce the retained austenite. Further reduction is possible with high magnetic field processing. Applying HTMP to the strip application will reduce the consumption of liquid nitrogen and possibly reduce the rejection rate for the finished strip. Both benefits would reduce the energy consumption by 3 to $5 \%$. ASR intended to implement the technology as soon as it was viably demonstrated on their material through the outcome of this project. However, during the course of the project ASR was bought out by Schick temporarily putting implementation of the technology on hold. Similarly, Caterpillar was interested in this HTMP approach to reduce RA in their fuel injector tips, (Fig. 5), which would also result in improved high cycle fatigue behavior. The experiments and quantitative results on the safety razor high performance steel served a dual purpose in providing supporting data for Caterpillar's tool steel fuel injection system application. 


\section{Schematic of ASR Razor Blade Thermal Processing}

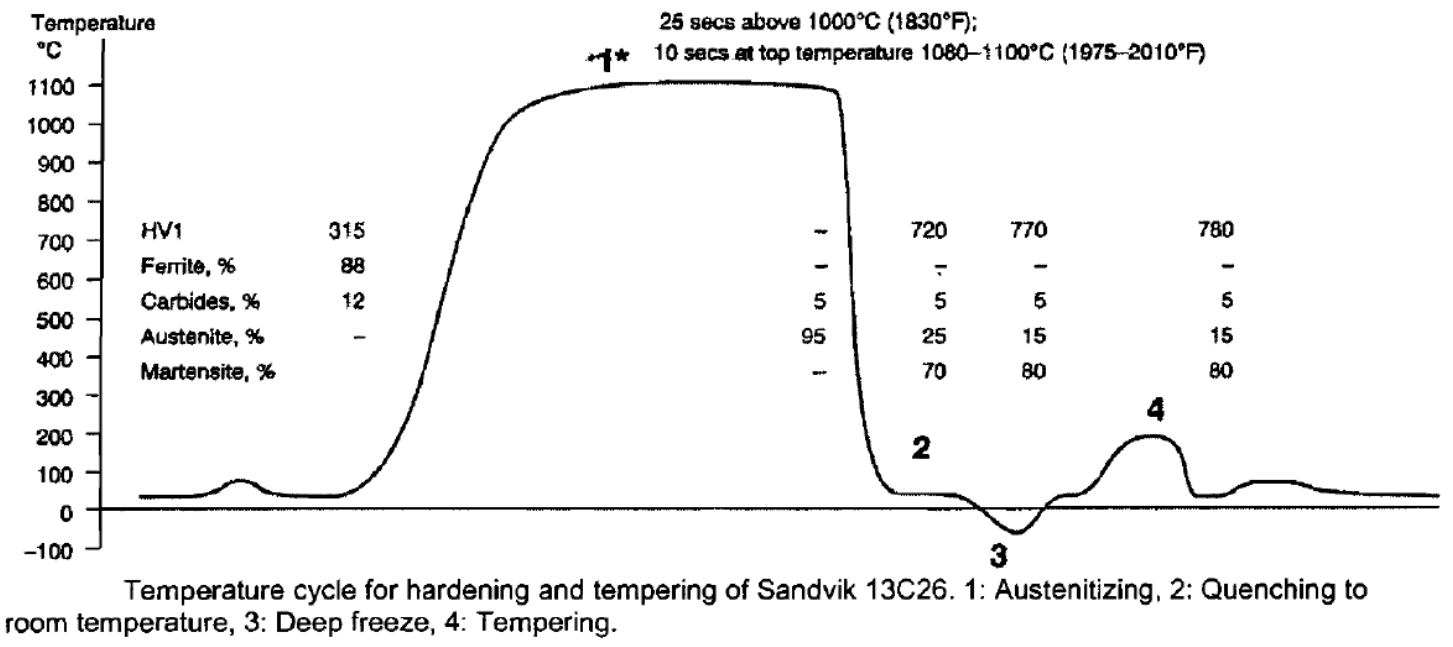

Figure 4. Schematic of the original ASR process showing processing conditions and subsequent microstructural constituent volume fractions.

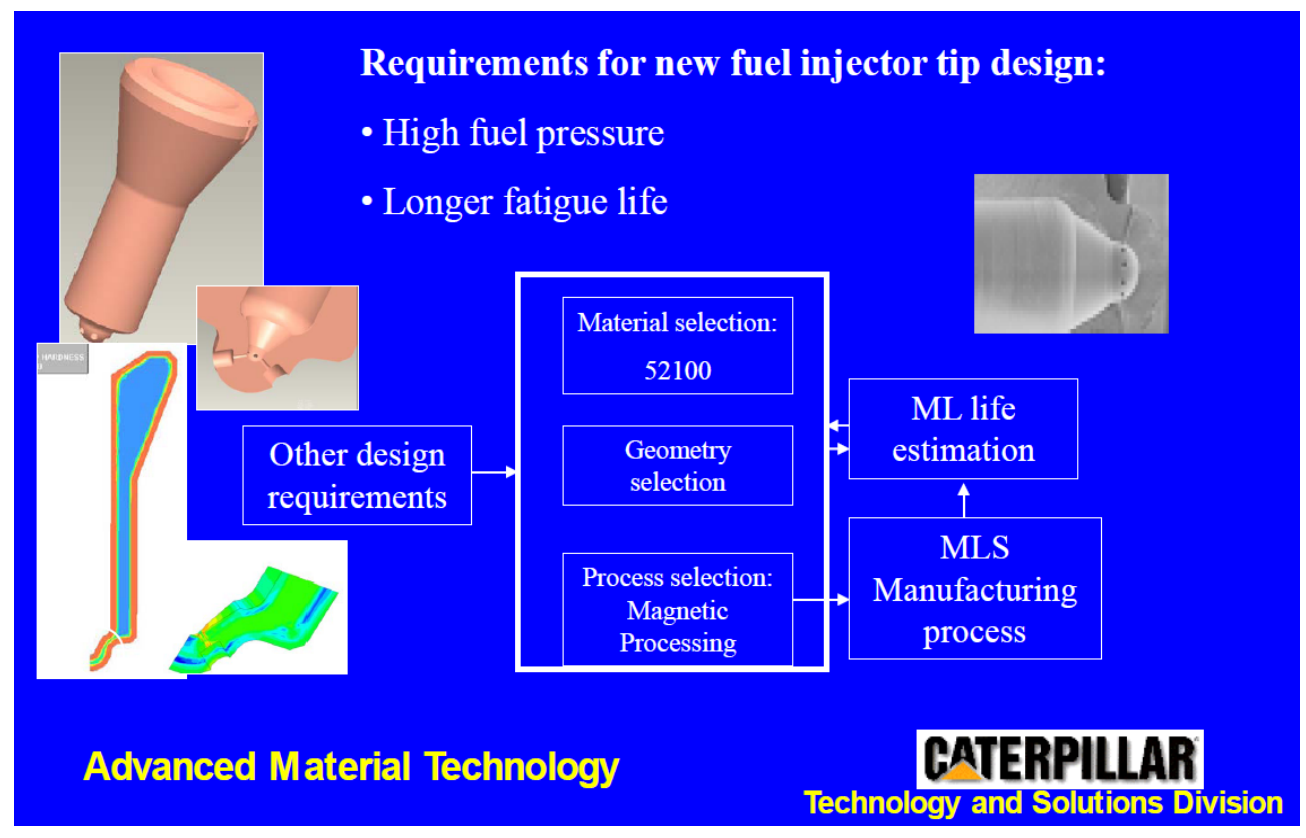

Figure 5. Caterpillar's application for the RA conversion for fuel injector tip advanced design.

In order to demonstrate this technology for the razor blade application in static (or batch processing rather than continuous processing) experiments, several induction coil and sample holding systems were designed to accommodate the more difficult sheet configurations and are shown in Figs. 6-10. 


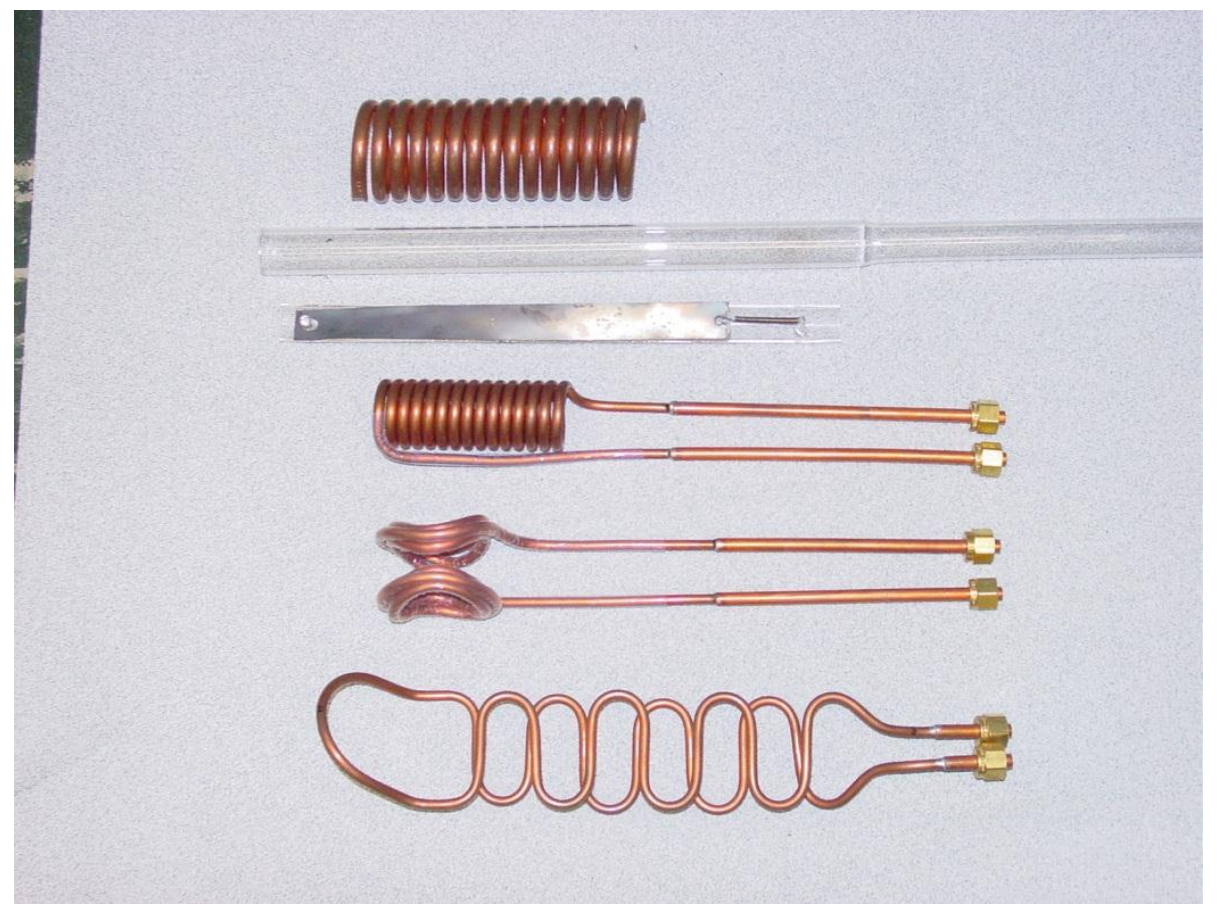

Figure 6. Induction coil designs used in initial experiments to develop uniform temperatures across the entire face of the safety razor strip.

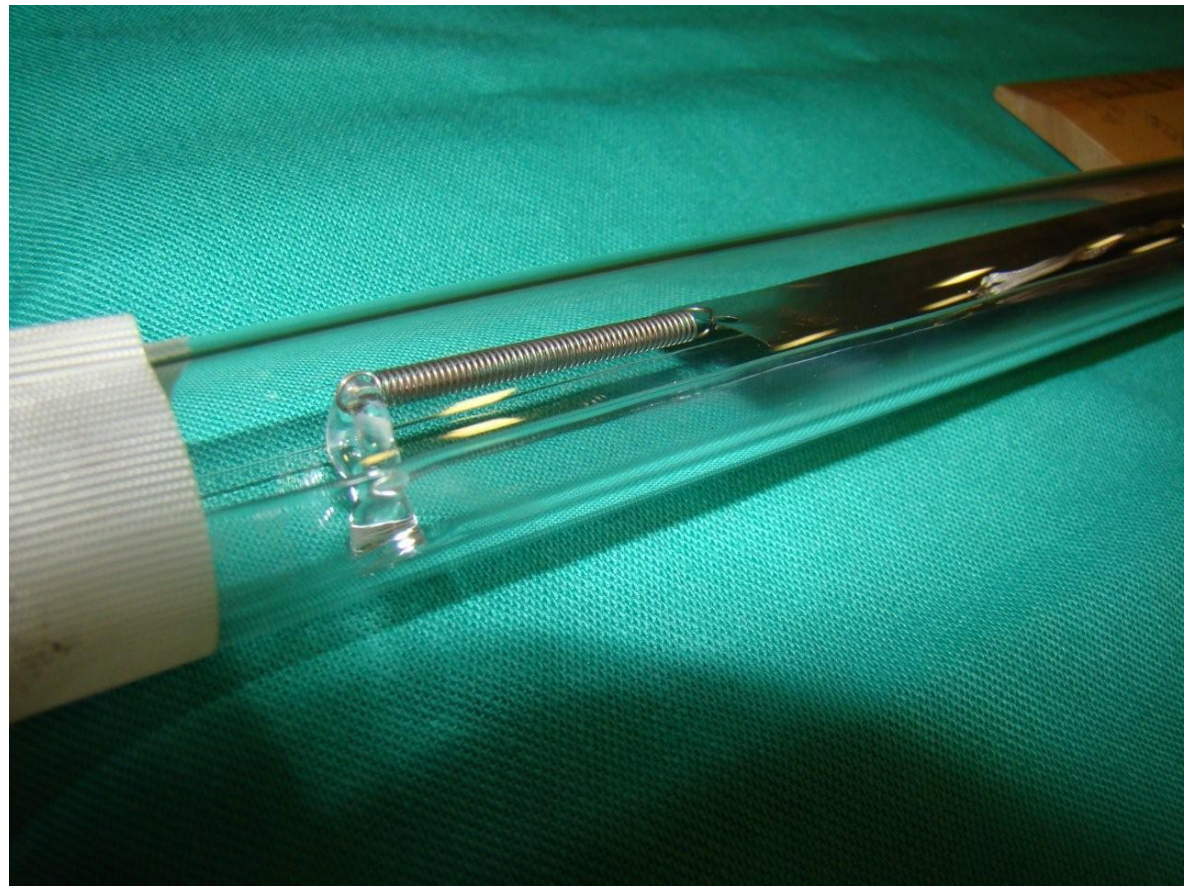

Figure 7. A novel spring holding design was employed to keep the razor strip in tension while applying the HTMP process for the thermal transient. 


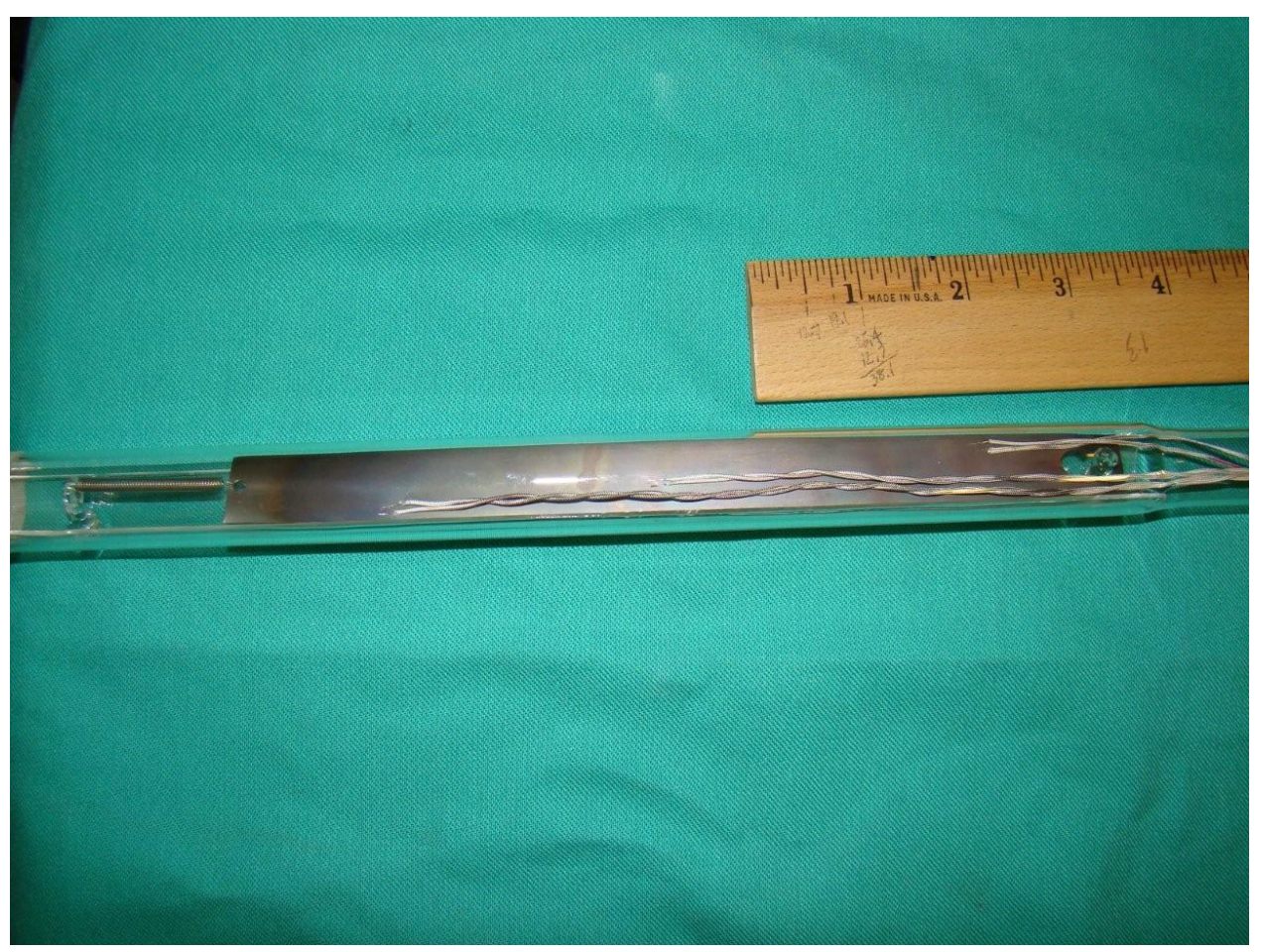

Figure 8. A quartz environmental tube was employed to surround the razor strip so an inert gas could be blown across the sample while at elevated temperature to prevent oxidation.

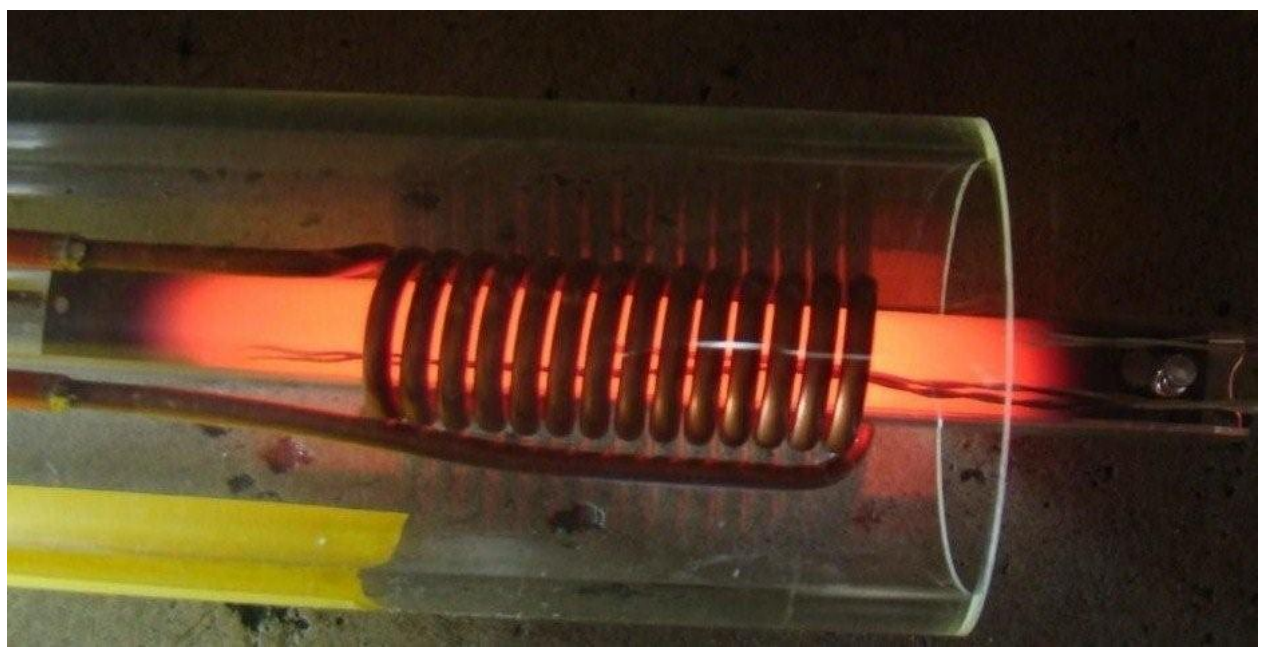

Figure 9. An example of the heating uniformity using an elliptical-turn induction coil for the razor strip.

Thermocouples were mounted at various locations across the sample to monitor temperature uniformity for each heating coil design. 


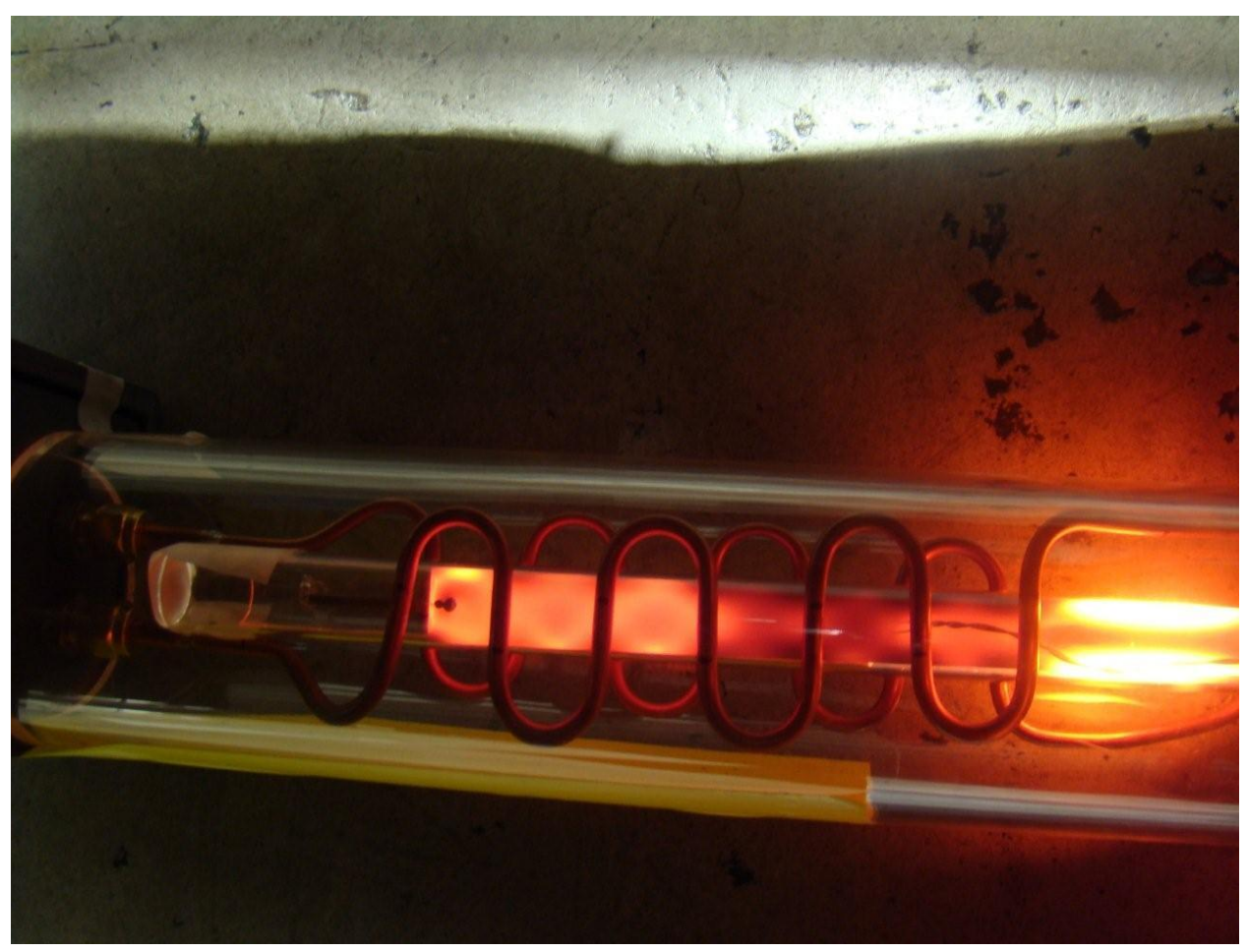

Figure 10. Two parallel flat induction heating coils could not achieve temperature uniformity and so the design in Fig. 9 was used in the batch processing experiments.

\subsubsection{Material Characterization}

Characterization and delineation of retained austenite from carbides in stainless steel was accomplished by combined electron backscatter electron diffraction (EBSD), energy dispersive spectroscopy- energy dispersive X-ray (EDS-EDX)), and X-ray diffraction (XRD). Measurement of the volume fraction, grain size, and crystallographic texture of the ferritic (or martensitic) matrix, the retained austenite, and carbides (if present), was essential to understanding the steel's processing-properties relationships. Normally electron backscatter diffraction (EBSD) is a good tool for RA measurement, however RAcontaining steels are challenging because the cubic phases give similar EBSD patterns [1]. In this work, a thermomagnetically processed (TMP) $\mathrm{Fe}-13.0 \mathrm{Cr}-0.7 \mathrm{Mn}-0.4 \mathrm{Si}-0.68 \mathrm{C}$ steel (hot-rolled thin strip) was analyzed with XRD and found to contain a ferritic/martensitic matrix, RA, and $\mathrm{M}_{23} \mathrm{C}_{6}$ carbides. However, overlapping XRD peaks and strong texture made it difficult to quantify the RA volume fraction, which is a vital metric to compare processing paths.

After XRD analysis the Fe-13.0Cr-0.7Mn-0.4Si-0.68C steel was polished in colloidal silica and analyzed using EBSD in a JEOL6500F Scanning Electron Microscope (SEM) with a Hikari EDX system. An area of $30 \times 30 \mu \mathrm{m}$ was analyzed using $100 \mathrm{~nm}$ steps and a $10 \mathrm{kV}, 3.0 \mathrm{nA}$ probe. Figs. $11 \mathrm{a}, 11 \mathrm{~b}$, and $11 \mathrm{c}$ show the SEM image, the phase map, and the confidence index (CI), respectively, not including chemical information. Clearly, the phase map in Fig. $11 \mathrm{~b}$ is meaningless, with both ferrite and $\mathrm{M}_{23} \mathrm{C}_{6}$ giving $\sim 45$ area\% each, and the CI's in Fig. 11c are poor ("ferrite" refers to BCC ferrite and BCT martensite phases the martensite tetragonality was insufficient to index). Since all three phases are cubic, the EBSD patterns are similar and the EBSD algorithm is unable to find unique solutions for phase/compound delineation despite using a large number of Hough peaks (12-15) for indexing. 

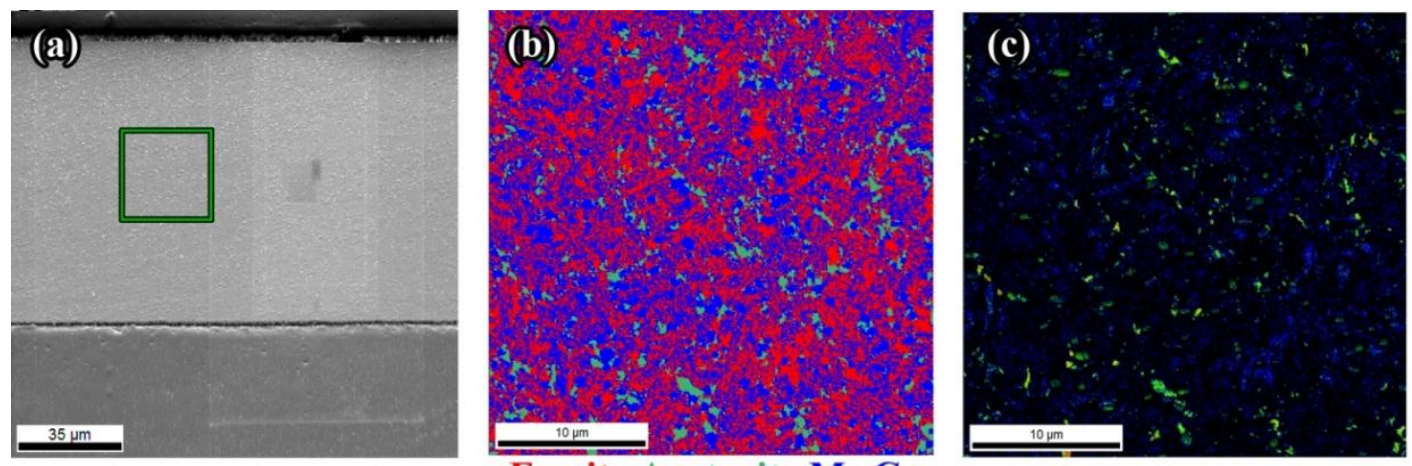

\section{Ferrite Austenite $\mathbf{M}_{23} \mathrm{C}_{6}$}

Figure 11. (a) SEM image of polished sample - box indicates $30 \mu \times 30 \mu \mathrm{m}$ EBSD scan area, (b) EBSD phase map, and (c) Confidence Index map.

The phase map was acquired simultaneously with elemental maps via EDS. Fig. 12a shows an image quality (IQ) map, and Figs. 12b and 12c show the Fe and Cr X-ray maps, respectively. Fig. 12d shows a red-blue-yellow-magenta map of four partitions identified by statistical analysis using EDX Orientation Imaging Microscopy software of the $\mathrm{Cr}, \mathrm{Fe}$, and IQ maps. The Hough peaks were re-indexed offline with the red partition restricted to ferrite + austenite, yellow to austenite $+\mathrm{M}_{23} \mathrm{C}_{6}$, and blue and magenta to $\mathrm{M}_{23} \mathrm{C}_{6}, \mathrm{M}_{7} \mathrm{C}_{3}$ and $\mathrm{Fe}_{3} \mathrm{C}$, respectively.
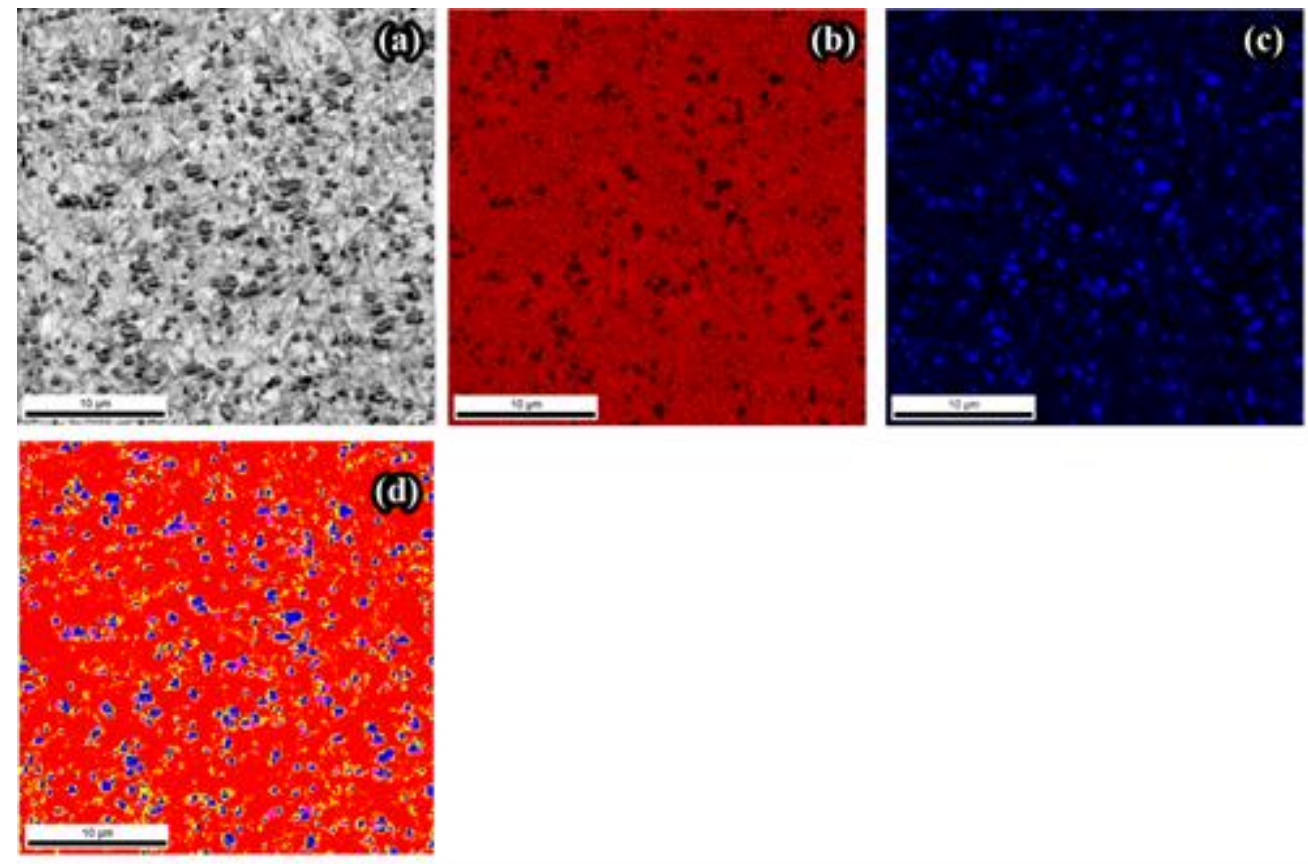

Figure 12. (a) Image quality map, (b) Fe X-ray map,(c) Cr X-ray map, and (d) automated partitioning of the $\mathrm{IQ}+\mathrm{Fe}+\mathrm{Cr}$ maps into four regions for re-indexing.

Figs. 13a and 13b show the re-indexed phase map and the CI map, respectively. From the re-indexed data, the RA is approximately 7.1 area\%, a qualitatively reasonable number and $\mathrm{M}_{7} \mathrm{C}_{3}$ and $\mathrm{Fe}_{3} \mathrm{C}$ are both approximately 1 area\%, indicating they are not likely present but are simply mis-indexing artifacts. Clearly, the indexing in Fig. 13a is more consistent and the confidence (Fig. 13b) is higher compared to Fig. 11. Therefore, combining EDS and EBSD is a very reasonable approach for resolving the problem of identifying cubic carbides in a matrix of ferrite/martensite and austenite. Problems to still be addressed 
are surface relief from sample preparation (resulting in lowered IQ near harder phases) and the intrinsically different spatial resolution in EBSD and EDS signal generation [2].
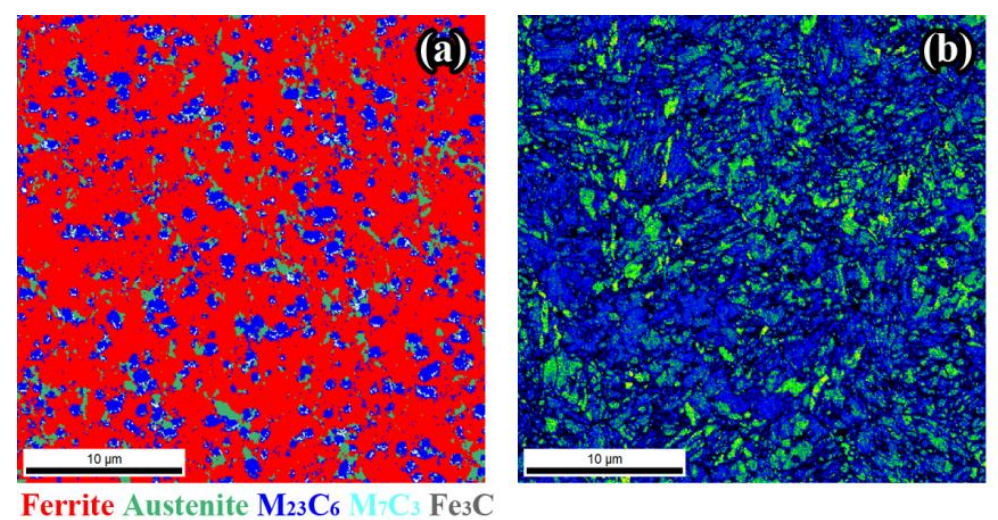

Figure 13. (a) Re-indexed phase map using chemical information. (b) Confidence index map using chemical information.

Acknowledging the precision limits of RA determination, the analysis showed that the ambient temperature HTMP processing dramatically reduced RA from values on the order of $25 \%$ to extremely low levels (Fig. 13a). The results were highly desired for the razor strip and were applied to the RA reduction applications for Caterpillar's fuel injection nozzle.

\subsection{SUPERIOR STRENGTH AND DUCTILITY IN STEELS VIA HTMP}

Carpenter Technologies provided ORNL a bainitic high strength alloy steel and the accompanying processing history, as-received material microstructural characterization (optical/SEM metallography, grain size), the mechanical properties, and sufficient materials needed to conduct the experiments agreed upon in this focus area. Since continuous cooling transformation (CCT) information did not exist for the steel, ORNL developed the CCT using dilatometer specimens supplied by Carpenter Technologies.

Carpenter machined the mechanical property test specimens for ORNL to Thermo-magnetically process and Carpenter performed all the mechanical testing. ORNL determined via dilatometry how the martensite start temperature shifted with magnetic processing. This effort was necessary in order to define the process control parameters for the high magnetic field experiments. Knowing the CCT curves prior to high magnetic field processing aided in guiding ORNL in determining the thermo-magnetic processing temperatures needed to obtain the proper/optimized heat treatment practices.

Carpenter Technologies staff, upon review of their ferrous alloy systems, down-selected two candidate alloys for proof-of-principal HMFP experiments. One was their Custom 465 stainless steel alloy, the other was a new, high strength bainitic alloy. The reason for evaluating the Custom 465 stainless steel was that in thick cross sections (e.g., >8-inches in diameter) this alloy developed RA upon cooling. Experiments run on this alloy on smaller diameter samples $(\sim 0.5$-inch) that fit inside the induction coil in the bore of our SC magnet system could not duplicate the formation of the RA because of the inherent higher quench rates achievable in these smaller samples for even the no-field cases. No further experiments were conducted and details of that limited investigation on the Custom 465 alloy will not be reported here. The materials characterization results for the bainitic alloy are detailed below.

\subsubsection{High Strength Bainitic Alloy}


The chemical composition of the high strength bainitic alloy is shown in Table 2. The alloy is used in the austenitized + quenched + cryogenic treatment + tempered condition. The primary goal in processing the alloy was to develop a more energy-efficient thermal magnetic processing sequence that would eliminate the energy-intensive cryogenic processing step that is currently needed to reduce the amount of retained austenite in the alloy. The mechanical properties and performance of the alloy are strongly influenced by the $\%$ retained austenite.

Table 2. Chemical Composition of super bainitic alloy (Heat 010964)

\begin{tabular}{|l|l|l|l|l|l|l|l|l|l|l|l|l|l|}
\hline Element & $\mathbf{C}$ & $\mathbf{M n}$ & $\mathbf{S i}$ & $\mathbf{P}$ & $\mathbf{S}$ & $\mathbf{C r}$ & $\mathbf{N i}$ & $\mathbf{C u}$ & $\mathbf{V}$ & $\mathbf{T i}$ & $\mathbf{A l}$ & $\begin{array}{l}\mathbf{N} \\
{[\mathrm{ppm}]}\end{array}$ & $\begin{array}{l}\mathbf{O} \\
{[\mathrm{ppm}]}\end{array}$ \\
\hline wt.\% & 0.36 & 0.78 & 0.94 & $<.005$ & $<.0005$ & 1.26 & 3.81 & 0.52 & 0.30 & $<.003$ & .004 & $<10$ & $<10$ \\
\hline
\end{tabular}

\subsubsection{Materials Characterization}

To determine/establish the important phase transformation temperatures prior to planning the targeted TMP experiments for this material, Carpenter provided mechanical and dilatometer test samples to ORNL, ORNL performed high speed quenching dilatometry experiments on the samples using a high quench rate Figure 14 shows that the martensite start temperature was determined to be $238 \mathrm{C}$. As a comparison, the martensite start temperature was also estimated by using the standard Andrews equation, i.e.,

Martensite start $(K)=785-453 C-16.9 \mathrm{Ni}-15 \mathrm{Cr}-9.5 \mathrm{Mo}+217 C^{*} \mathrm{C}-71.5 C^{*} \mathrm{Mn}-67.6 \mathrm{C}^{*} \mathrm{Cr}$

Using this equation, the martensite start temperature was estimated to be $243^{\circ} \mathrm{C}$, showing excellent agreement between the predicted/estimated and actual experimental values determined for the martensite start temperature.

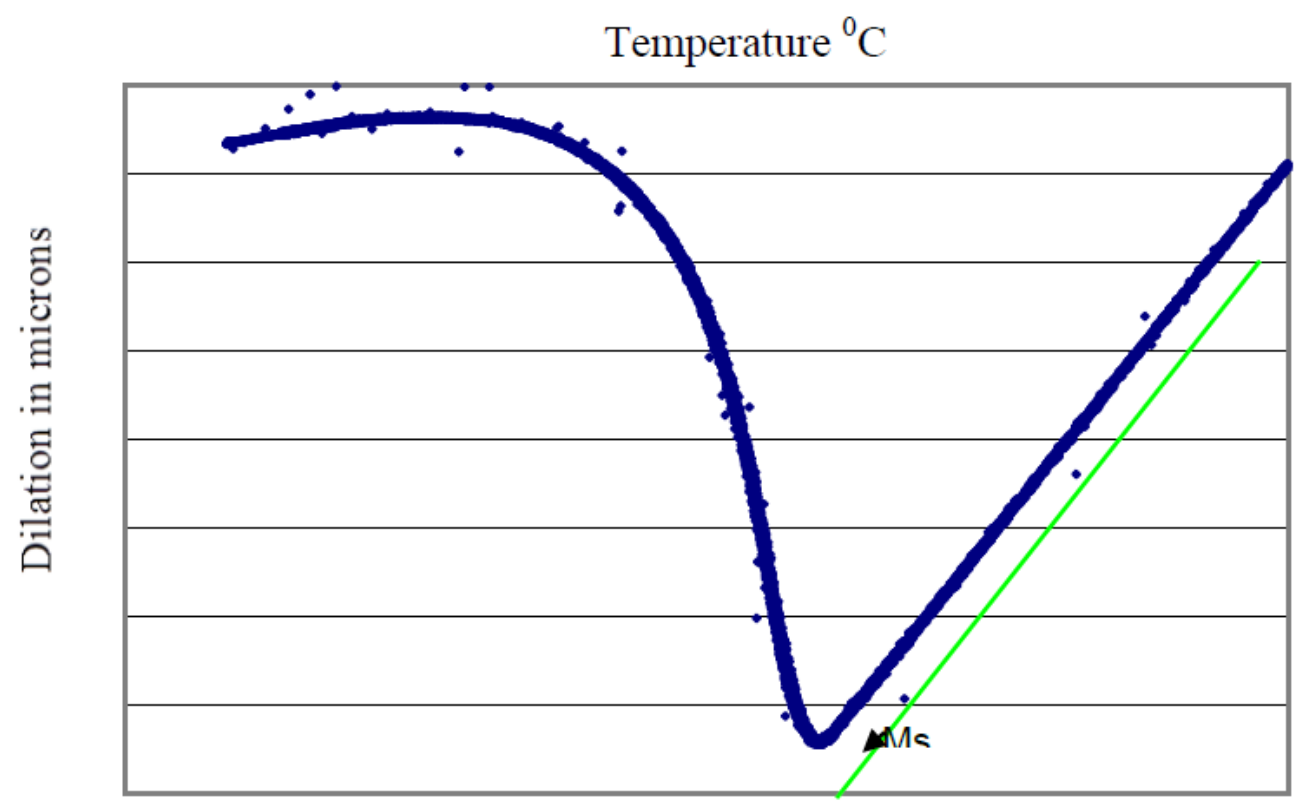

Figure 14. The experimentally determined martensite start $(\mathrm{Ms})$ phase transition temperature $\left(238^{\circ} \mathrm{C}\right)$ for a baseline steel composition using high speed quenching dilatometry techniques during high speed helium gas quenching $\left(>\mathbf{2 0 0}{ }^{\circ} \mathrm{C} / \mathrm{s}\right)$ from the austenite single phase field. 
ORNL performed metallographic evaluations to characterize the bainitic steel samples processed with nofield and with magnetic field processing. The characterization demonstrated a profound difference in microstructure between the two processing routes. Figure 15 shows the striking distinction in the microstructural response of this alloy by aging with and without a magnetic field imposed. Aging in the presence of a magnetic field appears to essentially eliminate the obvious "banding" that results following aging this alloy without a magnetic field imposed during aging. Consequently, aging under the influence of a magnetic field appears to significantly reduce the banded/periodic structure that resulted without a magnetic field imposed. In other alloys, this type of banding is typically associated with local chemistry variations (apparent alloy segregation). Thermal magnetic processing appears to homogenize the alloy on a micro scale resulting in a uniform microstructure throughout the bulk.
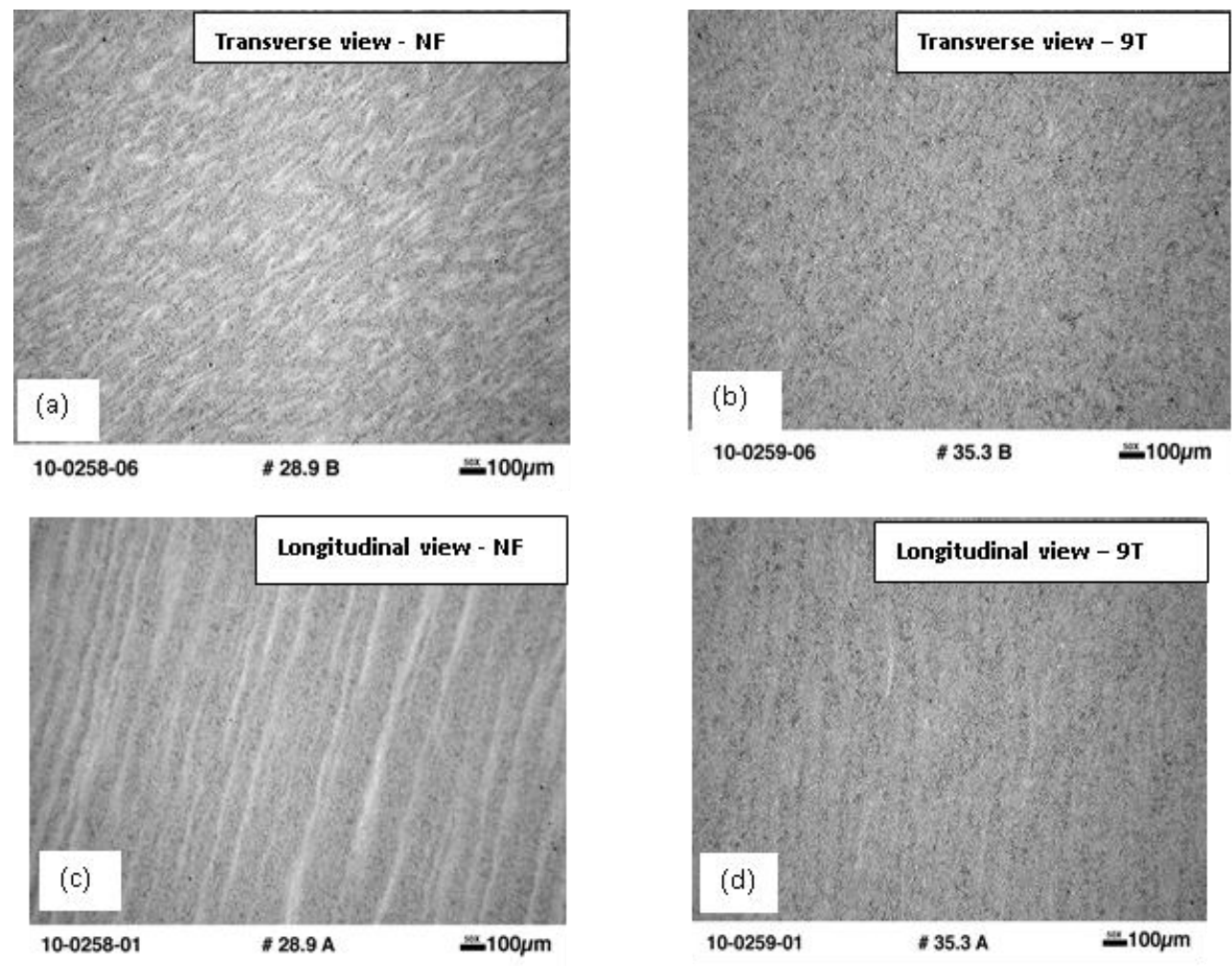

Figure 15. Preliminary metallographic micrographs of a high strength bainitic alloy austenitized and aged for 8 hrs without (Fig. 15 a \& c), the No Field (NF) condition and with (Fig. 15 b \& d) a magnetic field (9T) indicate that magnetic field processing appears to refine the microstructure ((Fig. 15 a vs. b: transverse view) and significantly reduce the banded structure ((Fig $15 \mathrm{c}$ vs. d: longitudinal view) when compared to the nofield conditions.

\subsubsection{Mechanical Properties}

Using the experimentally determined martensite start phase transformation temperature of $238^{\circ} \mathrm{C}$ for the bainitic steel alloy, a test matrix was developed to investigate and determine the influence that thermomagnetic processing has on mechanical properties after austempering tensile and Charpy impact tests conducted on samples with and without HTMP. HTMP samples had higher yield strength, slightly lower ultimate strength, higher \% elongation and \% reduction in area, and increased energy absorption compared to the no-field (NF) trials. While the lower ultimate strength and increased elongation and increased energy absorption during impact testing could be explained by the temperature difference 
between the two trials, the higher yield strength indicates that the magnetic field narrowed the gap between the yield strength and the ultimate tensile strength. This narrowing of the gap is considered favorable for some industrial applications.

Table 3 summarizes the property data and demonstrates that HMFP results in significant improvements in mechanical property performance. The TMP results represent a major breakthrough in materials property enhancements not previously attained. Namely, both strength and ductility are simultaneously improved. These mechanical property results are unprecedented, and cannot be achieved by any other processing method. These results demonstrate that TMP can provide simultaneous improvements in yield strength and percent elongation. For this bainitic steel alloy $12 \%, 10 \%, 13 \%$, and $22 \%$ increases in yield strength, elongation, reduction-in-area, and impact energy, respectively were achieved.

Table 3. Mechanical property results for this high strength bainitic alloy demonstrate that HTMP processing produces unprecedented, and simultaneous improvements in both yield strength and ductility.

\begin{tabular}{|c|c|c|c|c|c|c|}
\hline & $\frac{\frac{0.2 \%}{\text { Yield }}}{\text { strength }}$ & $\frac{\frac{\text { Ultimate }}{\text { Tensile }}}{\frac{\text { Strength }}{(\mathbf{k s i})}}$ & $\underline{\frac{\%}{\text { Elongation }}}$ & $\frac{\frac{\%}{\text { Reduction }}}{\underline{\text { in Area }}}$ & $\begin{array}{c}\text { Charpy V- } \\
\underline{\text { notch (ft-lbs) }}\end{array}$ & $\frac{\text { Hardness }}{\underline{\text { HRC }}}$ \\
\hline \multirow[t]{2}{*}{$\underline{\text { No field }}$} & $\overline{172.69}$ & $\overline{250.49}$ & 15.3 & 52.08 & 28.9 & 49.0 \\
\hline & 164.05 & 250.67 & $13.8^{*}$ & $49.27 *$ & & 49.0 \\
\hline Average & 168.37 & 250.58 & 15.3 & 52.08 & 28.9 & 49.0 \\
\hline
\end{tabular}

* Note: specimen broke very near line mark. \% Elongation and $\%$ R.A. are unreliable

\begin{tabular}{|c|c|c|c|c|c|c|}
\hline & $\frac{\frac{0.2 \% \text { Yield }}{\text { strength }}}{\underline{\text { (ksi) }}}$ & $\frac{\text { Ultimate }}{\text { Tensile }}$ & $\frac{\%}{\text { Elongation }}$ & $\frac{\frac{\%}{\text { Reduction }}}{\underline{\text { in Area }}}$ & $\frac{\text { Charpy V- }}{\text { notch (ft-lbs) }}$ & $\frac{\text { Hardness }}{\underline{\text { HRC }}}$ \\
\hline \multirow{2}{*}{$\begin{array}{l}9 \text { T Mag } \\
\underline{\text { Field }}\end{array}$} & 189.45 & 243.65 & 16.8 & 58.49 & 35.3 & 49.0 \\
\hline & 188.6 & 241.42 & 16.9 & 59.52 & & 49.0 \\
\hline Average & 189.025 & 242.535 & 16.85 & 59.01 & 35.3 & 49.0 \\
\hline $\begin{array}{c}\text { Property } \\
\text { Change with } \\
\text { H-field }\end{array}$ & $12.30 \%$ & $-3.20 \%$ & $10 \%$ & $13 \%$ & $22.10 \%$ & 0.0 \\
\hline
\end{tabular}

Figure 16 demonstrates, that after this bainitic alloy was processed using TMP, its Charpy V-notch performance out-performs a premium alloy such as $250 \mathrm{M}$ (Maraging) steel, a high cost, Co-containing alloy with $30 \mathrm{wt} \%$ alloy constituents. This is significant because it demonstrates that a much lower alloy content $(\sim 6 \%)$ steel that is selectively processed using the Thermomagnetic Processing Technology can replace the high cost maraging steel for mechanical performance applications. 


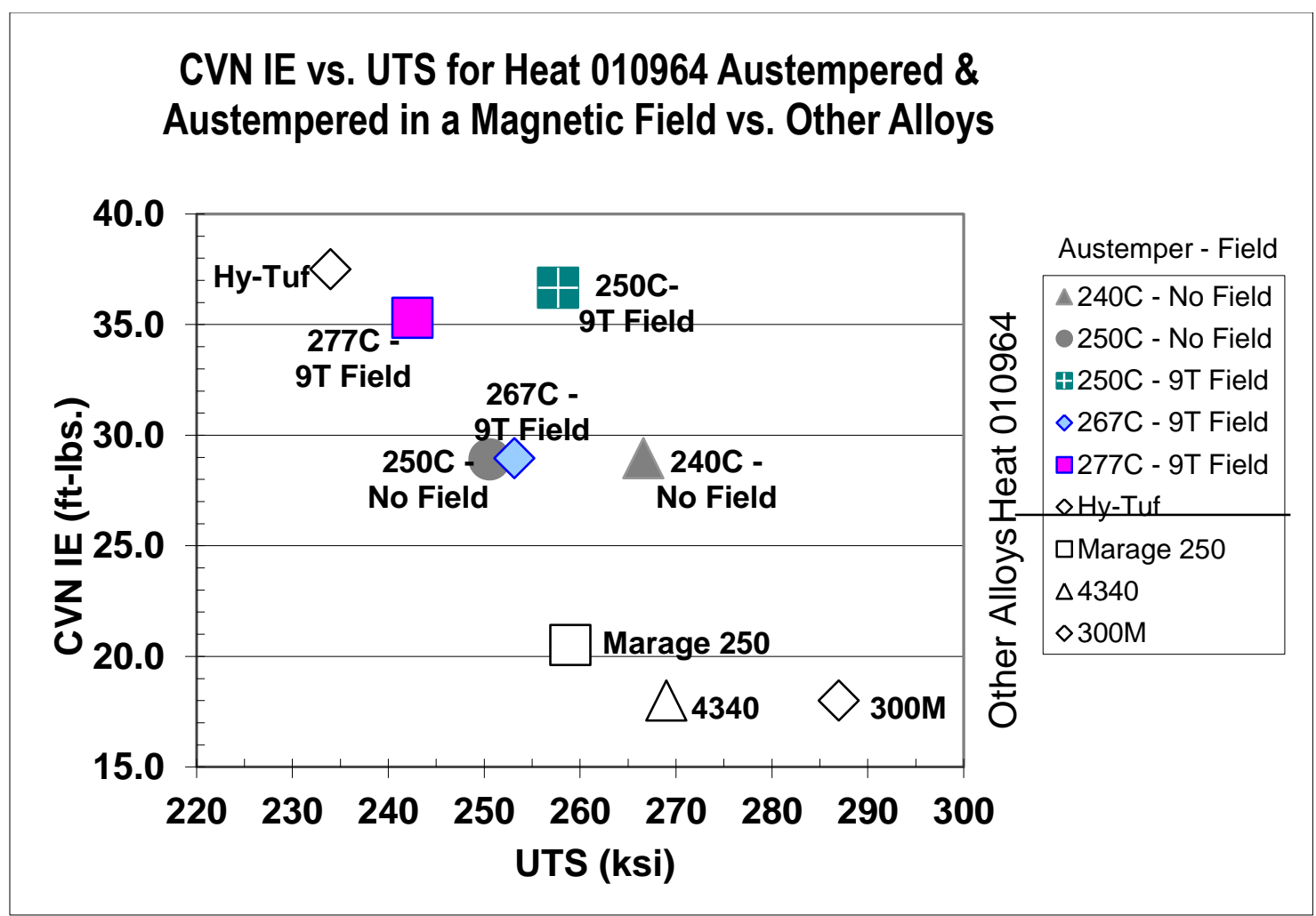

Figure 16. Charpy V-notch property results for this high strength bainitic alloy out-perform maraging 250 steel.

\subsubsection{High Resolution Microscopy Evaluation}

Characterizations of the field versus no-field conditions involved high resolution Scanning Electron Microscopy (SEM) techniques to reveal fine details of the microstructure. SEM Electron Backscattered Diffraction (EBSD) images enabled individual phases to be delineated on the basis of their crystallographic orientation which facilitated determination of possible texture differences as well as quantitative grain size distribution. Fig. 17 below shows the fine detail of one of the banded regions ("bright areas" in SEM inversely correspond to the "dark areas" in optical micrographs) for the longitudinal section of the No-Field (NF) case of Figure 15c. These micrographs show a very fine microstructure with a fine dispersion of carbides. 


\section{Sample 28.9A (No folde, long,}
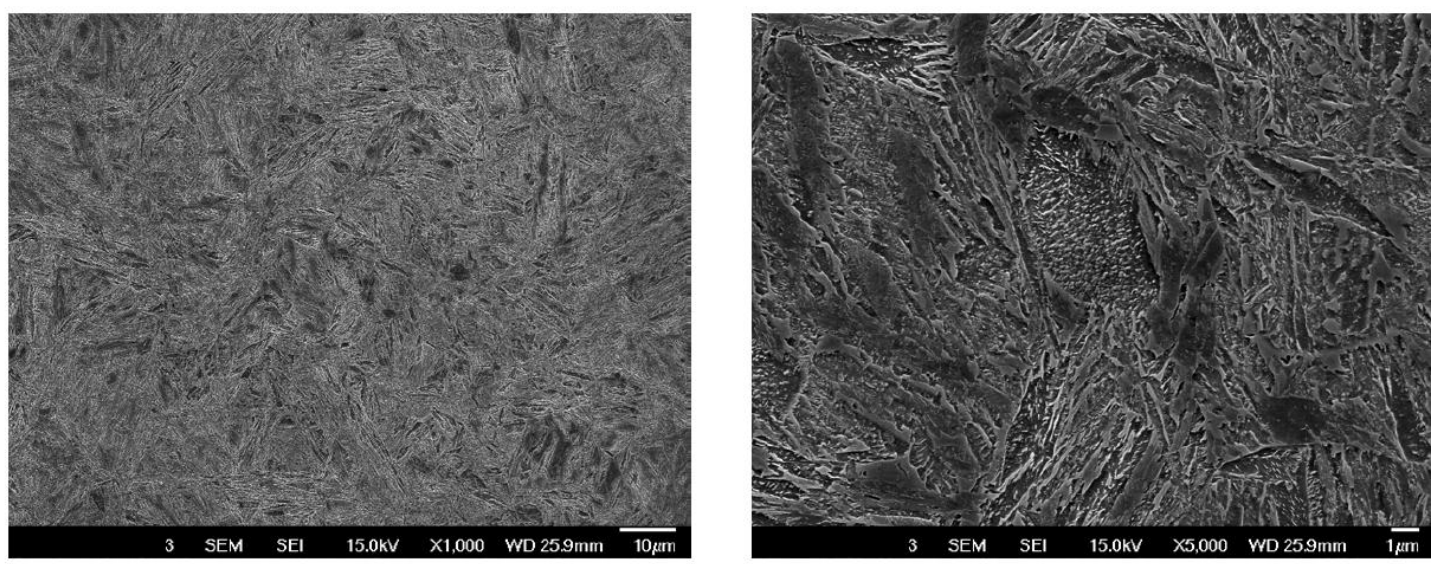

"Bright" area

Fine microstructure

Possible carbides seen?

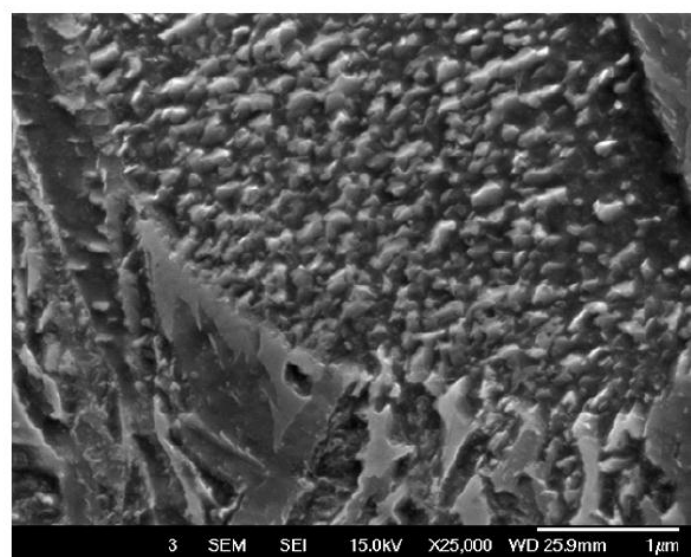

Figure 17. Scanning Electron Microscopy (SEM) micrographs of the NF (no-field) longitudinal section exhibiting very fine microstructural features (possibly a fine carbide dispersion) for a region that appears bright in the SEM (opposite to perspective in optical micrographs).

Similar examination of the alternating contrast banded region in this longitudinal no field sample using SEM shows a fine microstructure (Fig. 18) but with different morphological features (note the dominance of fine spherical carbides). Fig. 19 is an SEM image from material processed with the $9 \mathrm{~T}$ magnetic field. The longitudinal sample shows microstructural differences between the bright and dark regions observed in the optical micrographs. 


\section{Sample 28.9A (No field, long.)}
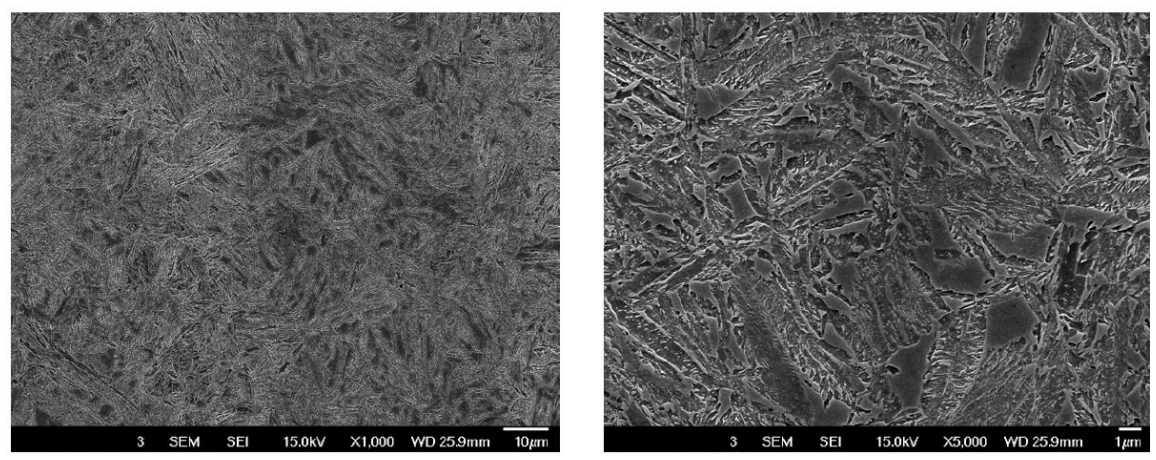

"Dark" area

Fine microstructure

Possible carbides seen?

No qualitative difference

from "Bright" area

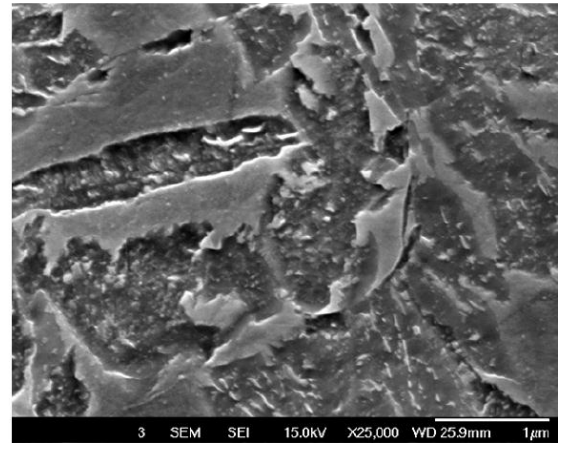

Figure 18. Scanning Electron Microscopy (SEM) micrographs of the alternating contrast region to Figure 17 for the NF (no-field) longitudinal section exhibit very fine microstructural features (possibly a fine carbide dispersion) for a region that appears bright in the SEM (opposite to perspective in optical micrographs).

\section{Sample 35.3A (9т, long.)}

"Bright" area

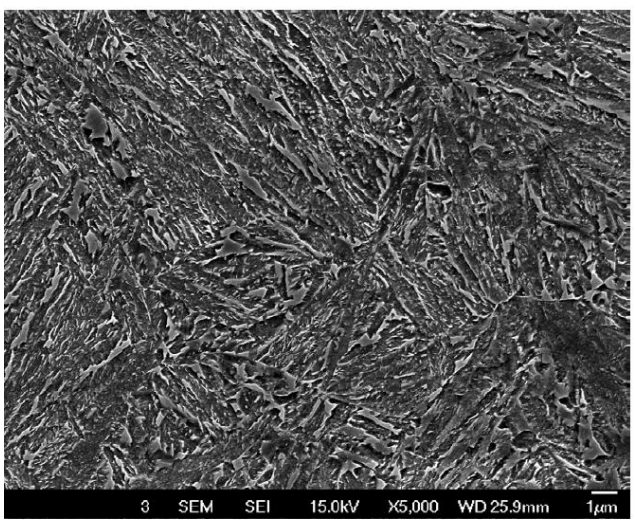

"Dark" area

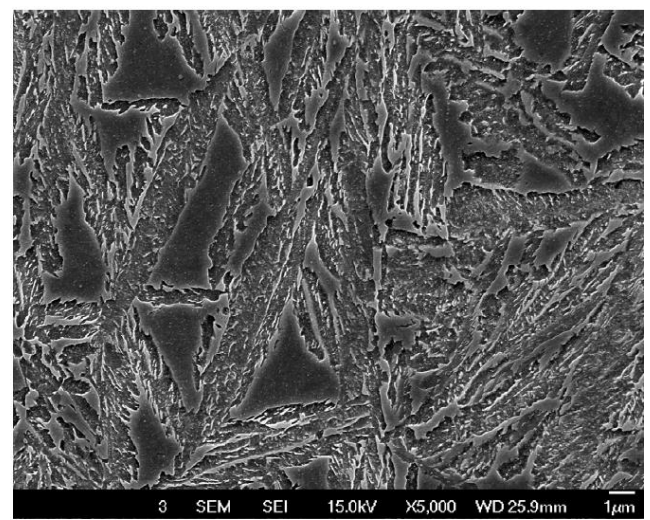

Microstructure appears much finer in the "bright" area. In the dark area, it appears to be a mixture of fine and coarse.

Figure 19. Scanning Electron Microscopy (SEM) micrographs of the alternating contrast regions in the 9T longitudinal section exhibit very fine microstructural features for the bright region that contrasts with a mixture of fine and coarse in the darker regions that were visible in the optical micrographs. 
One of the significant advantages of SEM EBSD is that it reveals the individual microstructural constituents very clearly (since each neighboring phase is at a different crystallographic orientation) enabling texture determination and grain size distributions to be measured when sufficient areas are evaluated. EBSD analyses summarized in Figures 20 and 21 (NF versus 9 T samples respectively) show that thermomagnetic processing (TMP) has a reduced grain size, likely resulting from to enhanced nucleation rates during phase evolution while under a high magnetic field. Insufficient statistics have been generated with the current number of sampled areas to make definitive conclusions as to similarities or differences in texture between the NF versus $9 \mathrm{~T}$ conditions.

\section{EBSD analysis 28.9A (no field, long.)}
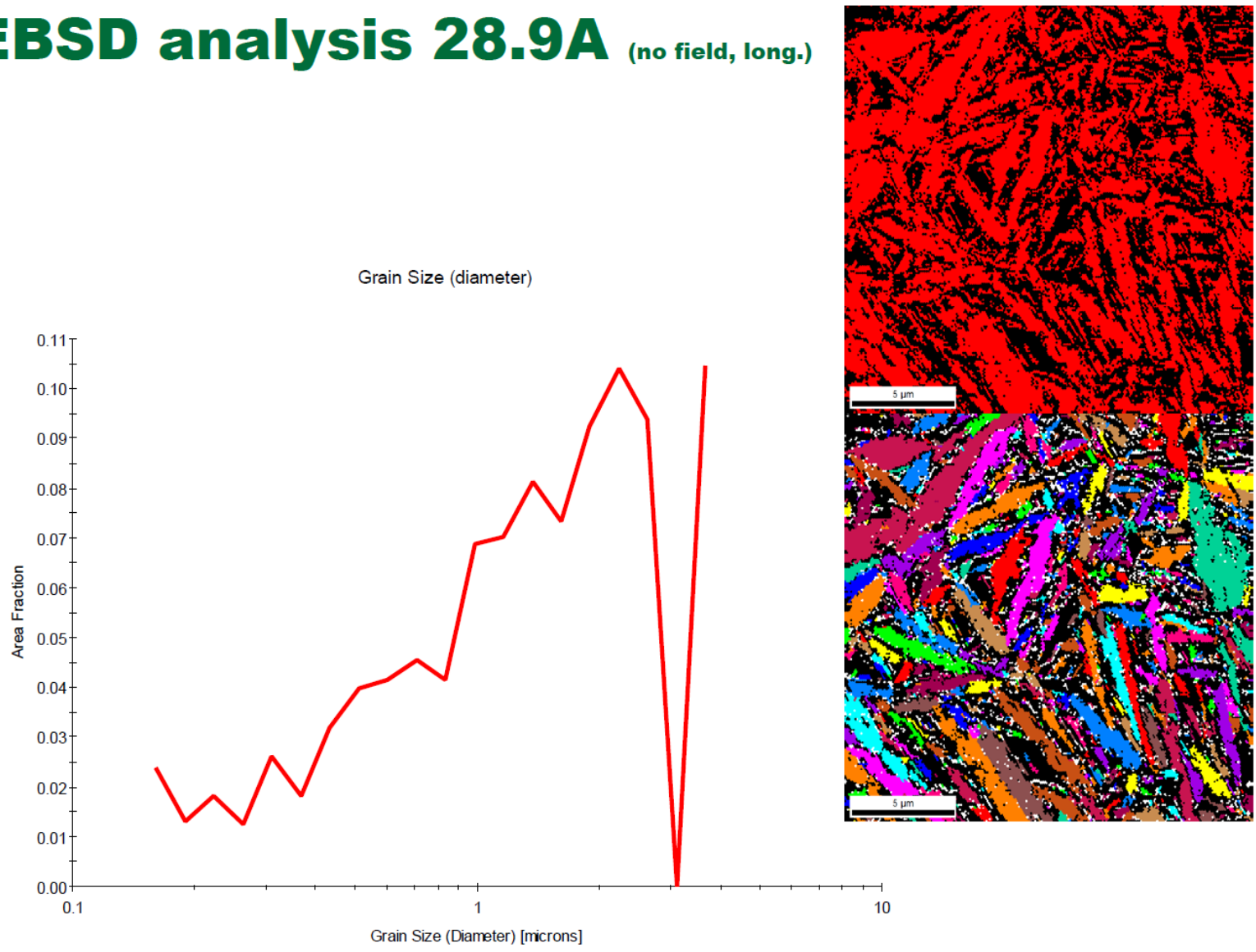

Figure 20. EBSD analyses determination of the grain size distribution in the longitudinal direction for the NF case.

The inverse pole figure (IPF) color plots to the right of figure 20 show qualitative differences in crystallographic orientation between neighboring grains and enable grain size measurements to be made. 


\section{EBSD analysis 35.3A (9т, long.)}

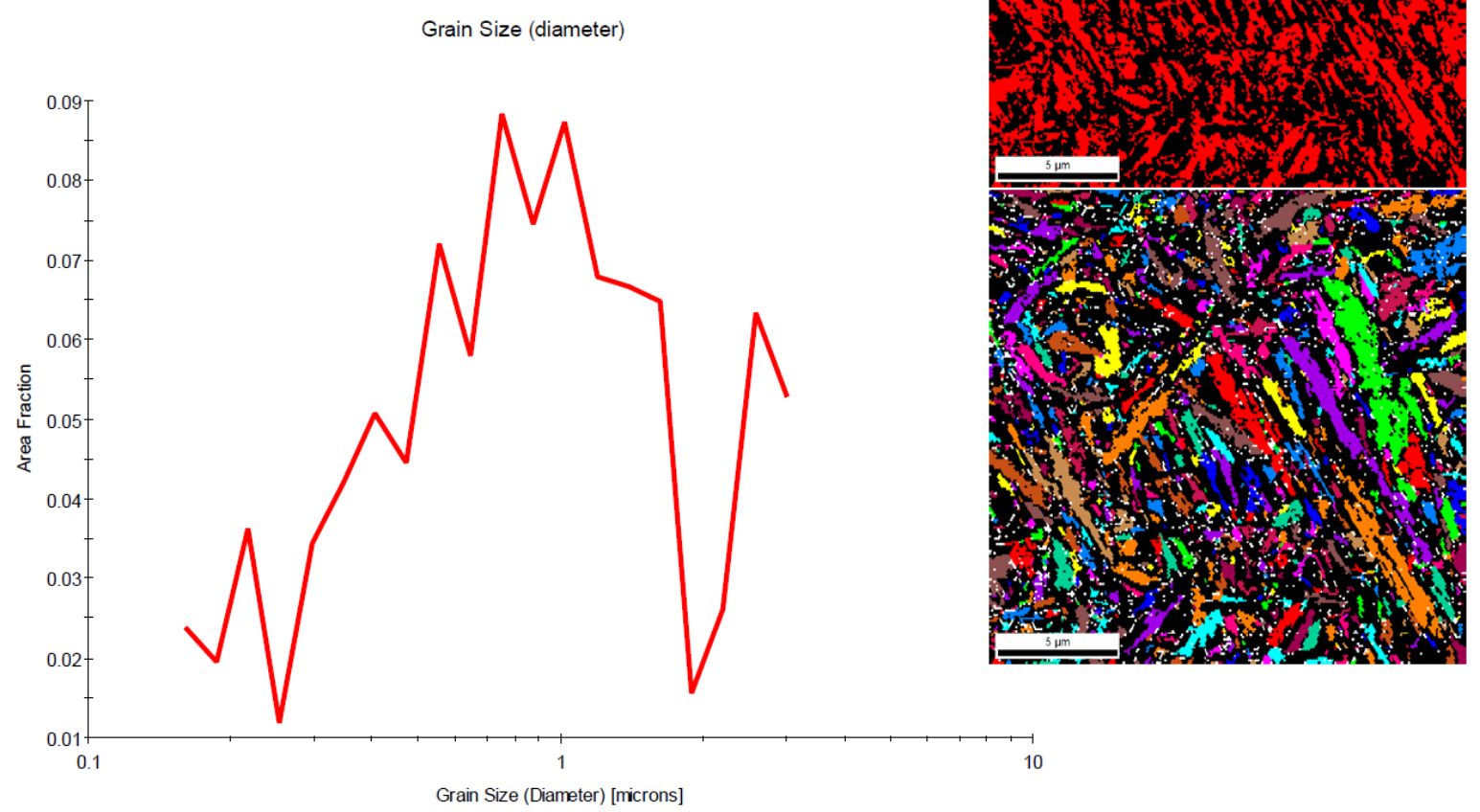

Figure 21. EBSD analyses determination of the grain size distribution in the longitudinal direction for the $9 \mathrm{~T}$ TMP case.

The inverse pole figure (IPF) color plots to the right of figure 21 show qualitative differences in crystallographic orientation between neighboring grains. When compared with figure 20 data, these data demonstrate that the $9 \mathrm{~T}$ TMP sample has a finer grain size distribution than the NF sample.

Scanning transmission electron microscopy was conducted on the HTMP processed bainitic steel sample ID 35.3A. The bright field (BF), and high angle annular dark field (HAADF, a dark field technique sensitive to differences in atomic number), micrographs in Figure 22 show that the TMP sample exhibits a dual population of elongated carbides and finely dispersed spherical carbides. Elemental mapping of some of these carbides indicate that the elongated carbides are dominantly iron-rich whereas the spherical carbides appear to be $\mathrm{V}$ (and possibly $\mathrm{Cr}$ ) rich. These results indicate that TMP appears to result in a much finer and more homogeneous population of spherical carbides than achievable with conventional processing. The carbide morphology and dispersion would help explain both the increase in strength accompanied by the simultaneous increase in impact energy absorption and increased elongation. 
Sample 35.3A

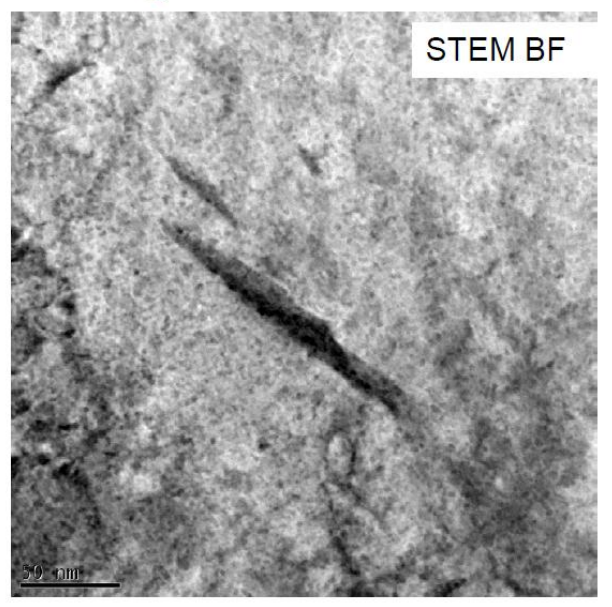

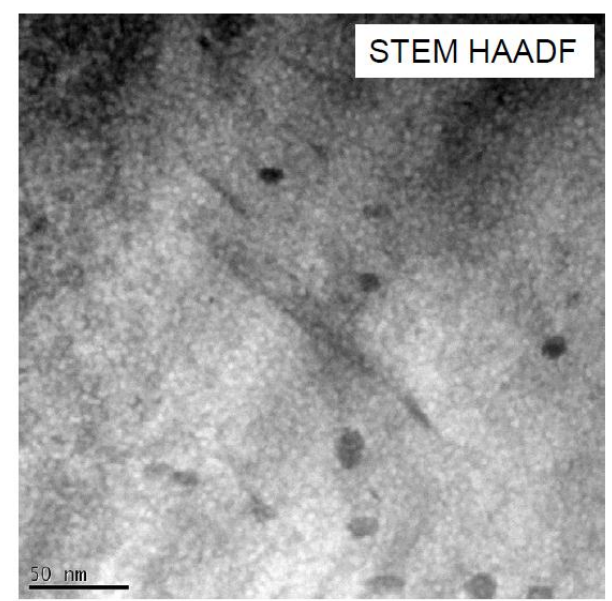

Figure 22. Scanning transmission BF and HAADF micrographs reveal a dual population of fine carbides in the TMP sample consisting of elongated carbides and very fine and copious spherical carbides.

The non-TMP sample ID 28.9 was evaluated using scanning electron microscopy (SEM) to understand differences (inhomogeneity) in the chemical composition in the light and dark areas (banding) shown in Figure 23. (note: light versus dark area contrasts are opposite in the optical microscopy image compared to the secondary electron image in the SEM). The results (Figure 24) indicate that the "dark" regions are slightly enriched in $\mathrm{Si}, \mathrm{V}, \mathrm{Cr}$, and $\mathrm{Ni}$. This suggests that TMP processing promotes more uniform composition throughout the microstructure likely caused by enhanced diffusion of $\mathrm{Si}, \mathrm{V}, \mathrm{Cr}$, and $\mathrm{Ni}$ during the elevated temperature TMP cycle, as well as enhancing fine precipitate nucleation (due to carbide Curie temperature effects) when coupled with the STEM results mentioned above.

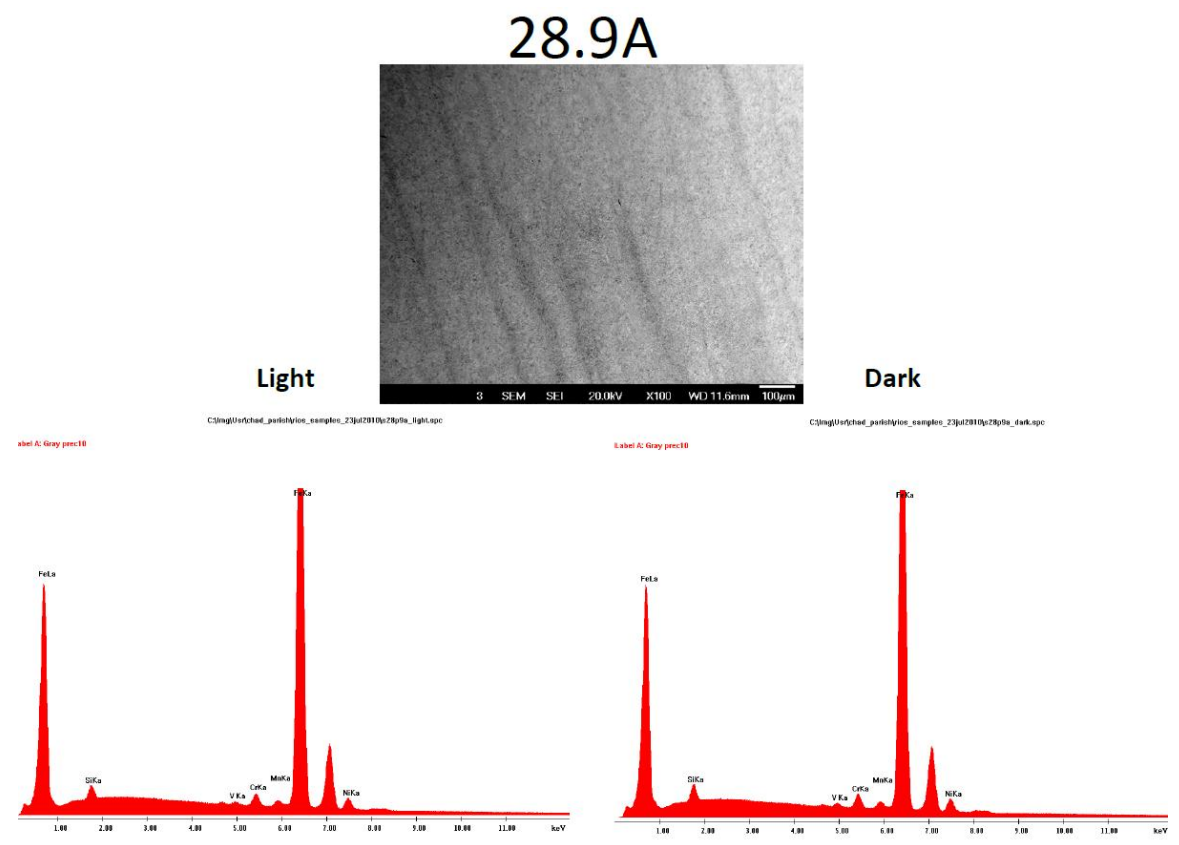

Figure 23. Elemental spectra obtained in the SEM for the light versus dark contrast regions in the non-TMP sample ID 28.9A (These data were further processed in Fig. 24.) 


\section{"Light” vs “Dark” spectrum - S28.9A \\ Took point spectra in light and dark areas}

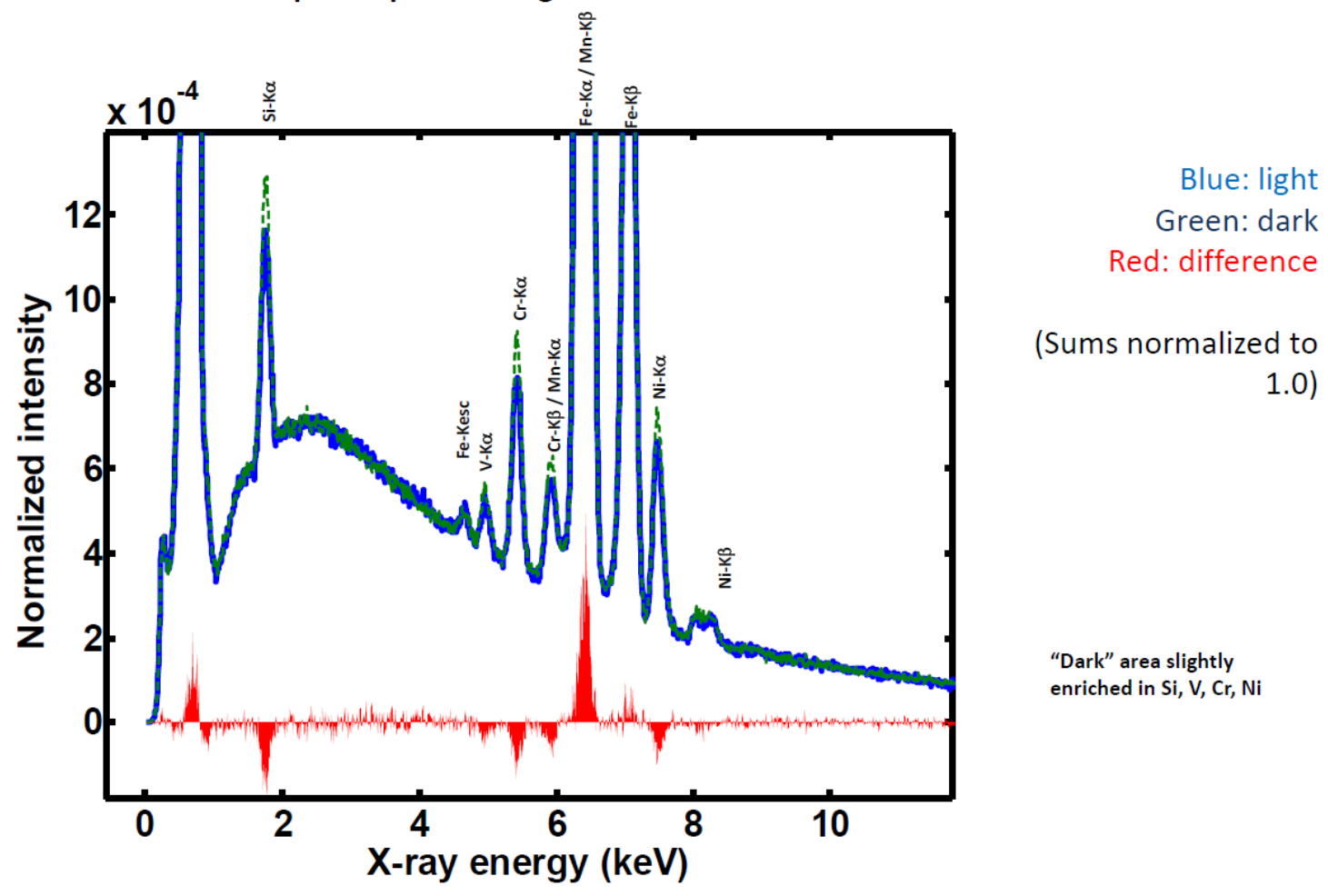

Figure 24. The elemental spectra data shown in Fig. 23 were analyzed to show the local chemistry differences of the various elements indicating that the dark areas appear to be enriched in $\mathrm{Si}, \mathrm{V}, \mathrm{Cr}$, and $\mathrm{Ni}$.

Figure 25 summarizes the results of the high resolution characterization of the Carpenter Technologies bainitic alloy by showing that there are very fine nanoclusters of carbon (at arrow) not present in conventionally processed materials. Thermomagnetic processing appears to mitigate the inhomogeneities normally associated with alloys and some of their substitutional solute alloy content. These fine nanoclusters are responsible for the concomitant improvement in both yield strength and impact energy. 


\section{TMP Produces Nano-Carbide Clusters and 2 Populations of Fine Carbides vs. Only 1 for the NF Case (not shown) in This Carpenter Alloy}

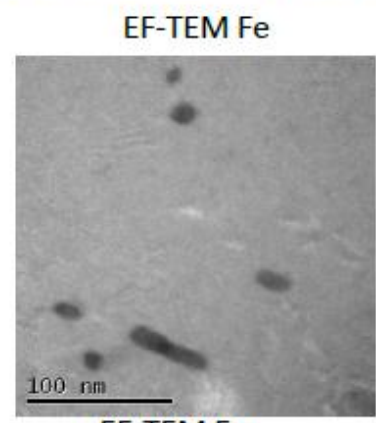

EF-TEM Fe

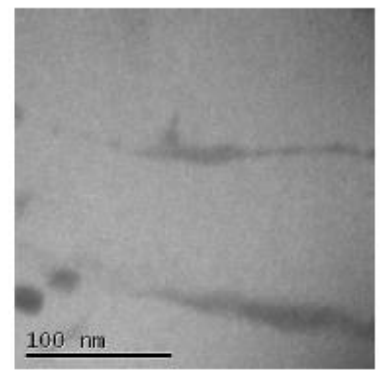

NOTE: EF-TEM is an "ener

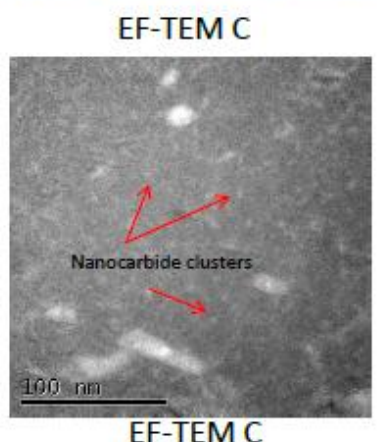

EF-TEM C

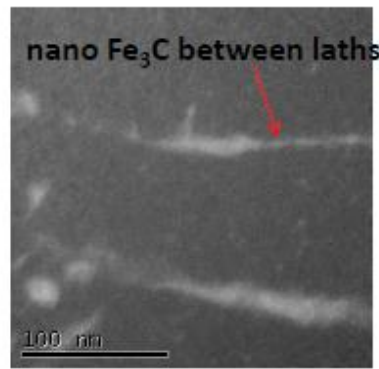

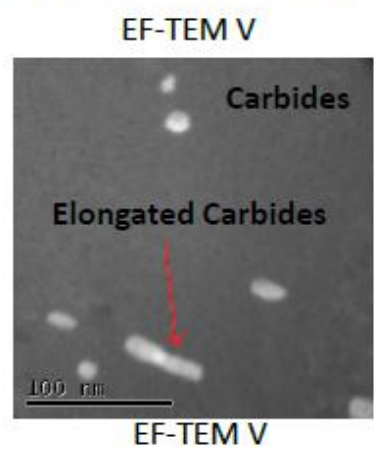

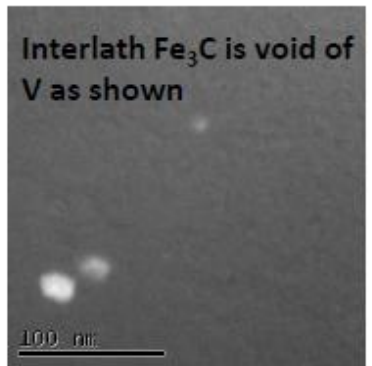

Figure 25. Microstructural evaluation of the fine microstructure in thermomagnetically processed Carpenter bainitic alloy has discovered a very fine and copious nano-carbide cluster dispersion throughout the microstructure that does not appear in non-thermomagnetically processed samples.

\subsection{IMPROVED CASTING HOMOGENEITY AND PROPERTIES VIA EMAT}

A series of solidification experiments was conducted at the National High Magnetic Field Laboratory (NHMFL) in an effort to evaluate the potential benefits of utilizing the Electro-magnetic Acoustic Transducer (EMAT) processing technology on a variety of materials, specifically cast iron and nanoparticle reinforced magnesium. The vertical orientation of the bore of the NHMFL's $195 \mathrm{~mm}$ (7.7inch) diameter bore, 20-T magnet afforded the perfect configuration for conducting these types of solidification experiments. [ORNL's commercial prototype 8-inch $(200 \mathrm{~mm})$ diameter, vertical bore superconducting magnet system (described in Section 3.4) became operational at the end of this project and was not available to conduct these experiments. Future EMAT experiments in subsequent research will be conducted in this new facility at ORNL.]

The primary goal of these experiments was to improve the physical and/or mechanical properties of cast iron and nanoparticle reinforced magnesium (NpR-Mg) while demonstrating significant energy efficiency improvements for a variety of materials and processing applications. A series of well-focused experiments was designed for both cast iron and NpR-Mg to determine if HTMP/EMAT would beneficially impact microstructural phase equilibria and kinetics in the case of cast iron, and, facilitate more homogeneous distributions of nanoparticles in the case of NpR-Mg where unsatisfactory nanoparticle agglomeration occurs under conventional processing conditions. 


\subsubsection{Cast Iron}

DuraBar, is a world leader in providing continuously-cast, cast iron products up to 20-inches in diameter. ORNL investigated using the EMAT for cast iron applications on behalf of DuraBar, with the goal of obtaining wrought-like properties in a cast product.

The first series of experiments was conducted on an ORNL developed cast iron designated GMC010. The composition of the alloy was: Fe-2.78C-0.14Cr-0.07Cu-0.05Mg-0.5Mn-0.01Mo-0.03Ni-4.98Si-0.17Ti$0.04 \mathrm{~V}-1.32 \mathrm{~W}$ (the values are in wt. \%). Alternately, this chemistry in atomic percent is: $\mathrm{Fe}-11.3 \mathrm{C}-0.13 \mathrm{Cr}-$ $0.05 \mathrm{Cu}-0.1 \mathrm{Mg}-0.44 \mathrm{Mn}-0.005 \mathrm{Mo}-0.02 \mathrm{Ni}-8.67 \mathrm{Si}-0.17 \mathrm{Ti}-0.04 \mathrm{~V}-0.35 \mathrm{~W}$.

Modifying the form of the graphite in nodular ductile iron (NDI) can result in special properties such as a high degree of ductility and shock resistance. These property improvements make it attractive for use, and NDI accounts for about 20-30\% of the cast iron market of most industrialized countries. The objective of these experiments was to employ EMAT processing to obtain wrought-like properties in a cast product, broadening the applications where cast iron can be used. Prior to initiating these experiments, a thermodynamic software modeling code was used to estimate the processing temperatures for this alloy. The mushy zone was predicted to be within a $60^{\circ} \mathrm{C}$ window. Fig. 26 shows the phase stability predictions for the GMC010 alloy as a function of temperature that were determined using an equilibrium model to define the temperature regime where EMAT would have biggest impact.

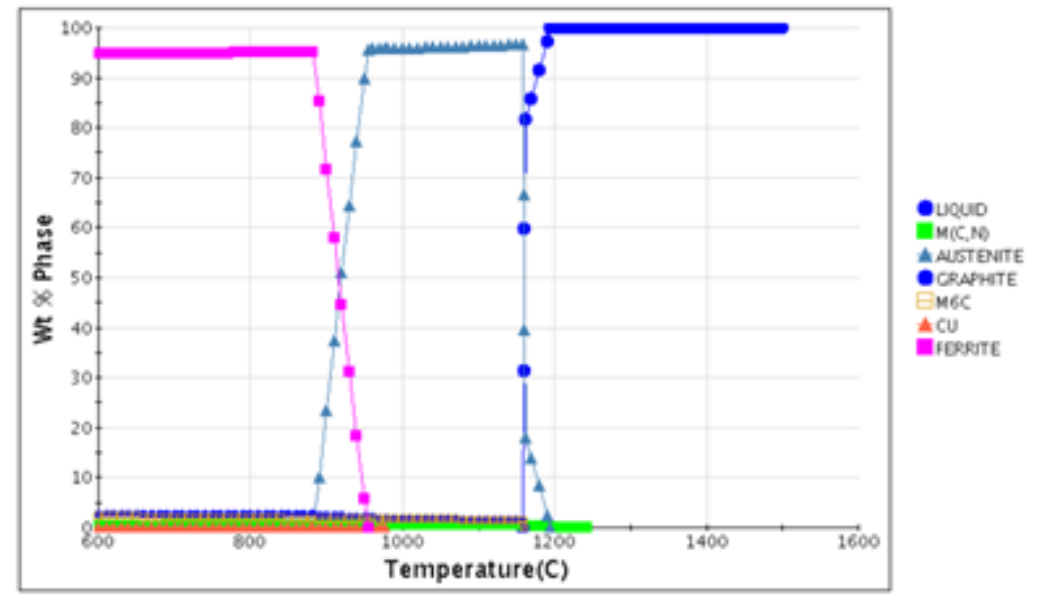

Figure 26. Thermodynamic software calculation predicting phase stabilities and weight fraction of each phase for the GMC010 alloy as a function of temperature to define optimum EMAT processing conditions in the mushy, two-phase liquid plus solid field.

Magnetic field processing during solidification was performed in a custom induction furnace that fit in the bore of the 20 tesla magnet at the National High Magnetic Field Laboratory (Fig. 27). The crucible was insulated with a woven, silicate insulation and taped in place using heat resistant tape. A thermocouple well was inserted into the melt to monitor the solidification process. Experiments were run at several magnetic field strength levels $(0,4.5,9$, and 18T), and the solidification progress was monitored and documented using ORNL's LabView-based software program.

In addition to the variable field experiments, two other experiments were added to gain some insight into the EMAT effect and to elucidate the impact of the EMAT on the solidification microstructure. One of the additional EMAT processed samples was co- processed with the variable field samples and cooled similarly until it reached the mushy zone, where the temperature stalled. The sample was reheated to the 
liquidus and rapidly quenched. The second sample was heated and then cooled into the mushy zone, and as soon as the temperature equilibrated, it was rapidly quenched.

Solidification was performed under the influence of acoustical stimulation at a frequency of $11-12 \mathrm{kHz}$ that resulted from an electromagnetic acoustical transducer effect from the interaction of induction (heating) current with the static high magnetic field. Optical microscopy, analytical electron microscopy in a scanning electron microscope (SEM), an electron microprobe analysis, transmission electron microscopy (TEM), and X-ray diffraction were performed to characterize the microstructure and phases present as a function of magnetic field strength. TEM characterization was performed on focused ion beam (FIB) lift-out specimens in order to minimize the interference between the field of the objective lens and the ferromagnetic material, which made scanning transmission electron microscopy (STEM) X-ray microanalysis and specimen tilting relatively simple.

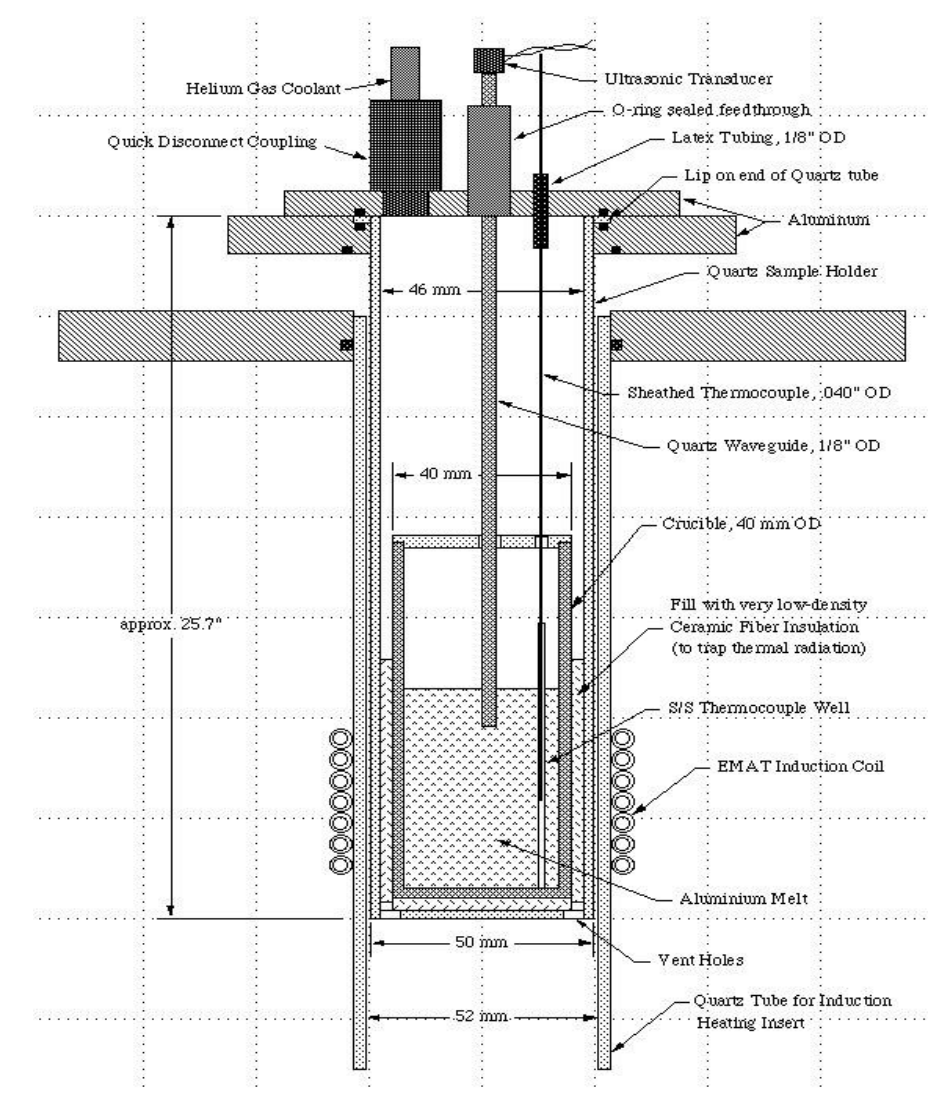

Figure 27. Experimental setup for inducing radial pulsating forces using a combination of a large axial magnetic field and induction coil to produce the EMAT effect.

EMAT processed cast iron showed a significantly modified microstructure, with unique carbides identified, along with an increase in measured hardness as shown in Fig. 28. The EMAT processing significantly increased the hardness of this cast iron material by $51 \%$ at the 9 Tesla condition over the nofield processed condition ( 421 vs. $278 \mathrm{VHN}$ ), which would be expected to provide enhanced wear performance and improved fatigue performance. 


\section{Non-contact EMAT Process Experiments for Solidification of a Ferrous Alloy under a HMF}

Goal: To achieve wrought like microstructures and properties in cast product.

As-received Cast Iron

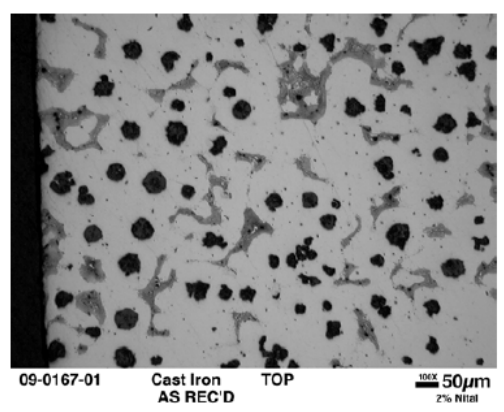

Consists of graphite nodules (dark round features) surrounded by a dominantly ferritic matrix (white regions) with some evidence of pearlite (irregular gray shaped islands) interspersed. The average hardness value is 278 VHN.
Cast Iron solidified under $4.5 \mathrm{~T}$

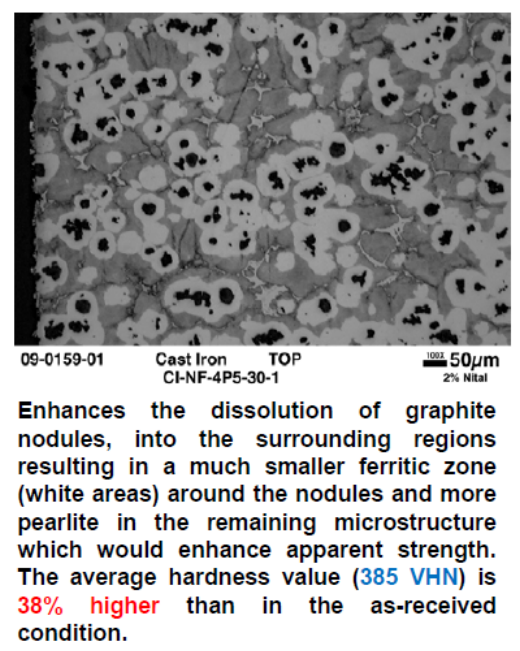

Cast Iron solidified under 9T

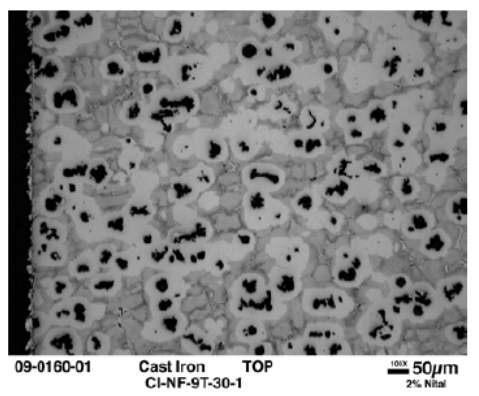

Further enhances the dissolution of some of the graphite nodules. The average hardness value ( $421 \mathrm{VHN}$ ) is $51 \%$ higher than the as-received and the 4.5T processed conditions.

Figure 28. The EMAT processing dramatically altered the appearance of the final solidified microstructures in the cast iron samples as well as significantly improved the hardness of the casting.

Backscattered electron (BSE) imaging in the SEM revealed the complex microstructure of the cast iron and the modification of the microstructure and phases present as a function of magnetic field (Fig. 29). The baseline reference material cast under no magnetic field had a similar microstructure to the asreceived cast iron, though on a slightly finer scale. The morphology/volume fraction of graphite nodules and volume fraction of bright-imaging phases appeared different for the as-received and no-field materials indicating a difference in casting parameters (cooling rate, etc.). The change in nodule morphology with magnetic field strength appears to be associated with increasing EMAT acoustic stimulation and enhanced HTMP solute solubility enrichment. The dark nodular phase (Fig. 29) is graphite, which is surrounded by a shell of columnar ferrite grains radiating from the nodules (Fig 30.a.). Pearlite, a lamellar mixture of ferrite and $\mathrm{Fe}_{3} \mathrm{C}$ cementite, is present on the outside of the ferrite shells (Fig. 30a insert). A fourth component of the microstructure consists of regions (indicated by arrows) that image brighter than the matrix, indicating a higher average atomic number than the ferrite (Fig. 30b inset). 


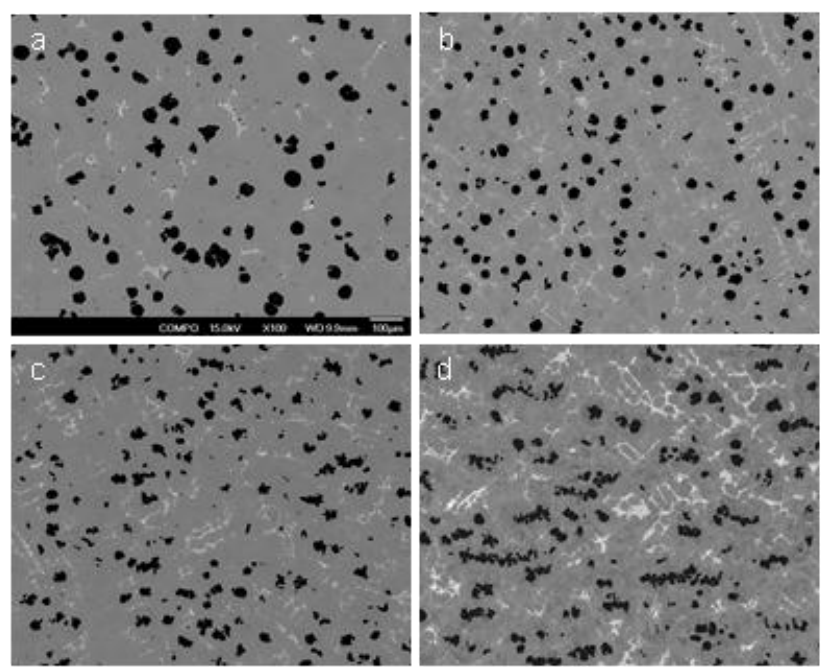

Figure 29. BSE images of cast iron as-received and processed under $0,4.5$ and 18 tesla fields, respectively. Note morphology change of the nodules and the increase of bright-imaging phases with increasing field level.
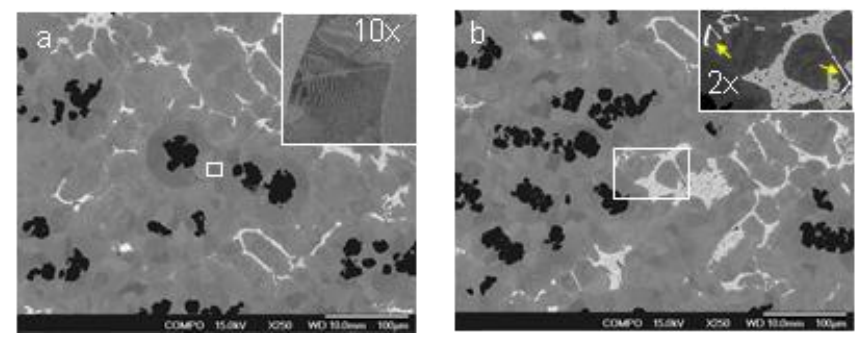

Figure 30. (a) Higher magnification BSE image of cast iron re-cast under 18 tesla field. Note ferrite shells surrounding graphite nodules and pearlite between ferrite shells (inset - small square enlarged), (b) Higher magnification BSE image of cast iron re-cast under 18 tesla field. Note the spatial separation of the nodules from the two bright-imaging phases (inset - small rectangle enlarged).

As magnetic field strength was increased, the graphite nodules changed from roughly equiaxed to agglomerates of smaller, more angular nodules. The density of the bright-imaging regions also increased with field strength and these regions contain higher concentrations of carbides with higher atomic number elements such as W. Both BSE imaging and X-ray microanalysis revealed that the bright-imaging regions represented several different phases depending on the material condition. SEM-based EDS analysis indicated that all these phases were carbides enriched in W (Table 4). The compositions shown in Table 4 are for the 18-tesla-processed material, and are similar to the as-received material. Carbide 1 and Carbide 2 are the light-gray imaging and bright-imaging phases in the BSE images, respectively (inset Fig. 31.b.). This imaging behavior results from the presence of $\mathrm{W}$ in both phases and the higher W/Fe ratio of Carbide 2. The as-received material exhibited two morphologies of Carbide 2, each with 45-50 at\% C. The first morphology of carbide 2 was elongated (designated I in Fig. 31b), and the second type of morphology of carbide 2 (designated II in Fig. 31a) had an equiaxed, more angular geometry. The second type of carbide 2 morphology also, contained significant $\mathrm{Ti}$ (as high as 20 at\%). Image analysis of both optical and SEM BSE images was employed to quantitatively determine the volume fraction of several of the important phases present (Table 5). The most significant of these data is the very noticeable increase for the $18 \mathrm{~T}$ condition in the volume fraction of the bright regions which are known to be $\mathrm{W}$-enriched carbides. 
Table 4 SEM-EDS characterization of the composition of the various phases present in the 18-T EMAT processed sample

\begin{tabular}{|l|c|c|c|c|c|c|c|c|}
\hline \multicolumn{1}{|c|}{$18 \mathrm{~T}$} & $\mathrm{C}$ & $\mathrm{Si}$ & $\mathrm{Ti}$ & $\mathrm{V}$ & $\mathrm{Cr}$ & $\mathrm{Mn}$ & $\mathrm{Fe}$ & $\mathrm{W}$ \\
\hline Ferrite & 0.6 & 10.1 & 0.0 & 0.0 & 0.1 & 0.4 & 88.8 & 0.1 \\
\hline Pearlite & 5.3 & 9.2 & 0.0 & 0.0 & 0.1 & 0.4 & 84.9 & 0.3 \\
\hline Carbide1 & 16.7 & 7.9 & 0.0 & 0.4 & 0.9 & 1.3 & 65.5 & 7.2 \\
\hline Carbide2 & 44.4 & 0.7 & 4.5 & 0.8 & 1.4 & 0.5 & 13.8 & 24.4 \\
\hline
\end{tabular}

\section{Both brightly-imaging phases enriched in W, C}
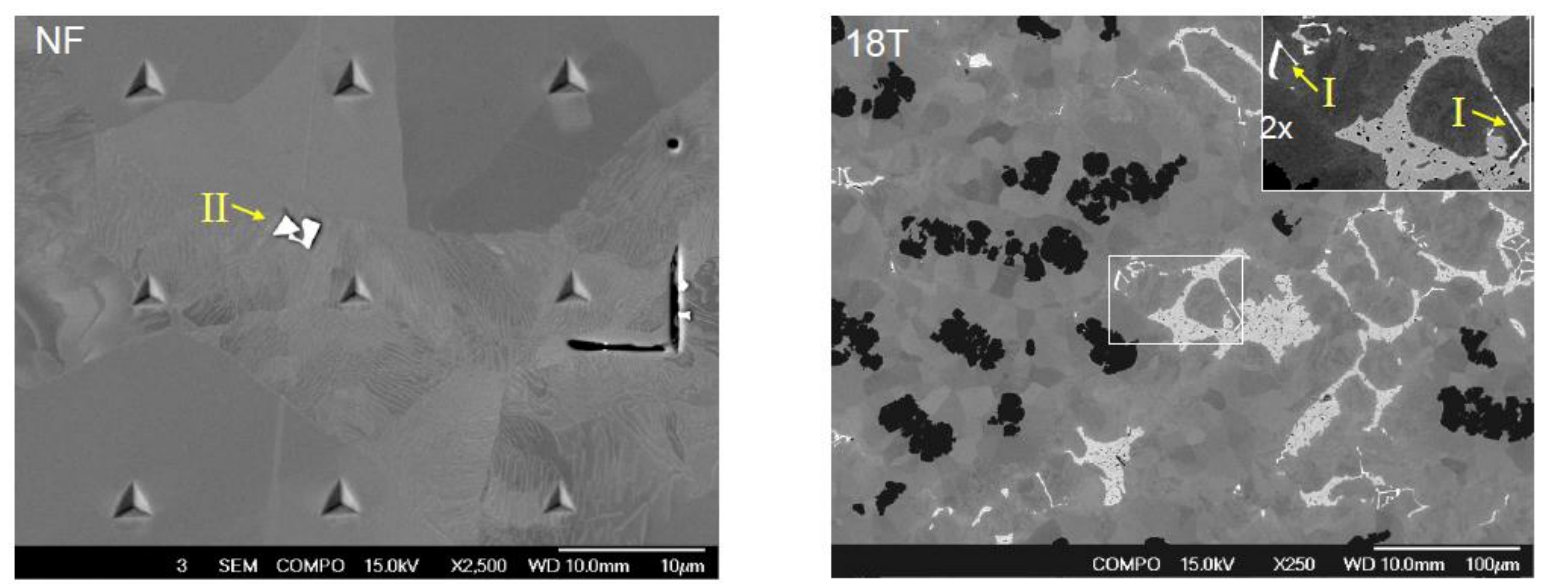

SEM-based EDS indicated W, C enrichment. EMPA-WDS analysis gave quantitative carbon levels and better separation of Si-K and W-M lines (at.\%, see below)

Figure 31. Different carbide types ( 1 and 2 ) and morphologies (I and II) were observed in the various conditions processed in EMAT experiments.

Table 5. SEM/BSE quantitative determination of phase volume fractions for several experimental conditions.

\begin{tabular}{|c|c|c|c|}
\hline & Carbon nodules & Pearlite & Bright regions \\
\hline As-received & 9.7 & 10.9 & $0.7^{* *}$ \\
\hline No field & 7.1 & 45 & $2.4^{* *}$ \\
\hline 18 tesla processing & 7.2 & 48 & $9.4^{* *}$ \\
\hline
\end{tabular}

** includes both Carbide 1 and Carbide 2

Additional microstructural characterization using TEM and electron diffraction helped further identify the bright-imaging phases as summarized in figures 32 and 33. Figure 32 indicates that the elongated Carbide 2 is identified from multiple zone axis obtained via TEM as a face-centered cubic (fcc) phase that is enriched in $\mathrm{W}$ and $\mathrm{C}$. Although there is not a previously known fcc $\mathrm{W}$ carbide, the presence of Ti, $\mathrm{V}$, and $\mathrm{Fe}$ (from Table 4) determined from SEM-EDS appeared to stabilize the fcc carbide phase for this Wenriched, $(\mathrm{W}, \mathrm{X})_{\mathrm{x}} \mathrm{Cy}$, type carbide. The existence of this fcc $\mathrm{W}$-rich carbide may be the result of the HTMP on altering phase equilibria by enhancing solute solubilities and allowing for additional phases to occur due to the additional thermodynamic degree of freedom that applying a high magnetic field brings to materials processing. Although not shown here, the second $\mathrm{W}$-containing carbide was also shown to be fcc. 


\section{TEM analysis required for identifying second phases}

FIB lift-out specimens for selecting phases and reducing ferromagnetic interaction
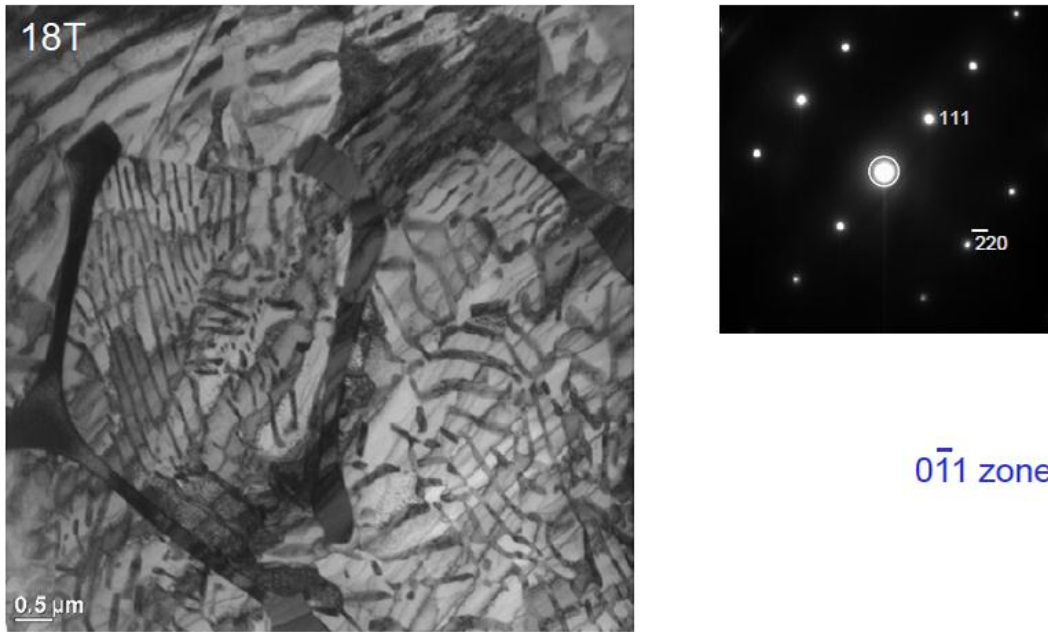

$\overline{1} \overline{1} 2$ zone

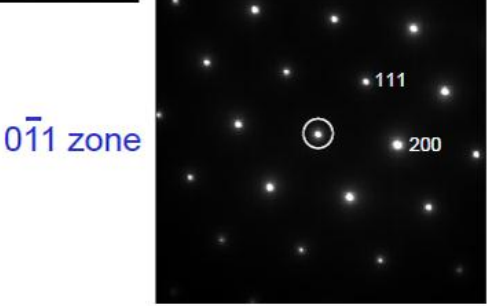

Figure 32. . The elongated Carbide 2 phase (darker elongated phase shown in the TEM Bright Field image on left) is shown to be face-centered cubic from these multiple zone axis electron diffraction patterns.

The complex nature of the microstructural constituents developed during the 18 T EMAT solidification experiment is shown Figure 33 where different regions of the specimen exhibit distinct compositional differences (Table 6). As shown by the First Order Laue Zone (FOLZ) diffraction pattern in this figure, a diamond cubic phase with a large lattice parameter was identified as the carbo-silicide eta $(\eta)$ phase.

\section{TEM analysis required for identifying second phases}

FIB lift-out specimen from complex, multiple phase cluster
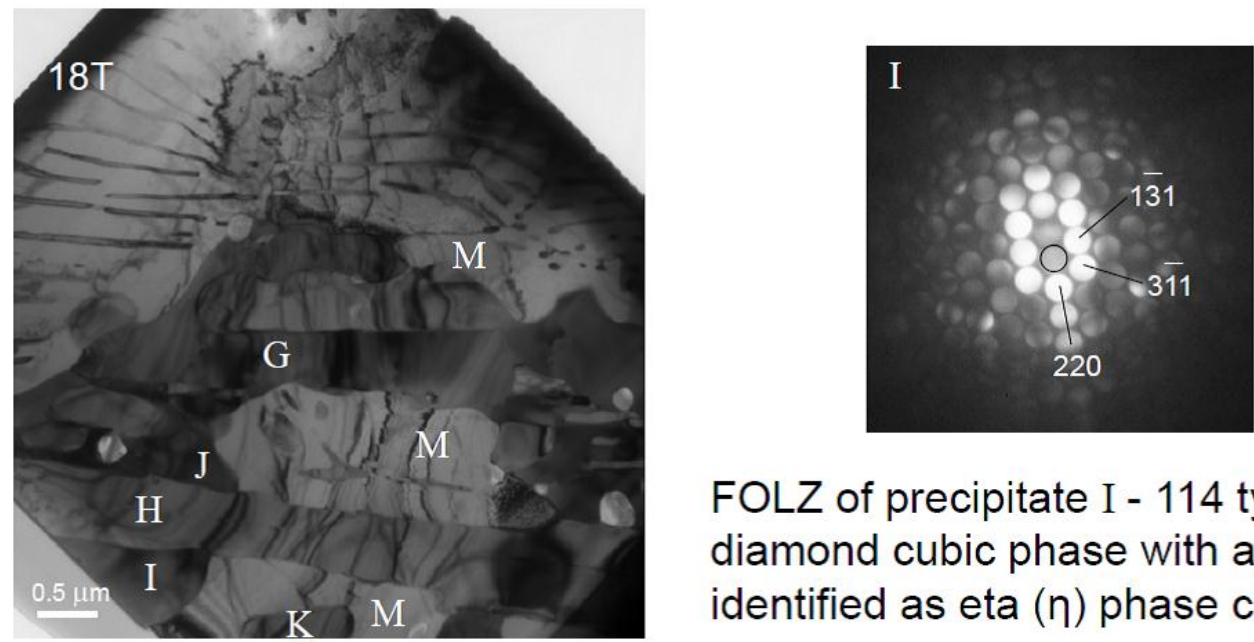

FOLZ of precipitate I - 114 type zone of diamond cubic phase with $a_{\circ}=10.7 \AA$ identified as eta $(\eta)$ phase carbo-silicide

Figure 33. The complex nature of the microstructure that evolved in the cast iron during the $18 \mathrm{~T}$ EMATsolidification experiment is clearly evident (in the TEM bright field image to the left) by the multiple phases (indicated as $\mathrm{M}$ [matrix], G, H, I, J, K) clustered in this small region. 
Table 6. Results of TEM analysis for W-modified cast iron

\begin{tabular}{|l|l|l|l|l|l|l|l|}
\hline At.\% & C & Si & V & Cr & Mn & Fe & W \\
\hline M matrix & n.d. & 9.8 & n.d. & 0.1 & 0.7 & 89.4 & n.d. \\
\hline G,H & Yes & 0.7 & 0.5 & 1.4 & 2.0 & 93.6 & 1.9 \\
\hline I,J,K & Yes & 10.3 & 0.2 & 0.5 & 1.5 & 81.8 & 5.7 \\
\hline
\end{tabular}

Clearly the microstructural analyses conducted in the cast iron EMAT study highlight the need for conducting very fundamental future studies, perhaps using real-time in-situ neutron diffraction methods available at the Spallation Neutron Source located at ORNL, to elucidate the full impact of HTMP/EMAT on the final microstructure and properties. A long-term program focused on systematically investigating the EMAT solidification processing methodology should be pursued to fully understand the major impact this new processing methodology will have on the microstructures and performance of the next generation of structural materials.

In summary, for the EMAT-processed cast iron samples analyzed:

- $9 \mathrm{~T}$ magnetic field EMAT increased the hardness of the cast iron from 278 to $421 \mathrm{VHN}$; a dramatic increase of $51 \%$.

- The percent of graphite nodules decreased and the morphology changed significantly with increased magnetic field strength (increased carbon in solution at high temperature)

- An increased pearlite volume fraction in EMAT processed cast iron relative to as-received condition was observed

- Several W-containing carbides were identified as field strength increased: - two fcc (W, X) C phases with different morphology and composition, and a W-containing diamond cubic eta, $\eta$, carbo-silicide $\left(\mathrm{a}_{\mathrm{o}}-10.7 \AA\right)$ were observed

- EMAT may provide the processing methodology to achieve wrought like properties in cast alloys

\subsubsection{Magnesium with Dysprosia $\left(\mathrm{Dy}_{2} \mathrm{O}_{3}\right)$ Nanoparticle Dispersion EMAT Evaluation}

A series of experiments was conducted at the National High Magnetic Field Laboratory (NHMFL) in the 8-inch diameter, 20-T bitter resistance magnet to evaluate whether the EMAT effect could produce a very fine grained microstructure in a pure material, as well as uniformly distribute nanoparticulate dysprosia in the final sample. Since there is a big thrust within industry for enhanced performance lightweight materials and for military applications, $\mathrm{Mg}$ was chosen as the pure metal to be studied. Typically pure metals solidify with a coarse grained microstructure, and attempts to disperse nanoparticles in melts result in massive agglomerations that do not have the beneficial impact that a finely dispersed powder would have on the microstructure and performance of the final product.

Samples were prepared for EMAT processing by sandwiching the nanoparticles (with sphere and rod morphologies) between two Mg layers, in a stainless steel crucible. Fig. 34 schematically depicts the experimental set-up for these experiments. 


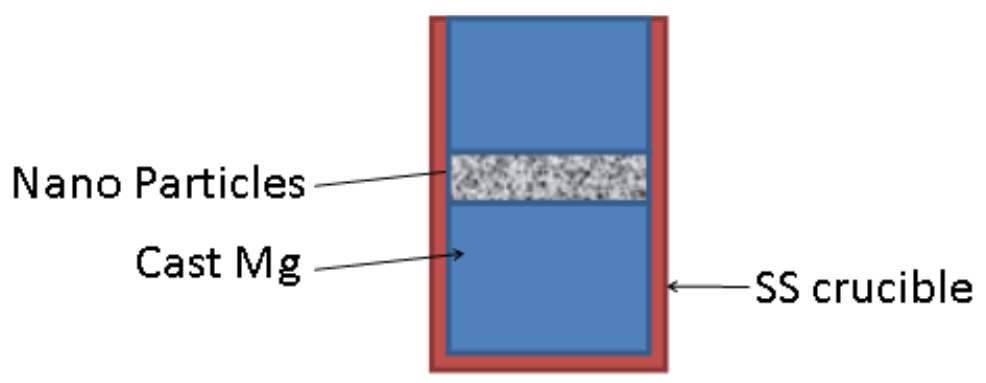

Figure 34. Schematic representing the experimental set-up for EMAT processing of pure Mg with nanoparticles incorporated into the set-up to achieve nano-particle dispersion.

The cast $\mathrm{Mg}$ sections were pressed into the stainless steel crucible, and all casting was performed in a glove box under an inert argon atmosphere. The goal of these experiments was to incorporate the nanoparticles $\mathrm{Dy}_{2} \mathrm{O}_{3}$ in $\mathrm{Mg}$, as a nano dispersion using EMAT processing, avoiding agglomeration. EMAT processing was conducted on two samples. Both samples were purged under Ar gas for 30 minutes; then the magnetic field was ramped up to 20T. Once at field, the EMAT processing was conducted by applying induction heat at $\sim 10 \mathrm{kHz}$ for a given power level. Once the $\mathrm{Mg}$ fully melted, as evident by the completion of the thermal arrest, the samples were rapidly cooled using a He-gas quench. Upon examination of the first EMAT processed sample, it was determined that the EMAT exposure for Sample 1 was excessive. Sample 2 was processed using a lower EMAT power level. Figures 35 and 36 show photos of the Mg sample contained in the stainless steel crucible after thermo-magnetic processing. The white strips are present help to provide a snug fit inside the quartz sample tube during the EMAT processing. The tube extending out of the crucible is for the thermocouple.

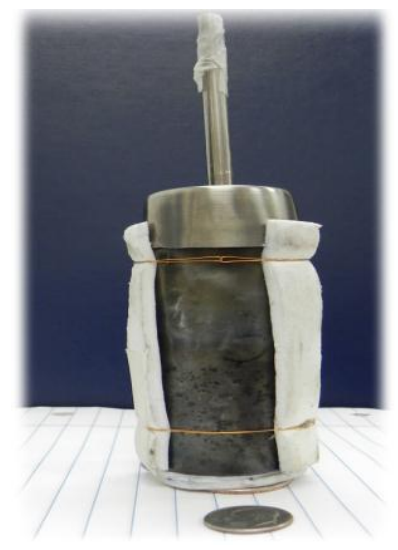

Figure 35. Mg sample stainless steel crucible after thermo-magnetic processing. 

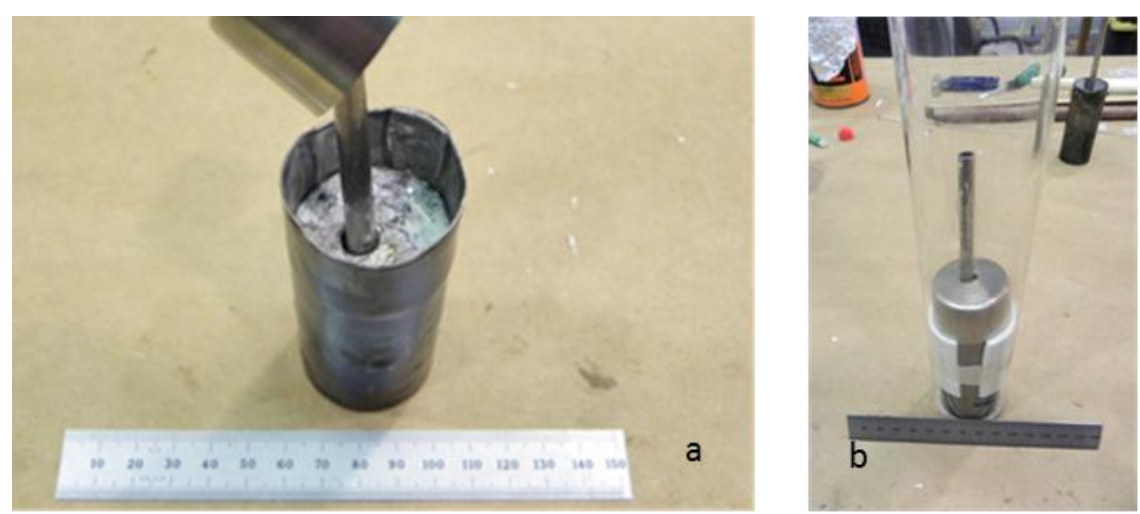

Figure 36. A pure Mg samples is shown in the stainless steel crucible prior to the EMAT experiments (a) the sample prior to placement of the loose nanoparticles in the assembly and (b) the final assembly with a containment lid on top of the crucible in the quartz, inert atmosphere experiment tube.

The Mg EMAT experiments were extremely successful in meeting the goals of grain refinement and uniform particle dispersion. Characterization results document that a nanocrystalline grain size was developed in the $\mathrm{Mg}$ matrix and the dysprosium oxide nanospheres and nanorods (two separate experiments) were very uniformly distributed throughout the casting with no significant evidence of agglomeration.

Transmission electron microscopy of the samples revealed the uniform (non-agglomerated) dispersion of the fine nanorods and nanospheres as shown in Figures 37.
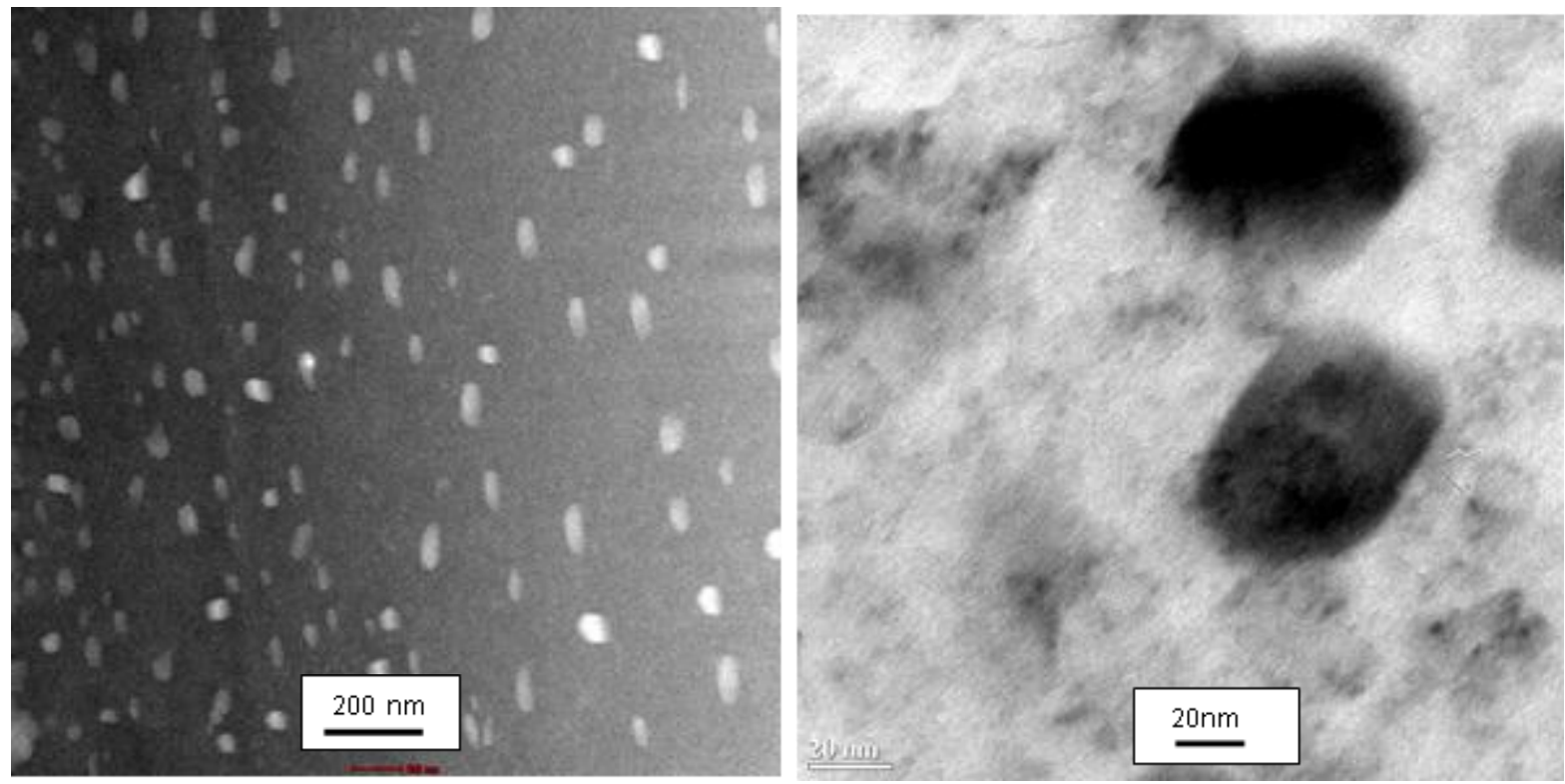

Figure 37. Transmission electron microscopy micrographs of the uniformly dispersed dysprosium oxide.

A cross section of the EMAT processed sample was prepared using a focused ion beam method (FIB) so that very thin foils could be obtained that would be suitable samples for STEM analyses. The initial FIB sample can be seen in Figure 38 in the upper left hand corner. The sample was imaged using both BF (bright field) and DF (dark field) diffraction conditions which are visible in Figure 38. For this location in the EMAT processed ingot, an extremely fine and uniform dispersion of the dysprosia nanoparticles is evident as seen in the bottom two images of Figure 38. Figure 39 shows a second location in this sample with comparable dispersions of the nanoparticles. Figures 40 and 41 show evidence of more agglomerated 
nanoparticles, which may be due to their location in the central part of the ingot that solidified last. Energy Dispersive X-ray Spectroscopy (EDS) was performed on the region shown in Figure 40 identifying the nanoparticles as dysprosia and not just contamination surface oxides on the thin foil. The HAADF (high angle annular dark field) technique which is atomic number ( $Z$ ), sensitive was used in Figure 41 to show contrast between the lower $\mathrm{Z} \mathrm{Mg}$ matrix and the higher Z Dysprosia. Clearly, these first EMAT experiments on dispersing nanoparticles in $\mathrm{Mg}$ were very successful, and provided the incentive to investigate dispersing different nanoparticle populations in both $\mathrm{Mg}$ and a $\mathrm{Mg}-7.5$ atomic percent Li alloy ( see section 3.3.3)
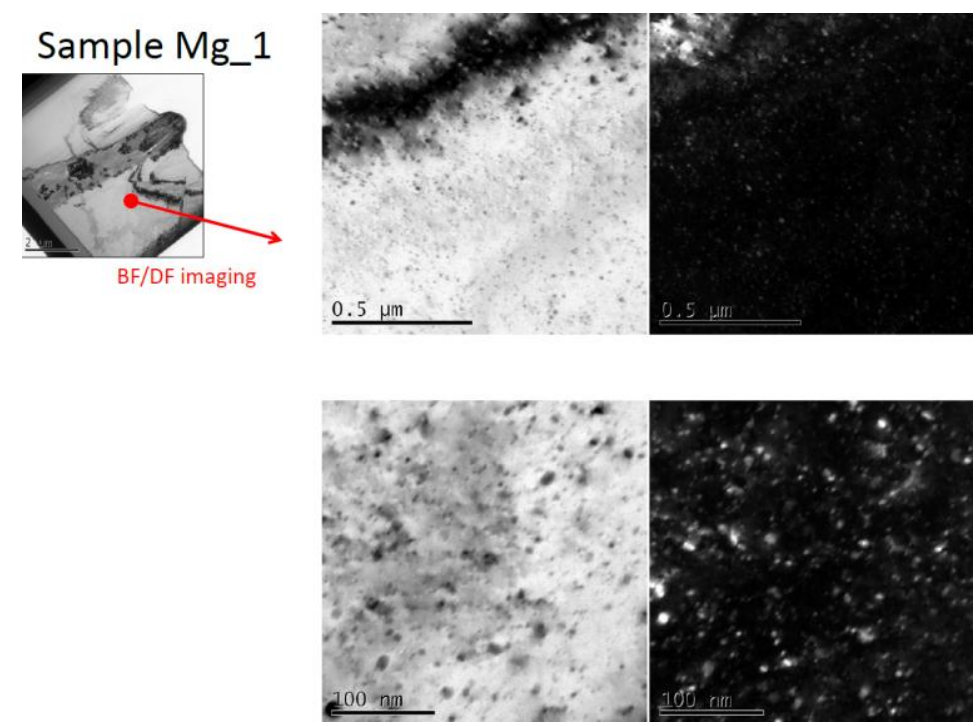

Figure 38. BF (middle two images) and DF (two right hand side images) images of one location of the EMAT processed $\mathrm{Mg}$ ingot clearly showing the uniformly distributed dysprosia nanoparticles achieved in this experiment.
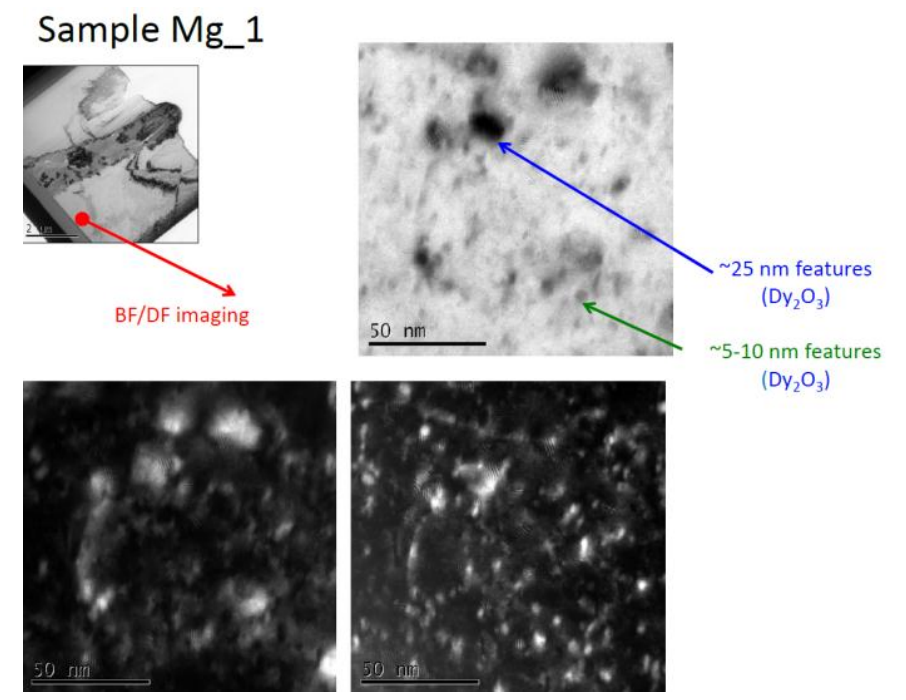

Figure 39. A second location in this cross section showed more evidence of the finely dispersed dysprosia nanoparticles. 


\section{Sample Mg_1}
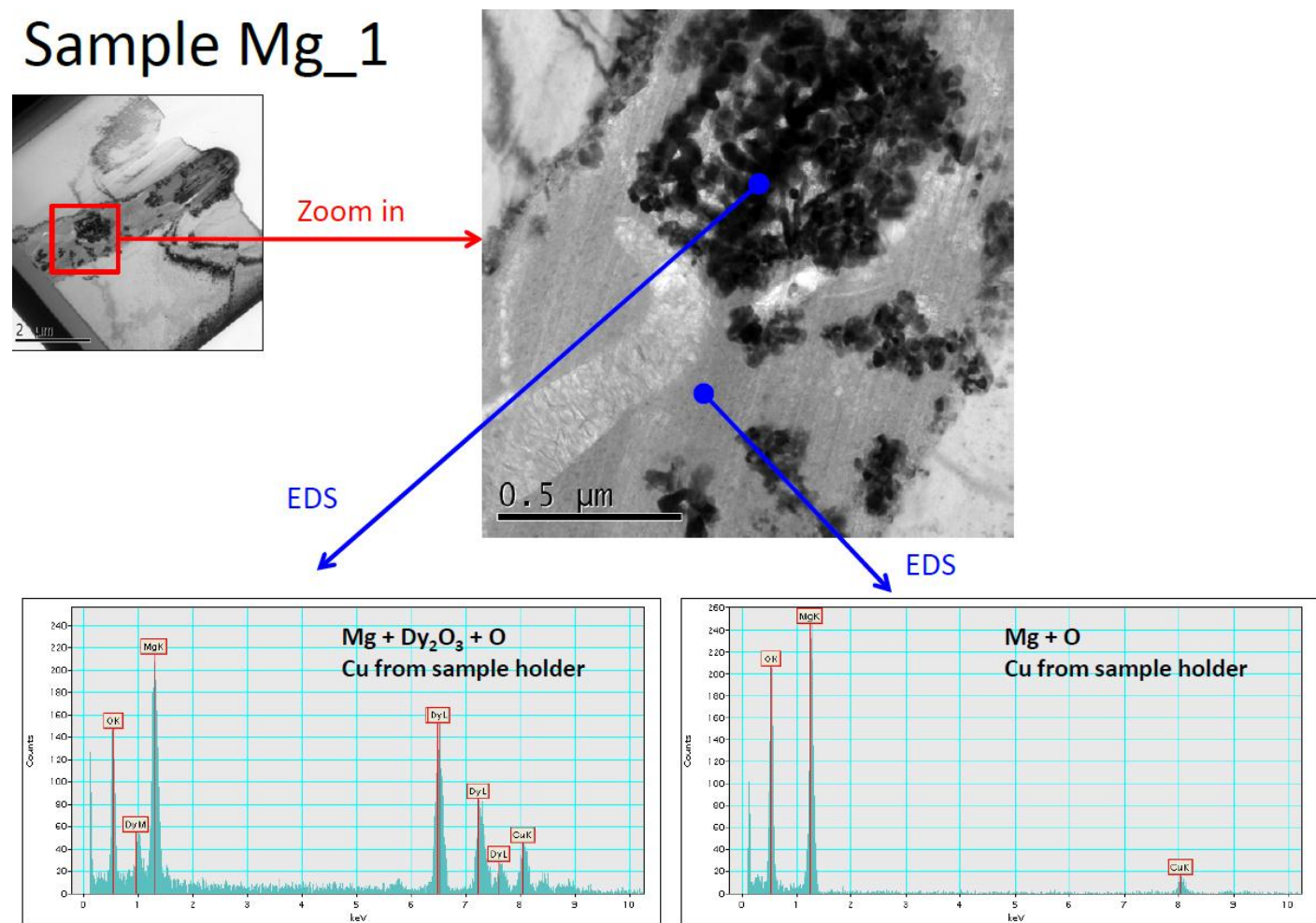

Figure 40. Energy Dispersive X-ray Spectroscopy (EDS) characterization clearly identified these agglomerated nanoparticles as dysprosia.
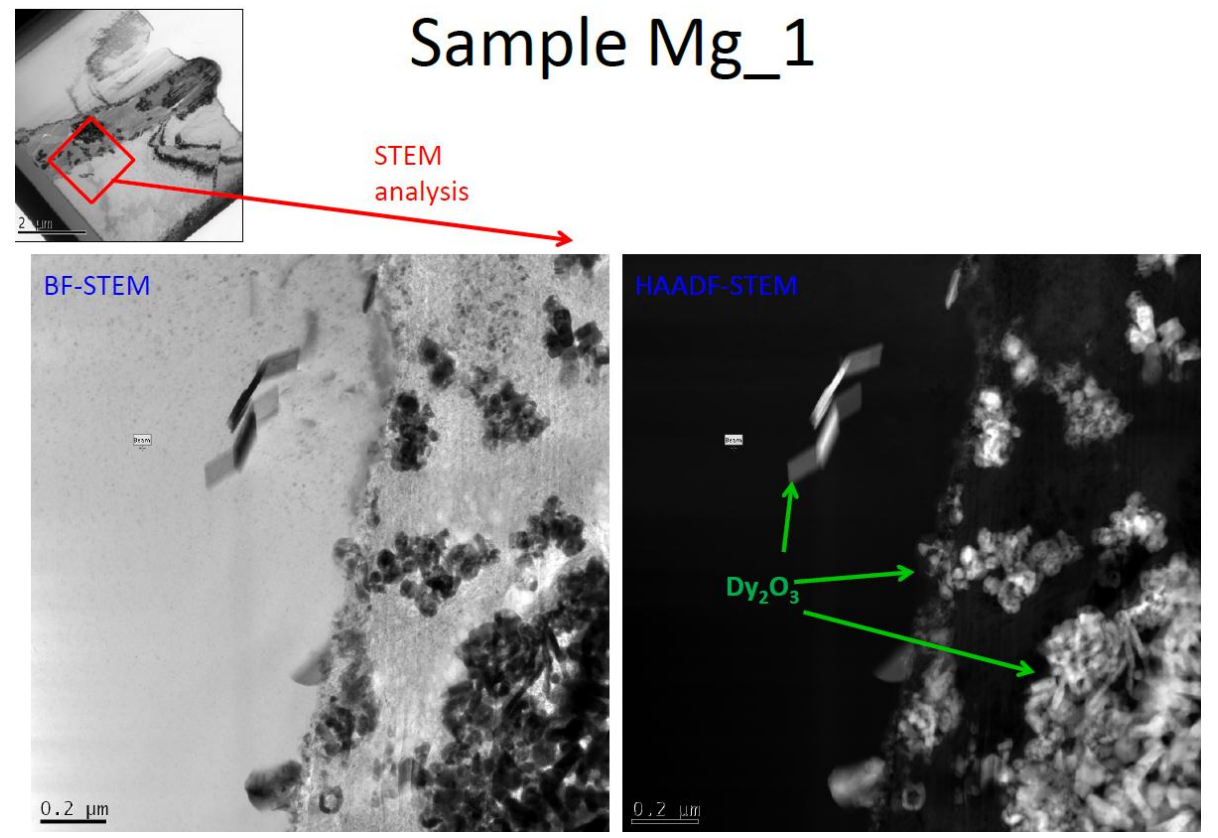

Figure 41. The HAADF (high angle annular dark field) STEM technique (which is atomic number, $\mathrm{Z}$,sensitive) clearly shows the contrast between the lower $\mathrm{Z} \mathrm{Mg}$ matrix material and the higher Z-based Dysprosia nanoparticles. 


\subsubsection{EMAT Technology for Developing Wrought Properties in Additional Mg As-cast Alloys}

The success of the Mg EMAT experiments reported in the previous section supports the premise that this technology will be the enabler to produce the next generation of nanoparticle reinforced metallic composites. The possibility of higher strength and higher ductility exists in magnesium alloys if nanodispersions of a ceramic phase are realized. Higher temperature structural applications for metal matrix composite nano-particulate reinforced magnesium alloys whereby the ceramic phase increases creep resistance are also possible through EMAT processing (impacting deformation mechanisms in hexagonal closed packed crystal structure $\mathrm{Mg}$ ) not only at ambient temperature, but at elevated temperatures beyond Mg's current relatively low elevated temperature limits. To make new inroads into this investigation of EMAT to disperse nanoparticles in $\mathrm{Mg}$, samples incorporating different nanoparticle populations as well as examining a Mg-7 at.\% Li alloy for the matrix material were prepared and provided to collaborators (led by Prof. Michelle Manuel) at the University of Florida (UF) for evaluation.

Although specific performance metrics were not measured on EMAT samples in this project (only hardness data), a series of magnesium experiments with various base chemistries, different nanoparticle species, and various EMAT processing conditions were conducted for microstructural and mini-tensile evaluation in the future at UF. The following information documents those experiments. In Table 7, the specific chemistry and nanoparticle identification summary data are given along with the scientific merit (goal behind each run) of each experiment.

Table 7. Definition of Mg EMAT experiment sample identification and goal.

\begin{tabular}{|c|c|c|c|c|c|c|}
\hline Run & Matrix & Particle & $\begin{array}{l}\text { Size } \\
(\mathrm{nm})\end{array}$ & $\begin{array}{l}\text { Volume } \\
\%\end{array}$ & $\begin{array}{l}\text { EMAT } \\
\text { Energy }\end{array}$ & Scientific Merit \\
\hline 1 & $\mathrm{Mg}$ & None & $\begin{array}{l}\mathrm{N} / \\
\mathrm{A}\end{array}$ & N/A & Normal & Control - No Particles \\
\hline 2 & $\mathrm{Mg}$ & $\mathrm{Er}_{2} \mathrm{O}_{3}$ & 45 & 1 & Normal & $\begin{array}{l}\text { Elastic Modulus and Coefficient of Thermal } \\
\text { Expansion Differences }\end{array}$ \\
\hline 3 & $\mathrm{Mg}$ & Diamond & 45 & 1 & Normal & $\begin{array}{l}\text { Elastic Modulus and Coefficient of Thermal } \\
\text { Expansion Differences Size }\end{array}$ \\
\hline 4 & $\mathrm{Mg}$ & Diamond & 45 & 1 & 0 & Control - No EMAT \\
\hline 5 & $\mathrm{Mg}$ & Diamond & 6 & 1 & Normal & Size, Volume Fraction \\
\hline 6 & $\mathrm{Mg}$ & Diamond & 6 & 0.1 & Normal & Volume Fraction \\
\hline 7 & $\mathrm{Mg}$ & $\mathrm{Er}_{2} \mathrm{O}_{3}$ & 45 & 1 & 0 & Control - No EMAT \\
\hline 8 & $\begin{array}{l}\mathrm{Mg}- \\
7.5 \mathrm{at} \% \mathrm{Li}\end{array}$ & None & $\begin{array}{l}\mathrm{N} / \\
\mathrm{A}\end{array}$ & N/A & Normal & Control - No Particles \\
\hline 9 & $\begin{array}{l}\mathrm{Mg}- \\
7.5 \mathrm{at} \% \mathrm{Li}\end{array}$ & Diamond & 45 & 1 & Normal & Nonbasal Slip Activation \\
\hline 10 & $\begin{array}{l}\mathrm{Mg}- \\
7.5 \mathrm{at} \% \mathrm{Li}\end{array}$ & $\mathrm{Er}_{2} \mathrm{O}_{3}$ & 45 & 1 & Normal & $\begin{array}{l}\text { Elastic Modulus and Coefficient of Thermal } \\
\text { Expansion Differences }\end{array}$ \\
\hline 11 & $\begin{array}{l}\mathrm{Mg}- \\
\text { 3.5at\%Li }\end{array}$ & Diamond & 45 & 1 & Normal & Nonbasal Slip Activation \\
\hline 12 & $\begin{array}{l}\mathrm{Mg}- \\
3.5 \mathrm{at} \% \mathrm{Li}\end{array}$ & None & $\begin{array}{l}\mathrm{N} / \\
\mathrm{A}\end{array}$ & N/A & Normal & Control - No Particles \\
\hline 13 & $\mathrm{Mg}$ & $\mathrm{Dy}_{2} \mathrm{O}_{3}$ & $\begin{array}{l}30, \\
25 \mathrm{x} \\
225\end{array}$ & 1 & Normal & 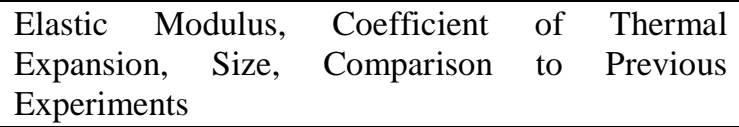 \\
\hline 14 & $\mathrm{Mg}$ & $\mathrm{Dy}_{2} \mathrm{O}_{3}$ & $\begin{array}{l}30, \\
25 \mathrm{x} \\
225\end{array}$ & 1 & 0 & Control - No EMAT \\
\hline
\end{tabular}


The EMAT processing conditions are summarized in Table 8. One series (crucible numbers 1-7) were treated with the EMAT superimposed through most of the solidification process but was stopped at $20^{\circ} \mathrm{C}$ above the liquidus as shown in Figure 42. A second series (\#8-14) kept the EMAT effect at a reduced induction power setting through solidification as shown in Figure 43.

Table 8. Summary of Mg EMAT experiment control parameters for each condition.

\begin{tabular}{|c|c|c|c|c|c|c|c|c|}
\hline $\begin{array}{l}\text { Sample } \\
\text { Name }\end{array}$ & $\begin{array}{l}\text { Crucible } \\
\text { Number }\end{array}$ & Matrix & Particle & Size (nm) & $\begin{array}{l}\text { Volume } \\
\%\end{array}$ & $\begin{array}{l}\text { Field } \\
\text { (Tesla) }\end{array}$ & $\begin{array}{l}\text { Induction } \\
\text { Power to } \\
\text { Liquid } \\
(\mathbf{k W})\end{array}$ & \begin{tabular}{|l|} 
Induction \\
Power \\
during \\
solidification \\
(kW)
\end{tabular} \\
\hline Mg None 1.2 & 6 & $\mathrm{Mg}$ & None & N/A & N/A & 18 & 2.8 & 0 \\
\hline Mg Erb 1.2 & 7 & $\mathrm{Mg}$ & $\mathrm{Er}_{2} \mathrm{O}_{3}$ & 45 & 1 & 18 & 2.8 & 0 \\
\hline $\mathrm{Mg}$ 45Dia 1.2 & 2 & $\mathrm{Mg}$ & Diamond & 45 & 1 & 18 & 2.8 & 0 \\
\hline $\mathrm{Mg}$ 45Dia 0 & 3 & $\mathrm{Mg}$ & Diamond & 45 & 1 & 0 & 2.8 & 0 \\
\hline $\begin{array}{ll}\mathrm{Mg} & \text { 6Dia(a) } \\
1.2 & \\
\end{array}$ & 5 & $\mathrm{Mg}$ & Diamond & 6 & 1 & 18 & 2.8 & 0 \\
\hline $\begin{array}{ll}\mathrm{Mg} & 6 \mathrm{Dia}(\mathrm{b}) \\
1.2 & \end{array}$ & 4 & $\mathrm{Mg}$ & Diamond & 6 & 0.1 & 18 & 2.8 & 0 \\
\hline $\mathrm{Mg}$ Erb 0 & 1 & $\mathrm{Mg}$ & $\mathrm{Er}_{2} \mathrm{O}_{3}$ & 45 & 1 & 0 & 2.8 & 0 \\
\hline $\begin{array}{l}\mathrm{Mg} 7 \mathrm{Li} \text { None } \\
1.2\end{array}$ & 10 & $\begin{array}{l}\mathrm{Mg}- \\
7.5 \mathrm{at} \% \mathrm{Li}\end{array}$ & None & N/A & N/A & 18 & 2.8 & 1.2 \\
\hline $\begin{array}{l}\mathrm{Mg} 7 \mathrm{Li} \text { 45Dia } \\
1.2\end{array}$ & 9 & $\begin{array}{l}\mathrm{Mg}- \\
7.5 \mathrm{at} \% \mathrm{Li}\end{array}$ & Diamond & 45 & 1 & 18 & 2.8 & 1.2 \\
\hline $\begin{array}{ll}\mathrm{Mg} 7 \mathrm{Li} & \mathrm{Erb} \\
1.2 & \end{array}$ & 8 & $\begin{array}{l}\mathrm{Mg}- \\
7.5 \mathrm{at} \% \mathrm{Li}\end{array}$ & $\mathrm{Er}_{2} \mathrm{O}_{3}$ & 45 & 1 & 18 & 2.8 & 1.2 \\
\hline $\begin{array}{l}\text { Mg15Li } \\
\text { 45Dia } 1.2\end{array}$ & 12 & $\begin{array}{l}\mathrm{Mg}- \\
\text { 3.5at } \% \mathrm{Li}\end{array}$ & Diamond & 45 & 1 & 18 & 2.8 & 1.2 \\
\hline $\begin{array}{l}\text { Mg15Li None } \\
1.2\end{array}$ & 11 & $\begin{array}{l}\mathrm{Mg}- \\
3.5 \mathrm{at} \% \mathrm{Li}\end{array}$ & None & N/A & N/A & 18 & 2.8 & 1.2 \\
\hline Mg Dysp 1.2 & 13 & $\mathrm{Mg}$ & $\mathrm{Dy}_{2} \mathrm{O}_{3}$ & $\begin{array}{l}30, \\
25 \times 225\end{array}$ & 1 & 18 & 2.8 & 1.2 \\
\hline Mg Dysp 0 & 14 & $\mathrm{Mg}$ & $\mathrm{Dy}_{2} \mathrm{O}_{3}$ & $\begin{array}{l}30, \\
25 \times 225\end{array}$ & 1 & 0 & 2.8 & 1.2 \\
\hline
\end{tabular}




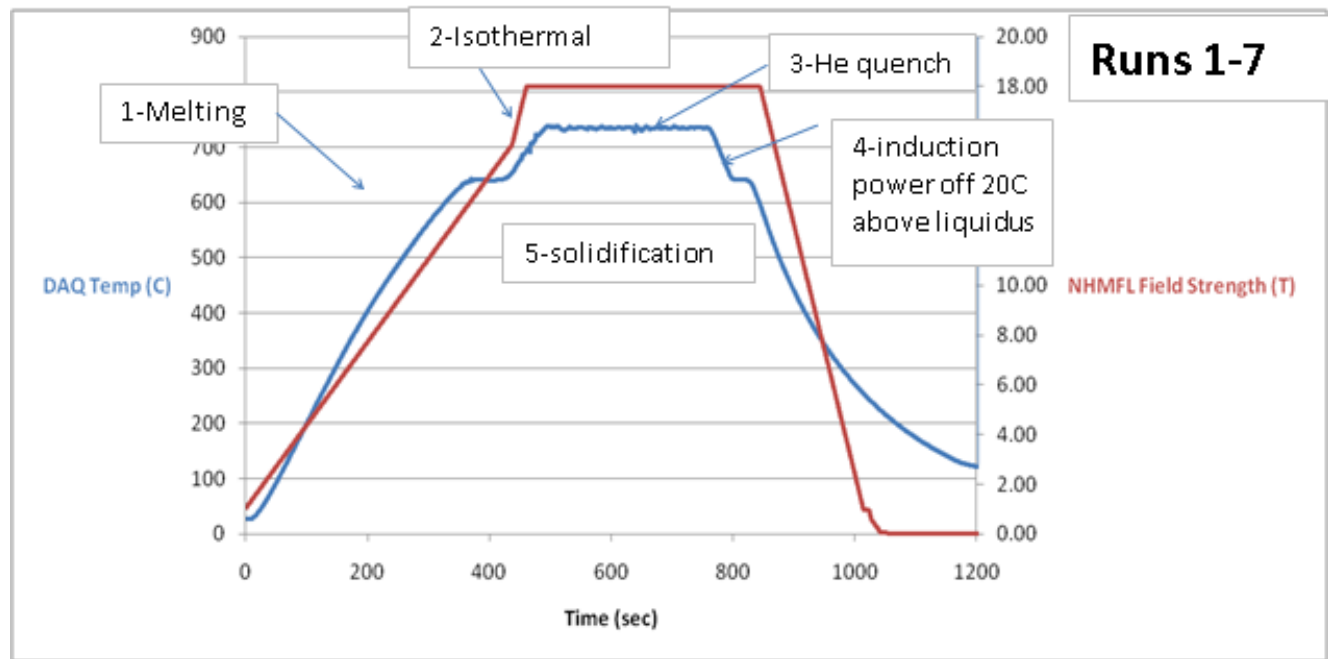

Figure 42. One series of EMAT experiments stopped the EMAT effect by turning off the induction power.

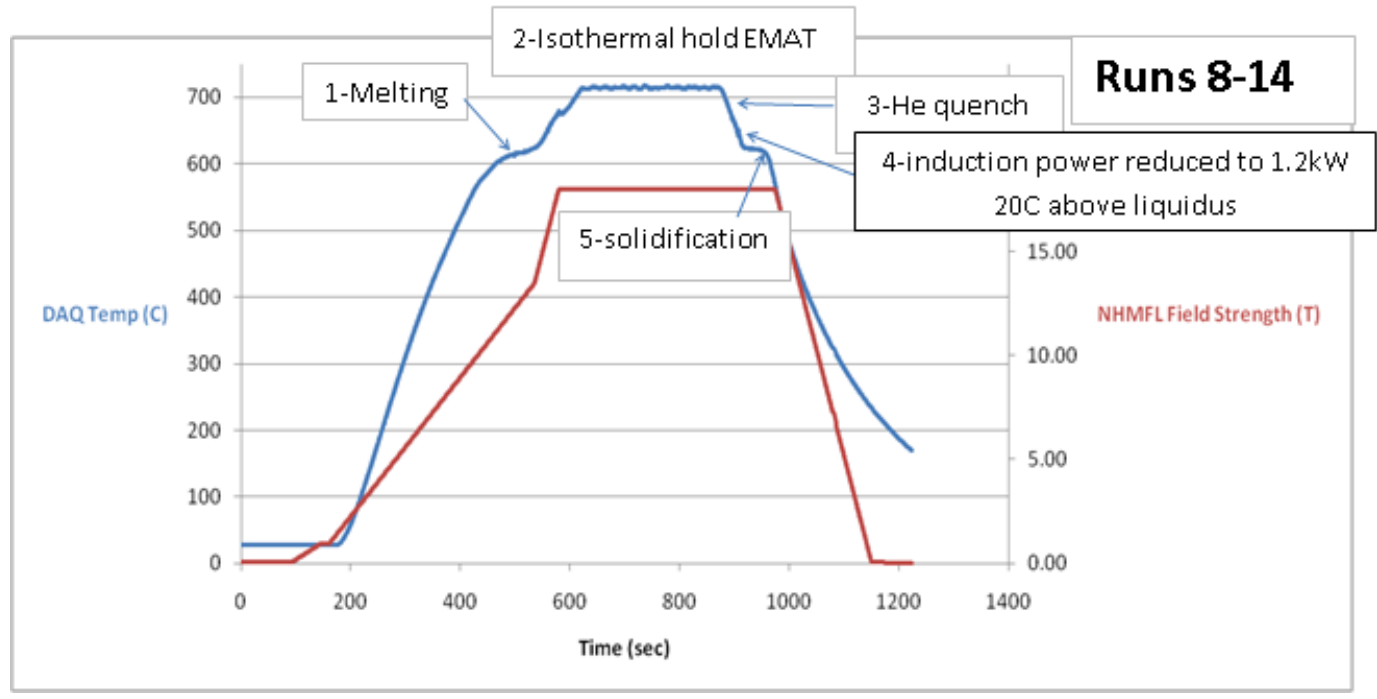

Figure 43. The second series of EMAT experiments continued the EMAT at a reduced induction power supply setting until solidification was completed.

By the conclusion of this project, these samples had only been cut in half using an electro discharge machining (EDM) process. The initial evaluation of appearance suggests that all of the samples solidified with high integrity, with the only obvious voids being associated with the stainless steel thermocouple wells that were inserted into the samples (via a pre-drilled hole). Figure 44 shows these samples together. Figure 45 shows a typical solidified sample. University of Florida collaborators led by Prof. Michelle Manuel will fabricate small test coupons and TEM samples from these small ingots. UF will report these data to ORNL, and incorporate results in a coauthored refereed literature publication to document the experiments outside of this report. 


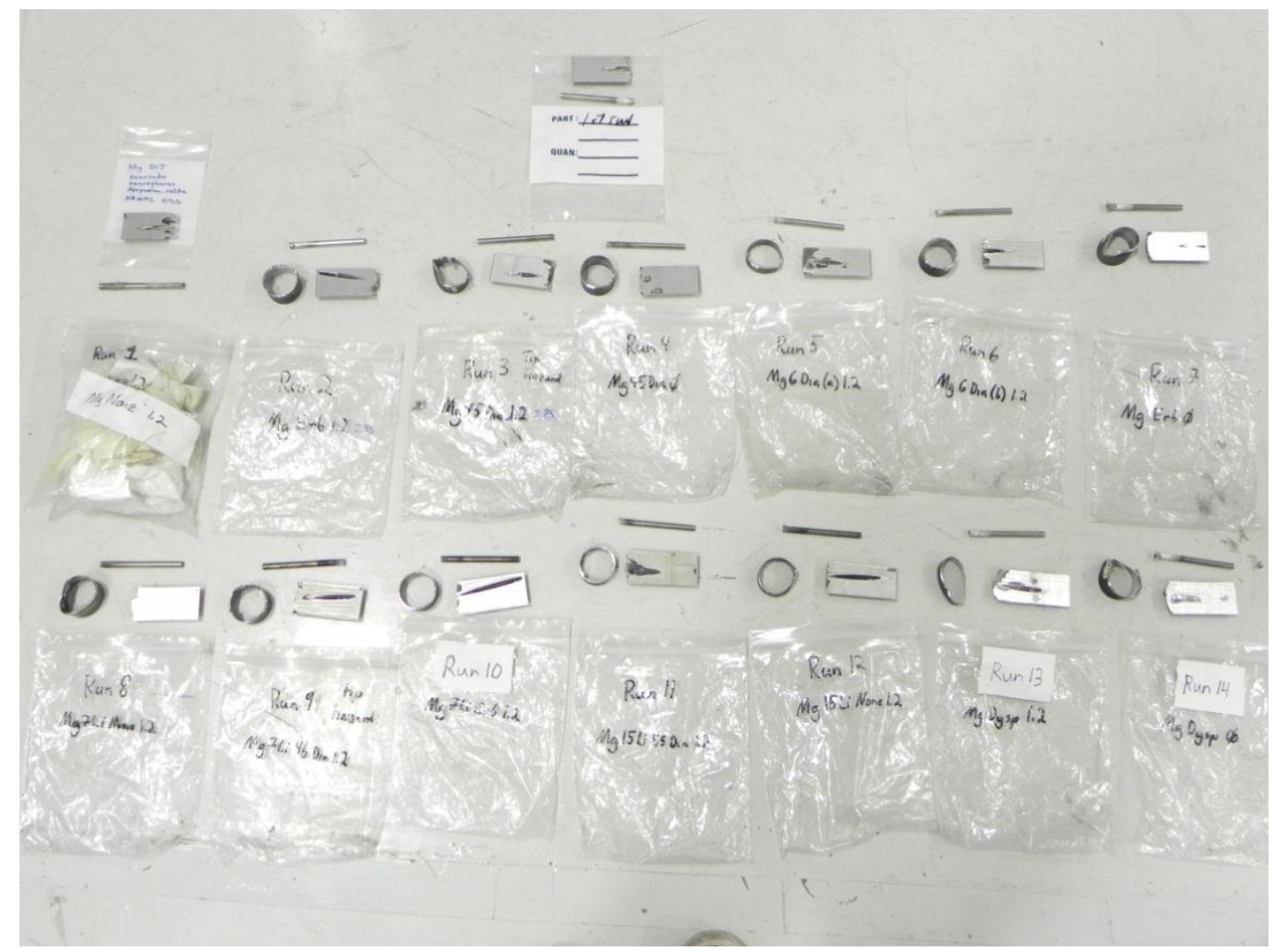

Figure 44. The recent EMAT experiments after being cut in half by EDM.

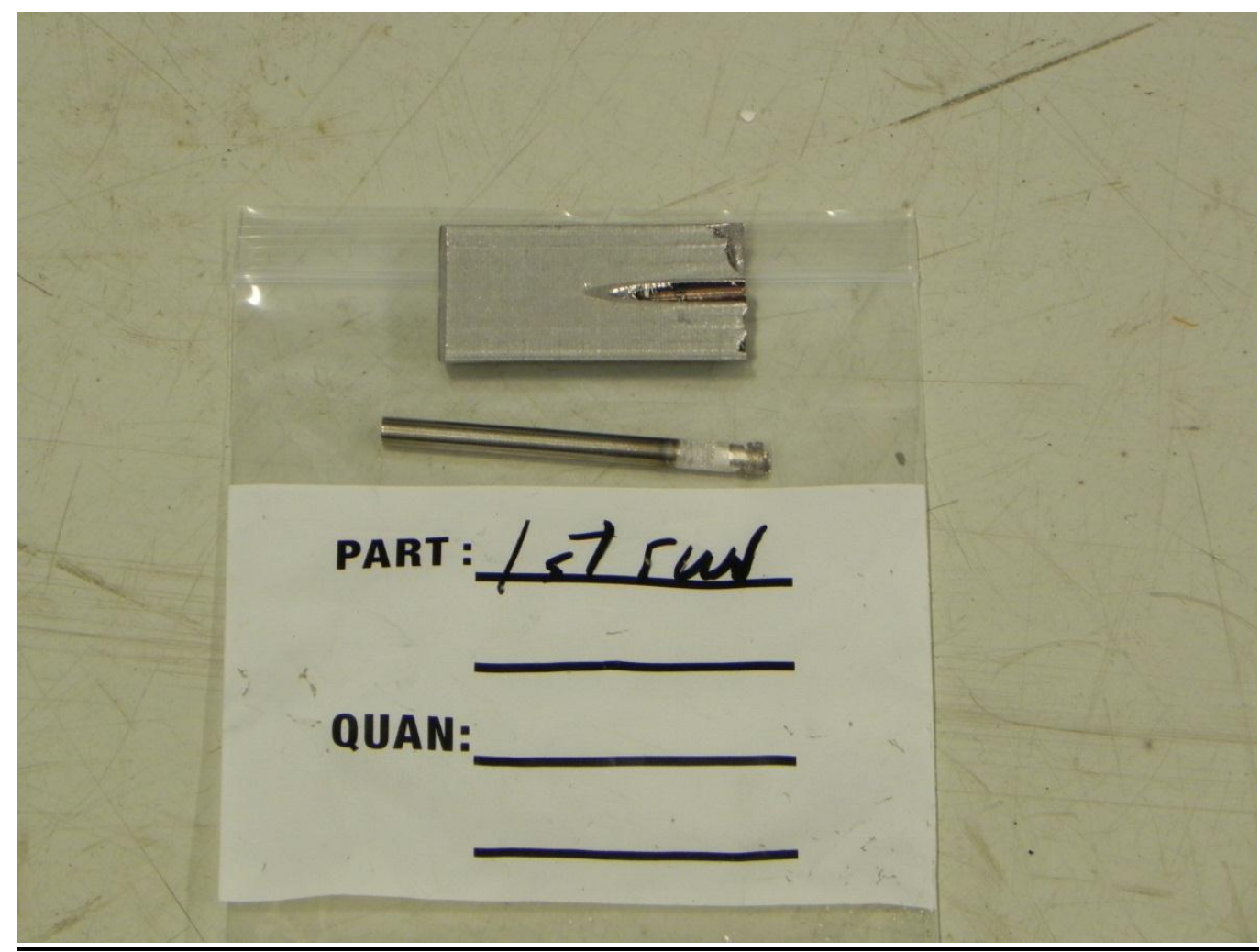

Figure 45. A typical example of a Mg ingot after EMAT processing and EDM cutting. 


\subsection{FACILITATION OF HTMP/EMAT TECHNOLOGY COMMERCIALIZATION}

During this project, Ajax-Tocco, AMI and ORNL agreed on the final specifications (e.g., H-field strength, uniform field length, extraction forces, rotational effects during quenching/heating, etc.) and finalized the design for a magnet system which was procured with outside funding. This magnet is an 8-inch diameter bore system that will allow both dual frequency thermomagnetic field processing, as well as an integrated heating/quench capability that can accommodate some larger industrial scale applications. This magnet was delivered in the FY 2011. This magnet represents an intermediate, but important step for AMI in that it incorporates both a large magnetic field (9T) and a large (8-inch) diameter bore magnet with a more energy efficient re-condensing style cryocooler system that significantly reduces (actually eliminates) the consumption of liquid cryogens previously required by superconducting magnets in earlier designs. This knowledge and the benefits gained through the development of this magnet provide a strong experience base and provide valuable leverage for the design of future industrial scale magnets that will be needed to commercial this HTMP technology.

Previous experience with conventionally cooled superconducting systems identified the effort and expense of regularly replacing liquid cryogens as a major barrier to commercialization. Recondensing cryocooler systems for liquid helium were identified as a priority for commercial designs to enable near lifetime operation with initial loading of liquid cryogens.

A second potential barrier to commercialization was identified relating to the EMAT effect. When lower frequency was employed at relatively modest $(>2 \mathrm{KW})$ induction power levels, the EMAT effect would cause the superconducting magnet to quench, lose all of its cryogens and no longer be superconducting. This event would result in almost a two-week down time to get the magnet refilled with cryogens and back to persistent mode at maximum magnetic field strength. Therefore, AMI developed possible solutions to mitigate this weakness, then, engaged NHMFL magnet design experts to review and confirm that incorporating the solutions that AMI proposed for the 9T, 8inch magnet. AMI implemented several proprietary internal system design changes to make the superconducting magnet resistant to EMATinduced quenches. In addition, critical to the final design of the superconducting magnet system coupled with a $220 \mathrm{KW}$ induction heating power supply/induction coil design was evaluating overall system design requirements factoring in the following:

1) Induction Coil Survival at $200 \mathrm{~kW}$ in $9 \mathrm{~T}$ Magnetic Field

2) Electromagnetic JxB Forces Acting on the Induction Heating Coil

3) Static Pressure and Hoop Stress in a 2.75" Diameter Coil for DC Current

4) Inertial-Mass Limited Radial Acceleration and Radial Strain above $10 \mathrm{kHz}$

5) Resonant Frequency of the Induction Coil for the Radially Symmetric Mode

6) Resonant Frequency of the EMAT Barrier Tube

These are addressed specifically below.

\subsubsection{Magnet Design Considerations}

\subsubsection{Induction coil survival at $200 \mathrm{~kW}$ in $9 \mathrm{~T}$ magnetic field}

For a helical coil that is rigidly pinned/secured at both ends, or where adjacent turns are rigidly tied together, the maximum stress for low frequency, or DC, operation can be estimated by considering the effective pressure developed by the Lorentz $\mathrm{JxB}$ force, and the associated hoop stress. At higher frequencies where the resulting radial motion of current carrying elements is limited by the inertial mass of the copper, the radial strain is reduced, and the stress is reduced accordingly. 
For a helical coil that is not rigidly tied down at both ends, the hoop stress will act to unwind the coil along the helical direction. In addition to the inertial mass limited motion in the radial direction, the ends of each turn are held in place by the inertia provided by the mass of adjacent turns, which acts not in the radial direction but along the length of the helical winding. The net result is a radial expansion coupled with a helically directed motion that propagates to the ends of the coils, such that a $10 \mu \mathrm{m}$ radial motion translates into up to $(2 \mathrm{p})(10)(12) / 2=380 \mu \mathrm{m}$ movement of the both ends of the helix, in the helical direction. The maximum stress that develops will be less than that for a helix that is pinned at both ends. The radial motion does includes a component that is related to hoop stress, which dominates at high frequency, but also includes a component related to the helical winding/unwinding motion in the helical direction, and the free movement at both ends, that dominates the response at low frequency.

To address the range of possibilities, and the possible range of frequencies, two different types estimates for the coil strain were examined, 1) based on the hoop stress for a coil that is pinned at both ends, in the low frequency and/or DC limit, and 2) the inertial-mass-limited strain that addresses the high frequency response, and provides the first step in understanding the case where the coil is free standing and is not significantly constrained at either end.

In addition, mechanical resonances must be considered and taken into account. If the induction coil is driven at a frequency near its mechanical resonance, the strain could be enhanced by an order of magnitude or more. In addition, one must also be aware of the radially symmetric resonance of the sacrificial liner (EMAT barrier) tube, which is driven by the Lorentz $\mathrm{JxB}$ force arising from the induction current induced on the inner surface of the tube by the external return flux of the induction coil.

Based on the present design, the diameter of the induction coil has a diameter of 2.5 " ID/ 3.0" OD, for a mean diameter of 2.745 " $(70 \mathrm{~mm})$. It is assumed that the induction coil will be fabricated from $1 / 4$ " soft copper tubing having a wall thickness of $0.032 "(0.8 \mathrm{~mm})$. For $200 \mathrm{~kW}$ operation, it is assumed that the coil current has a peak value (amplitude) of $2000 \mathrm{~A}\left(1410 \mathrm{~A}_{\mathrm{rms}}\right)$, and that the induction coil is located in a uniform axial magnetic field of 9 Tesla.

\subsubsection{Electromagnetic $\mathrm{JxB}$ forces acting on the induction heating coil}

The 9 Tesla magnetic field is oriented along the axis of the solenoid. The predominantly radial force resulting from the cross product of the azimuthally directed coil current and the axial 9 Tesla B-field is then given by:

$F_{r}=I_{\theta} \cdot B_{z}=(2000 \mathrm{~A})(9 T)=18,000 \mathrm{~N} / \mathrm{m}=18 \mathrm{~N} / \mathrm{mm}$

where $\mathrm{F}_{\mathrm{r}}$ is the peak radial $\mathrm{JxB}$ force per unit length of conductor.

\subsubsection{Static pressure and hoop stress in a 2.75" diameter coil for DC current}

Assume that the coil is not helical in shape, but rather each turn is a ring that rigidly connects on itself. [Alternatively, assume that both ends of a helical coil are rigidly pinned in place.] If a large number of rings are lined up side-by-side to form a continuous cylinder, then the Lorentz force constitutes a radial pressure, and the hoop stress can be estimated directly.

Since the Lorentz force on each $1 / 4$ " wide turn is 18 newtons per mm of length, or equivalently ( $18 \mathrm{~N} / \mathrm{mm})$ $(0.2248 \mathrm{lb} / \mathrm{N})(25.4 \mathrm{~mm} / \mathrm{in})=102.8 \mathrm{lb} / \mathrm{in}$, the pressure, $\mathrm{P}=\mathrm{F} / \mathrm{A}$, is then $102.8 /(0.25 \mathrm{sq}$ in $)=411 \mathrm{psi}$, as the force on each 1" length is acting on an area $1 / 4$ " by 1 " in area, or $0.25 \mathrm{sq}$ in. [ Or equivalently, one could consider 4 adjacent conductor element each with a 1 " length, in which case the force on a 1" 1 1" area is $4(102.8 \mathrm{lb} / \mathrm{in})(1 ”)=411 \mathrm{lbs}$. 
So the expression for the hoop stress for a thin walled pressure vessel can be used to estimate the stress, keeping in mind that the wall thickness is effectively given by the total cross sectional area of the copper tube spread over a width of $1 / 4$ ". The cross sectional area of the copper in the tube wall is given by $(\mathrm{p} / 4)\left[(0.250)^{2}-(.186)^{2}\right]=0.022 \mathrm{sq}$ in. This has the same cross sectional area as a solid wall element $1 / 4$ " wide and 0.088 " in thickness, or about 3 times the wall thickness of the refrigeration tube, which is about right. So the effective wall thickness is about $0.088^{\prime \prime}$.

The hoop stress for a thin walled pressure vessel, is given by the expression, $s=\mathrm{Pd} / 2 \mathrm{t}$, where $\mathrm{s}$ is the hoop stress, $\mathrm{P}$ is the pressure, $\mathrm{d}$ is the mean diameter of cylinder, and $\mathrm{t}$ is the wall thickness. Therefore, the hoop stress is $\mathrm{s}=\mathrm{Pd} / 2 \mathrm{t}=(411 \mathrm{psi})\left(2.75^{\prime \prime}\right) / 2\left(0.088^{\prime \prime}\right)=6422 \mathrm{psi}$.

Alternatively, one can consider just a single turn ring of copper tubing. The stress is then given by $\mathrm{s}=$ $\mathrm{F} / \mathrm{A}=[($ force/in $) \mathrm{d}] /[2$ (area) $]$, where the "force/in" is $102.8 \mathrm{lb} / \mathrm{in}$, the diameter, $\mathrm{d}$, is 2.5 inches, and "area" is the $0.022 \mathrm{sq}$ in cross sectional area of the copper that the radial expansion force is acting on. Therefore, $\mathrm{s}=(102.8 \mathrm{lb} / \mathrm{in})(2.75 \mathrm{in}) /\left[2\left(0.022 \mathrm{in}^{2}\right)\right]=6425 \mathrm{psi}$. In either case, using on an elastic modulus of 17,000 ksi for copper, the associated strain would not exceed $\mathrm{s} / \mathrm{E}=(6425 \mathrm{psi}) /(17.0 \mathrm{e}+6 \mathrm{psi})=0.00038$, which for a $35 \mathrm{~mm}$ radius coil corresponds to a radial displacement of $13.2 \mathrm{~mm}(0.038 \%)$.

Note that this estimate of the hoop stress, $6.42 \mathrm{ksi}$ is about $40 \%$ of the $14 \mathrm{ksi}$ yield strength inferred from the fatigue curves for $\mathrm{Cu}$. However, it might be noted that normally a safety factor of 3.5 to 4.0 is used for pressure vessels. In addition, pressure vessels are not ordinarily subjected to pressure oscillations with $10 \mathrm{kHz}$ repetition rate.

\subsubsection{Inertial-Mass Limited Radial Acceleration and Radial Strain above $10 \mathrm{kHz}$}

For high frequency operation, $\mathrm{f}>>10 \mathrm{kHz}$, a simple estimate of the maximum strain that can be effected by the Lorentz JxB force can be obtained by assuming that the conductor has finite mass but no strength (Young's modulus of zero). This is the inertial-mass limited strain. The inertial mass limited stain provides useful information when the frequency is sufficiently high that the inertial mass provides the dominant force that restrains the motion of the current carrying conductor elements, as opposed to the mechanical strength of the material.
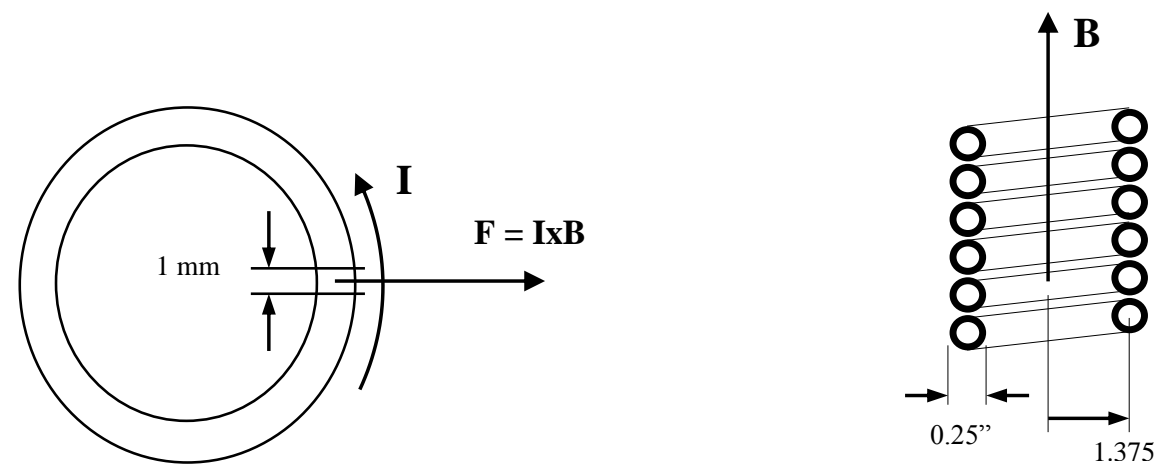

Figure 46. Top view and cross-section view of a single-layer helically wound induction heating coil showing the axial alignment of the 9 Tesla magnetic (B) field.

For this calculation, the mass of a $1 \mathrm{~mm}$ length of 1/4" OD hollow copper conductor (refrigeration tubing) will be used (Fig. 46). The mass of the cooling water within the tube is not included. Assuming a wall thickness of .032 " $(0.8 \mathrm{~mm})$, the conductor volume (per $\mathrm{mm}$ length) is then $\mathrm{V}=2 \pi \mathrm{rdr}(\mathrm{dl})=$ 
$2 \pi(2.8 \mathrm{~mm})(0.8 \mathrm{~mm})(1.0)=14.07 \mathrm{~mm}^{3}$. Based on the mass density of copper, $8.94 \mathrm{gm} / \mathrm{cc}$, the mass of this length of conductor element is then:

$m=\rho V=\left(.00894 \mathrm{~g} / \mathrm{mm}^{3}\right)\left(14.1 \mathrm{~mm}^{3}\right)=0.126 \mathrm{~g}=1.26 \times 10^{-4} \mathrm{~kg}$

This is the mass per millimeter length of the $1 / 4$ " OD conductor element. The peak radial acceleration on this $1 \mathrm{~mm}$ conductor element due to the electromagnetic $\mathbf{J x B}$ force is then given by:

$a_{o}=\frac{F}{m}=\frac{(18 \mathrm{~N} / \mathrm{mm})(1.0 \mathrm{~mm})}{1.26 \times 10^{-4} \mathrm{~kg}}=14.3 \times 10^{4} \mathrm{~m} / \mathrm{sec}^{2}$

Integrating the time dependent acceleration, $\mathrm{a}(\mathrm{t})=\mathrm{a}_{\mathrm{o}} \sin (\pi \mathrm{t})$, to obtain the velocity, $\mathrm{v}(\mathrm{t})$,

$v(t)=\int a(t) d t=a_{o} \int \sin (\omega t) d t=\frac{a_{o}}{\omega} \cos (\omega t)$

Integrating the time dependent velocity, $v(t)=v_{0} \cos (\pi t)$, to obtain the displacement, $d(t)$,

$d(t)=\int v(t) d t=v_{o} \int \cos (\omega t) d t=\frac{v_{o}}{\omega} \sin (\omega t)=\frac{a_{o}}{\omega^{2}} \sin (\omega t)$

The maximum (peak) velocity of the conductor element at $20 \mathrm{kHz}$ is therefore

$v_{o}=\frac{a_{o}}{2 \pi f}=\frac{14.3 \times 10^{4} \mathrm{~m} / \mathrm{sec}^{2}}{2 \pi(20 \mathrm{kHz})}=1.14 \mathrm{~m} / \mathrm{sec}$

and the maximum (peak) displacement is given by

$d_{o}=\frac{a_{o}}{(2 \pi f)^{2}}=\frac{14.3 \times 10^{4} \mathrm{~m} / \mathrm{sec}^{2}}{[2 \pi(20 \mathrm{kHz})]^{2}}=9.1 \times 10^{-6} \mathrm{~m}=9.1 \mu \mathrm{m}$

For the solenoid-shaped induction heating coil with a nominal radius of $35 \mathrm{~mm}$ (1.375"), this represents a maximum normalized dimensional change (strain) of

$\frac{\delta r}{r}=\frac{9.06 \mu m}{35 m m} \leq 2.59 \times 10^{-4} \quad(0.026 \%)$

in the radial direction, alternately stretching and compressing the individual turns of copper coil. This is comparable to the strain calculated from the expected hoop stress for static, or low frequency conditions. Therefore, for the frequency range below $20 \mathrm{kHz}$, including $10 \mathrm{kHz}$ operation, the expected strain would be similar to that inferred from the static pressure and hoop stress for DC current operation, whereas at higher frequencies the strain falls off as the reciprocal of the frequency-squared. For example, if the frequency were doubled from $20 \mathrm{kHz}$ to $40 \mathrm{kHz}$, then the peak velocity would be reduced by a factor of two to $0.57 \mathrm{~m} / \mathrm{s}$, and the peak displacement would be reduced by a factor of four to just $2.3 \mu \mathrm{m}$, corresponding to a strain of $0.65 \times 10^{-4}(0.0065 \%)$. Near the transition frequency of $20 \mathrm{kHz}$, both the hoop stress and the inertial mass act jointly to determine the strain. Based on these considerations alone, the frequency dependence of the expected strain is approximately as shown in Fig. 47. 


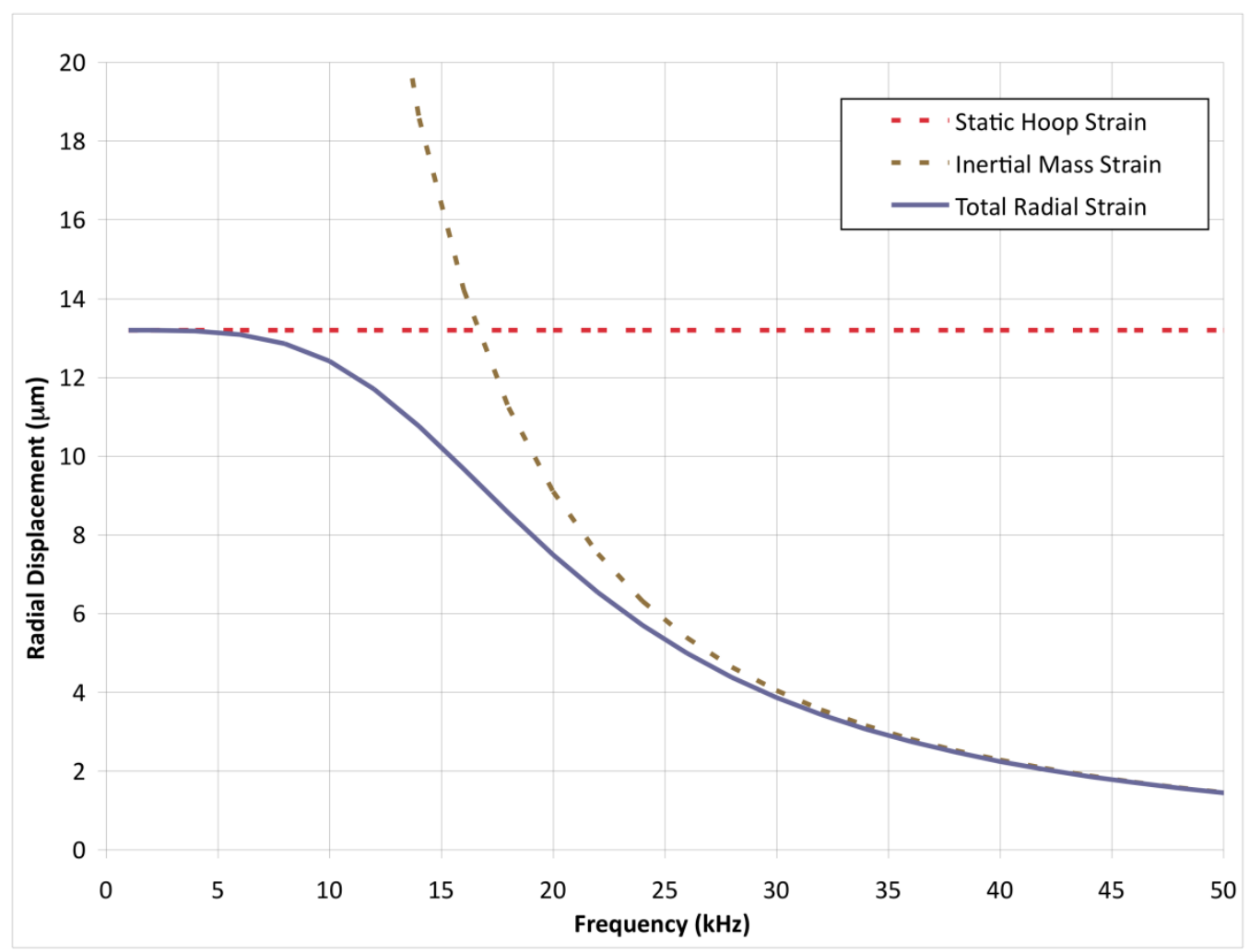

Figure 47. Total radial strain as a function of frequency for a $2.75^{\prime \prime}$ diameter coil, with 2000 amp peak coil current $(1410 \mathrm{~A}(\mathrm{rms}))$, and a 9T magnetic field

\subsubsection{Resonant frequency of the induction coil for the radially symmetric mode}

At the frequency where the mass-limited strain roughly matches the strain calculated from the static hoop force, the momentum of the conductor elements is sufficient to result in a mechanical resonant condition. The fundamental resonance frequency for a cylinder is given by

$f(k H z) \cong\left(\frac{1}{2 \pi r}\right) \sqrt{\frac{E}{\rho}}=\left(\frac{1}{2 \pi(0.035)}\right) \sqrt{\frac{1.17 e+11 \mathrm{~N} / \mathrm{m}^{2}}{8940 \mathrm{~kg} / \mathrm{m}^{3}}}=\frac{576 \mathrm{~m} / \mathrm{s}}{0.035 \mathrm{~m}}=16.45 \mathrm{kHz}$

where $\mathrm{E}$ is Young's modulus, $\mathrm{r}$ is the mass density, and $\mathrm{r}$ is the mean radius of the cylinder (i.e. the induction coil). Using $\mathrm{E}=1.17 \mathrm{e}+11 \mathrm{~N} / \mathrm{m} 2(17,000 \mathrm{ksi})$ for the modulus of copper, and a mass density of $8940 \mathrm{~kg} / \mathrm{m} 3$, the resonant frequency for a $35 \mathrm{~mm}$ radius cylinder $(2.75$ " dia.) is estimated to be $\mathrm{f}=16.45$ $\mathrm{kHz}$. This is the resonant frequency for a helical coil that is rigidly pinned at both ends. A coil that is not rigidly secured at both ends will likely have a lower frequency resonance. In any case, this is a definitely cause for concern, as the presence of mechanical resonance will enhance the radial coil strain anywhere in the planned operating frequency range of 10 to $30 \mathrm{kHz}$. The enhancement of the radial displacement is approximately as shown in Fig. 48, where the magnification of the motion is plotted as a function of frequency for the case where the resonant frequency of the copper coil is $16.45 \mathrm{kHz}$, assuming various values for the normalized damping factor. This plot is based on the formalism in Mechanical Vibration Theory and Applications by Tse, Morse, and Hinkle (similar to their Fig. 2-8). 


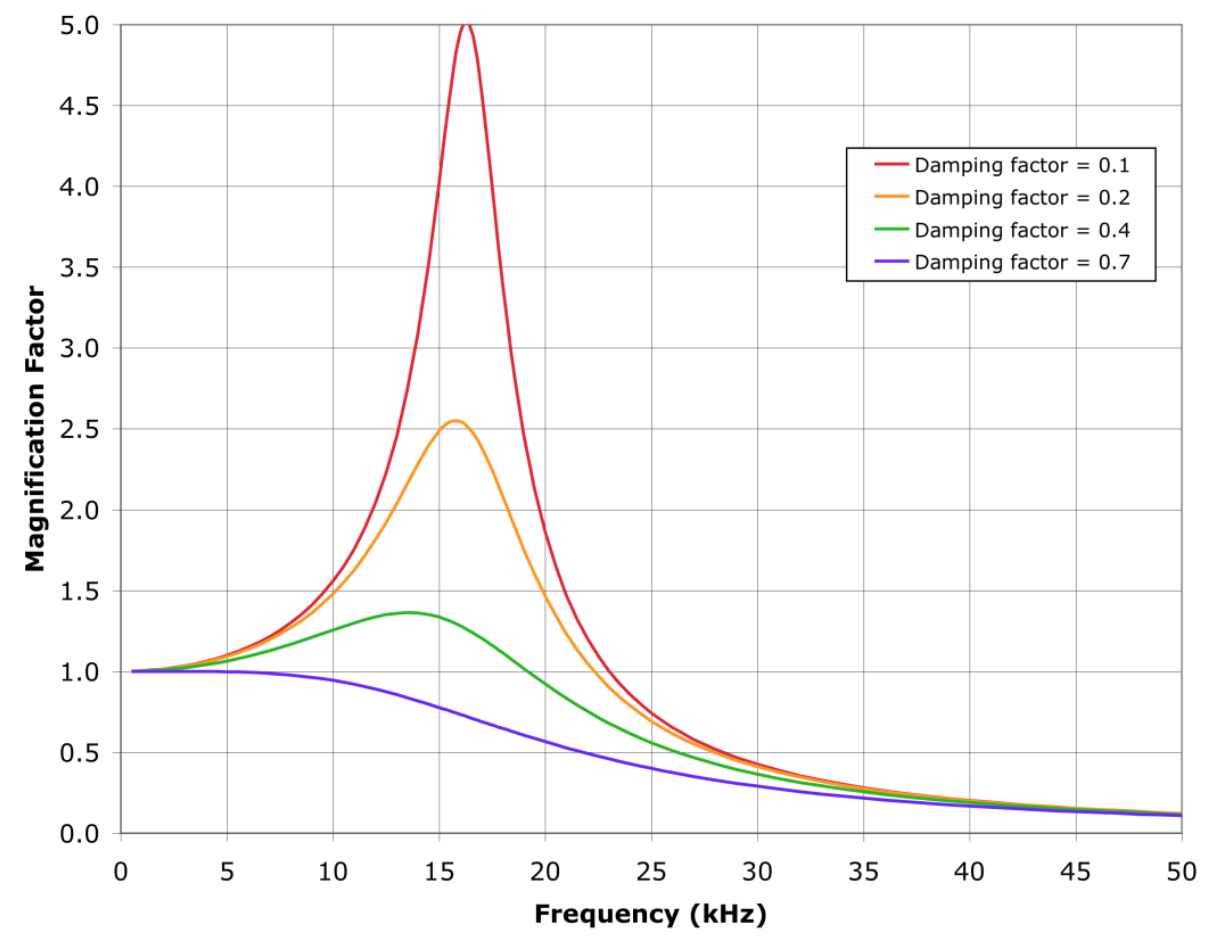

Figure 48. Resonant magnification as a function of frequency for various normalized damping factors.

\subsubsection{Resonant frequency of the EMAT barrier tube}

The EMAT barrier tube that encloses the induction insert for the 8" vertical magnet is expected to have a mean diameter of 7.375 " (7.5" OD/7.25" ID), with a radius of $93.7 \mathrm{~mm}$. Young's modulus for aluminum 6061-T6 is about $10.0 \mathrm{ksi}(6.89 \mathrm{e}+10 \mathrm{~N} / \mathrm{m} 2)$, and the mass density is $2710 \mathrm{~kg} / \mathrm{m} 3$. Therefore the predicted resonant frequency for the radially symmetric mode of vibration is roughly

$f \cong\left(\frac{1}{2 \pi r}\right) \sqrt{\frac{E}{\rho}}=\left(\frac{1}{2 \pi(0.094)}\right) \sqrt{\frac{6.89 e+10 \mathrm{~N} / \mathrm{m}^{2}}{2710 \mathrm{~kg} / \mathrm{m}^{3}}}=\frac{802.5 \mathrm{~m} / \mathrm{s}}{0.094 \mathrm{~m}}=8.54 \mathrm{kHz}$

If instead the EMAT barrier were made out of copper, with an elastic modulus of $17 \mathrm{ksi}$ and a density of $8940 \mathrm{~kg} / \mathrm{m} 3$, then the resonant frequency would be reduced to

$$
f \cong\left(\frac{1}{2 \pi r}\right) \sqrt{\frac{E}{\rho}}=\left(\frac{1}{2 \pi(0.094)}\right) \sqrt{\frac{1.17 e+11}{8940}}=\frac{576}{0.094}=6.1 \mathrm{kHz}
$$

The warm bore of the magnet cryostat consists of a nested set of aluminum cylinders, each with progressively larger diameters, and therefore progressively lower resonant frequencies, all of which are expected to be in the frequency range near $8 \mathrm{kHz}$. 


\subsubsection{Induction coil and EMAT barrier tube conclusions and commercial system fabrication strategy}

In the frequency range of 10-30 kHz, it appears that resonant magnification of the coil strain is likely to be a key factor in determining the survivability of the induction coil during $200 \mathrm{~kW}$ operation in a 9T magnetic field. Unfortunately the extent of the magnification of the radial motion, which depends on the damping factor, is unknown at this time. However, in the frequency range of $30 \mathrm{kHz}$, and above, survival appears to be more likely simply based on considerations of the inertial mass of the copper conductor, and the resulting frequency dependence of the strain (i.e. reciprocal frequency-squared). It is recommended that initial high power testing of the induction insert for the 8 " vertical magnet should be performed at a frequency near $30 \mathrm{kHz}$, or higher.

Another factor that could affect survivability is the interaction of the induction coil with the Zircar cylinder that secures it in position (see Fig. 49). Although not observed in the past in ORNL's other HTMP/EMAT systems, there is the concern as to whether the soft copper induction coil will be damaged as is vibrates against the surface of the Zircar cylinder. Frequent (weekly) examination of the copper coil integrity after initial experiments where the EMAT effect will dominate, will be scheduled to mitigate any coil failure from causing down time in this new commercial prototype system.

Use of copper for the EMAT barrier tube has the distinct advantage that for a given wall thickness it provides the best possible electromagnetic shielding of the aluminum tubes that make up the warm bore of the magnet cryostat. In addition, the natural mechanical resonance frequency $(6 \mathrm{kHz})$ of a copper EMAT barrier tube would be: 1) farthest below the lowest induction heating frequency under consideration $(10 \mathrm{kHz}), 2)$ well below the mechanical resonance frequency of the induction coil (16.5 $\mathrm{kHz}$ ), and 3) detuned below the natural resonance frequencies of the aluminum tubes that make up the warm bore of the magnet cryostat (all near $8 \mathrm{kHz}$ ).

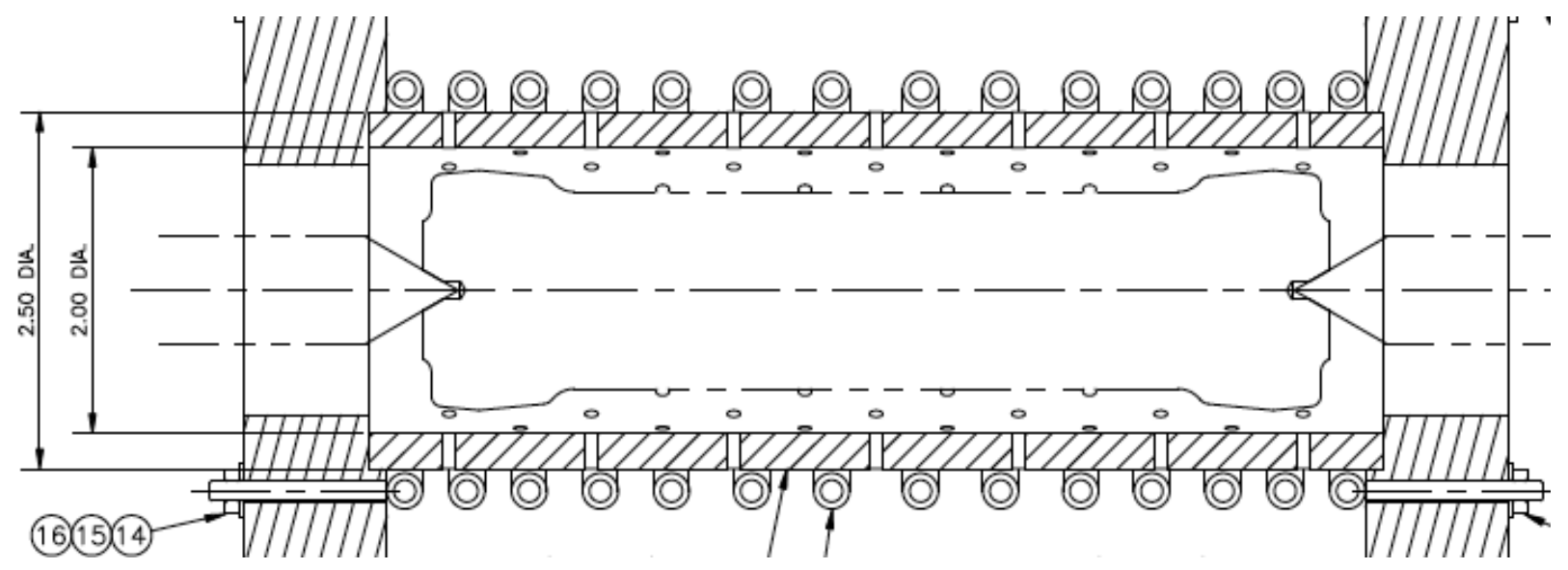

Figure 49. Image of the induction coil extracted from a design drawing of the induction insert for the 8" vertical magnet.

\subsubsection{Commercial Prototype System Designed, Fabricated, Installed, and Operational at ORNL}

Significant progress towards technology commercialization has been made in that fabrication and delivery of the new commercial prototype 9T-8 inch bore vertical superconducting magnet was accomplished by our industrial partner, American Magnetics Incorporated (AMI) and Ajax TOCCO designed and delivered an integrated sample handling system (2000 pound extraction force capability) coupled with a $220 \mathrm{KW}$ 
dual frequency $(10 \mathrm{KW}$ and $30 \mathrm{KW})$ power supply with rotating sample capability for polymer quenching with a 75 GPM pumping delivery system. The main superconducting magnet core was wound with $\mathrm{Nb}-$ Ti superconductor wire and successfully tested at cryogenic temperatures at full field of 9-T (Figure 50). This inner magnet coil provides the long (9-inch) and uniform (within $1 \%$ field uniformity) $9 \mathrm{~T}$ magnetic field used in our thermomagnetic processing experiments. Winding of the $\mathrm{Nb}-\mathrm{Ti}$ superconductor wire outer shielding magnet coil (to keep stray magnetic fields outside of the magnet down to levels $[<0.2 \mathrm{~T}]$ whereby they will not interfere with electronic equipment performance) around this main coil is shown assembled in Figure 51.

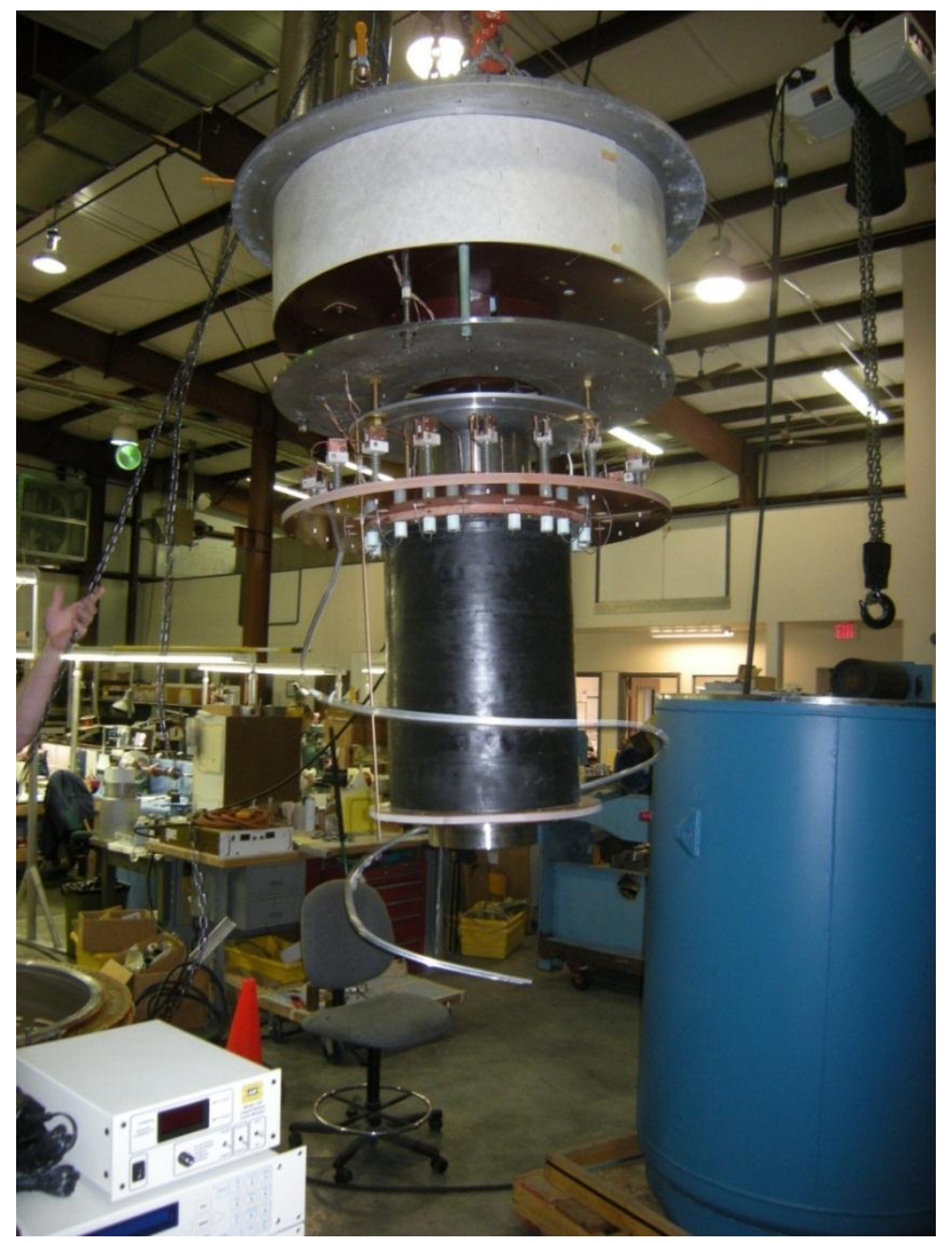

Figure 50. The inner main coil of the new commercial prototype 9-T, 8-inch diameter warm bore superconducting magnet system was fabricated and tested by American Magnetics, Inc. in Oak Ridge, TN.

This magnet is an 8-inch diameter bore magnet system that allows both dual frequency thermomagnetic field processing as well as an integrated heating/quench capability that can accommodate some larger industrial scale applications. This magnet represents an intermediate, but important step for AMI in building much larger recondensing superconducting magnet systems in that it incorporates both a large magnetic field (9T) and a large (8-inch) diameter bore magnet with a more energy efficient re-condensing style cryocooler system that significantly reduces the consumption of liquid cryogens previously required by superconducting magnets in earlier designs. This knowledge and benefits gained through the development of this magnet provide a strong experience base and provide valuable leverage for the design of future industrial scale magnets that will be needed to commercial this HTMP technology. 


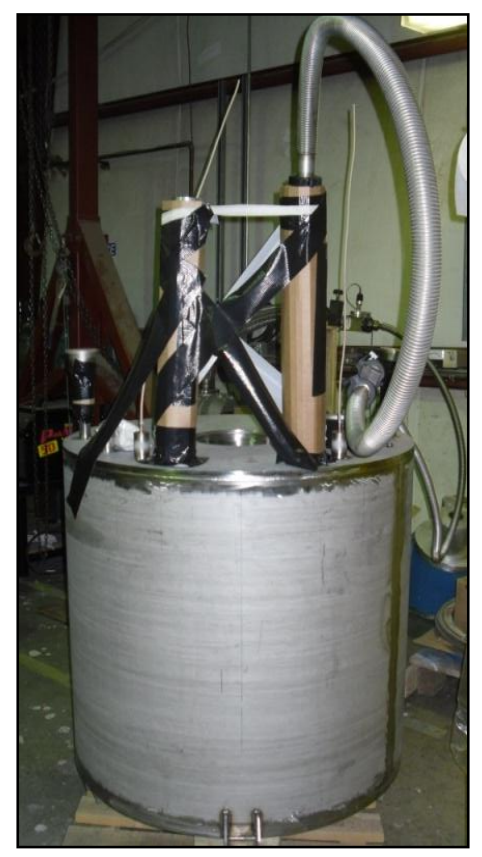

(a)

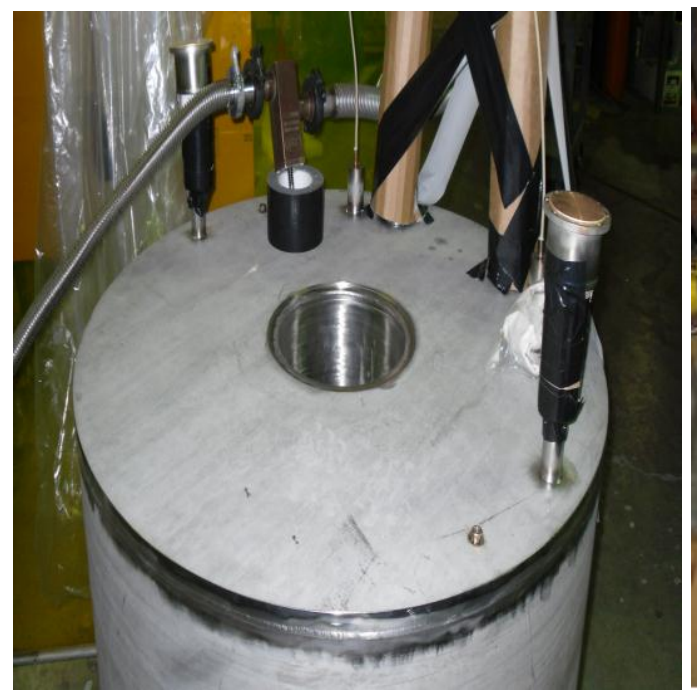

(c)

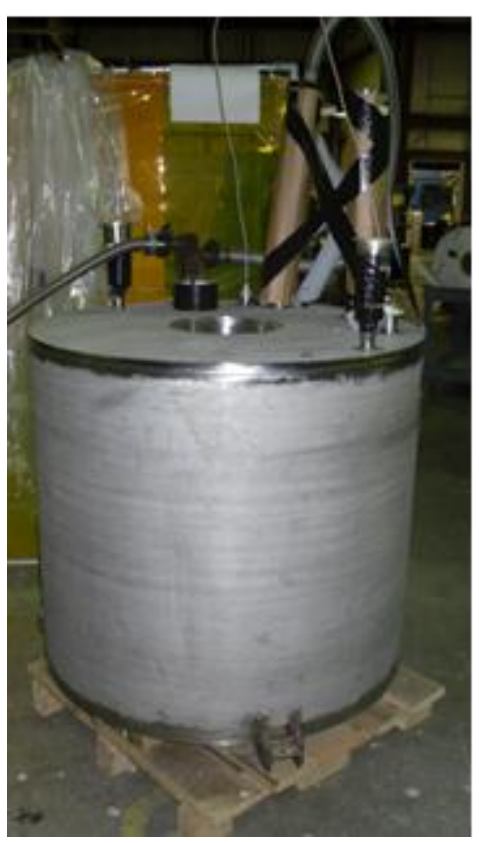

(b)

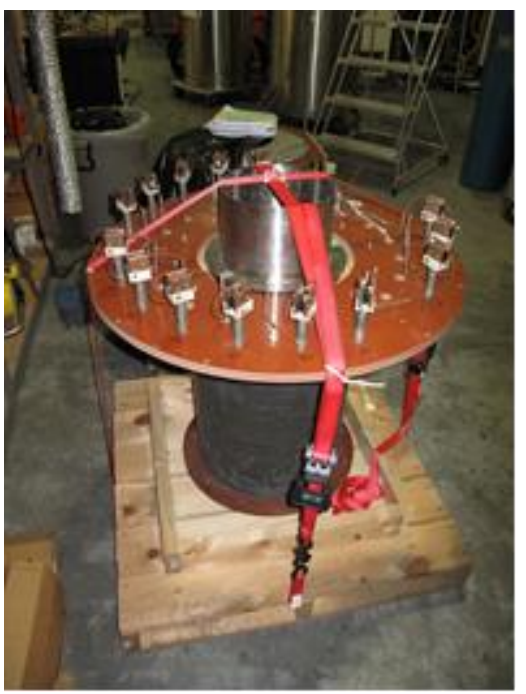

(d)

Figure 51. Views (a), (b), \& (c) show the vessel for the 8-inch diameter warm-bore, 9-T superconducting magnet system containing (d) the main superconducting solenoid coil with the quenching resistors exposed.

Figure 52(a) and 52(b) show the completed commercial scale scanner frame built by Ajax-Tocco that contains the 8-inch diameter bore, 9T superconducting magnet (Figure 52 [c and d]). This frame with provides sample handling capability, provide induction heating of industrial scale components as well as provides uniform spray quenching capability. This entire system was procured within a separate project, and has been used in a separate, DOE AMO industry-led project to provide a prototype demonstrate of the HTMP technology on a commercial scale. This system also provides the ability to conduct EMAT experiments for casting related experiments. 


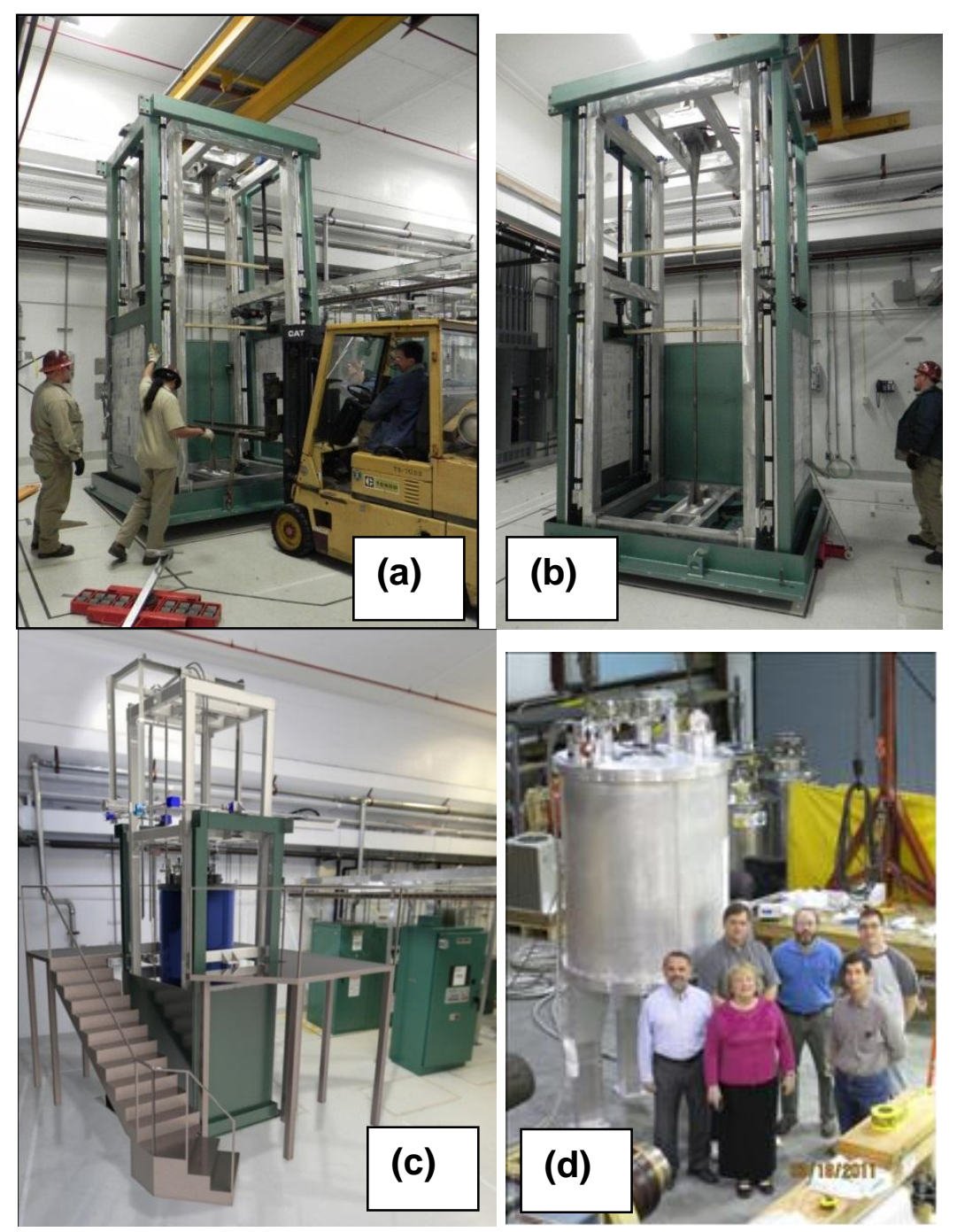

Figure 52. Photos (a) \& (b) show the delivery and placement of the commercial scale frame that will beintegrated with ORNL's 8-inch diameter bore, 9T superconducting magnet, shown here in (c) an artist's rendition (d) completed magnet.

Figure 53 shows the new commercial prototype 9T- $\sim 8$ inch bore vertical superconducting magnet after delivery to ORNL by our industrial partner, American Magnetics Incorporated (AMI) and installed in the sample handling system (capable of 2,000 pound extraction force) built by our other industrial partner, Ajax TOCCO. As reported earlier, although this system was procured through a combination of activities in a separate project and with capital funds not associated directly with a project, this system has been used as the fundamental basis for defining critical design parameters and capabilities for a commercial prototype thermomagnetic (HTMP)/EMAT processing system which this represents the world's very first. Figure 54 shows the walk-up platform surrounding this system (for easy access to the top of the superconducting magnet for insert and sample loading). This system enabled experiments with industrialscale components to be successfully conducted before the end of this project. 


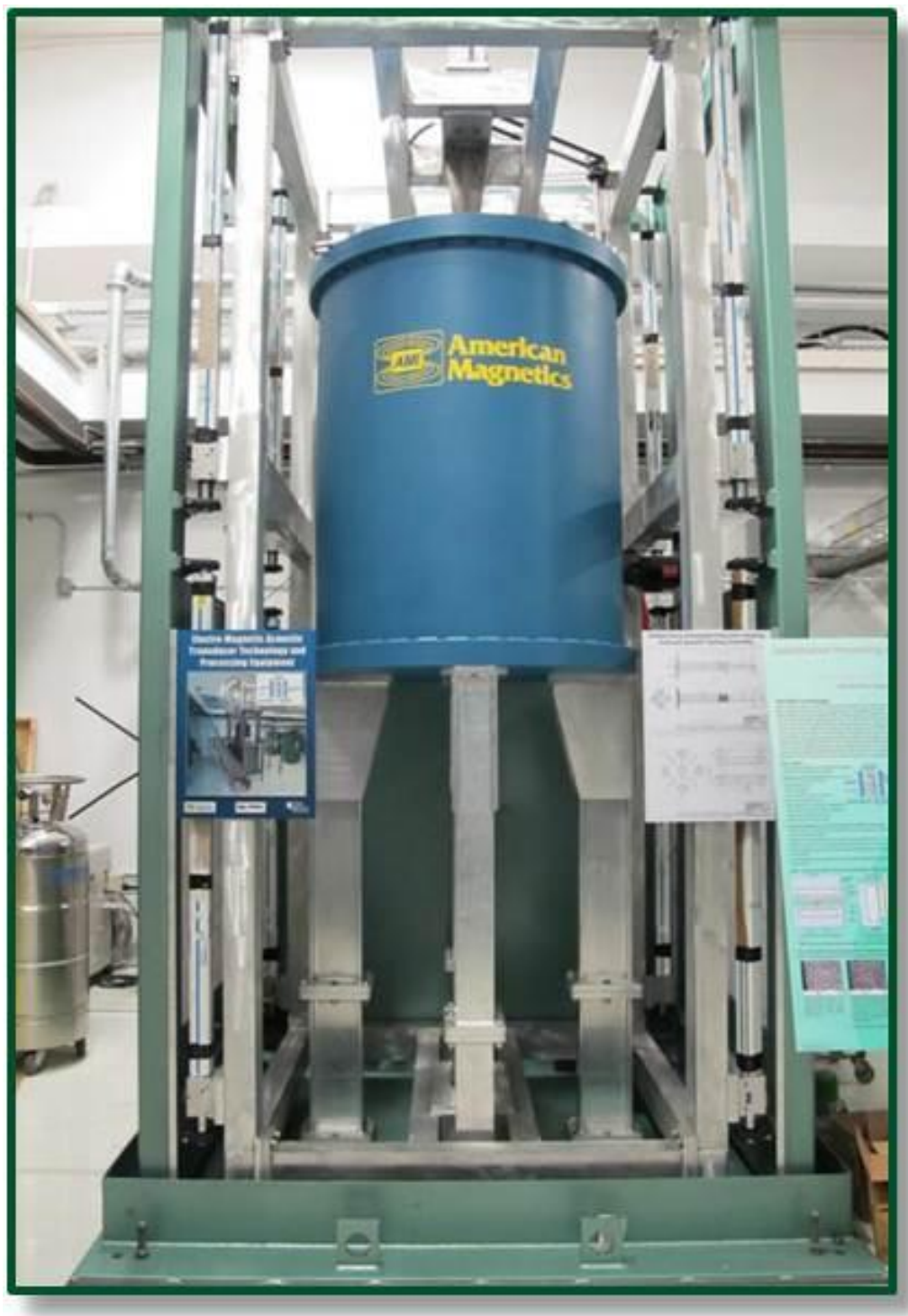

Figure 53. The world's first commercial prototype TMP/EMAT processing system is operational at ORNL and has been used for experimental trials on industrial-scale components. 


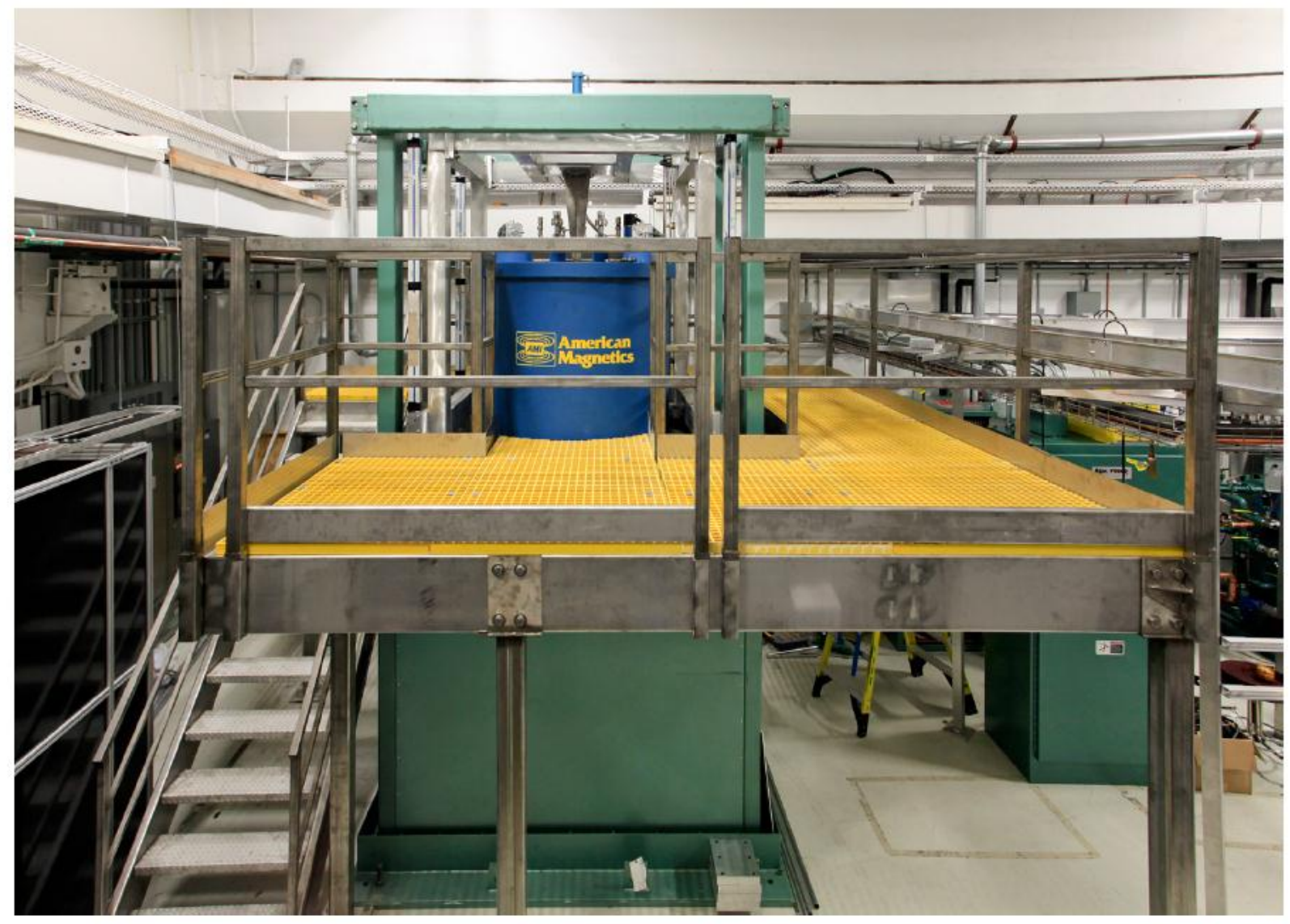

Figure 54. The ORNL commercial prototype HTMP/EMAT system with working platform installed.

The multiple, world-class HTMP/EMAT facilities established at ORNL are shown in Figure 55 along with their capabilities. 


\section{ORNL's World-Class H-\&TMP R\&D Processing Facility Has 4 Distinct Superconducting Magnet Processing Cells}

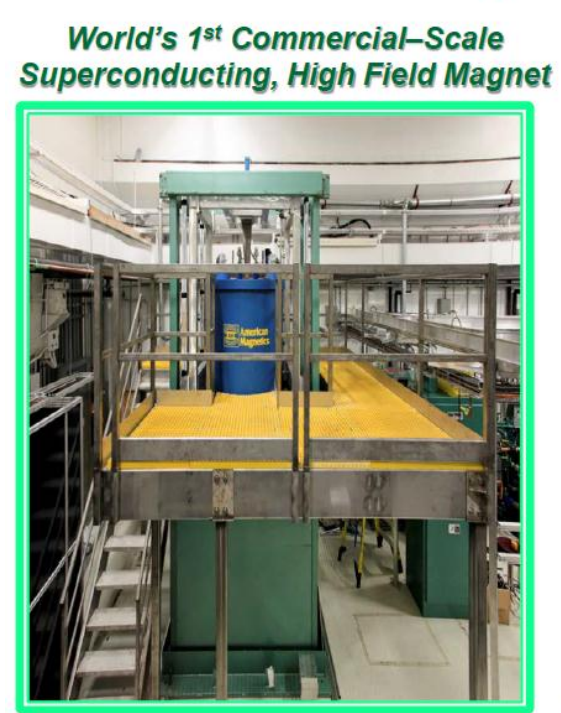

Continuous-Feed High \&

ThermoMagnetic

Processing

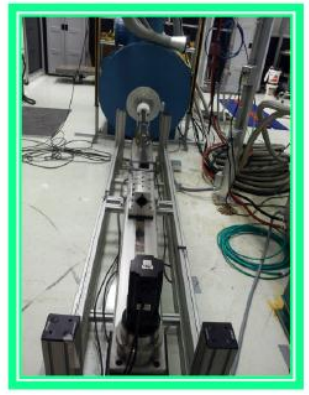

Two Horizontal, 5-inch Diameter Bore

Superconducting Magnetics with:

- 9-inch Long Uniform Field Zone

- 0 to 9T magnetic field capability

Operating Temperatures: $\sim 0 C->2200 C$

- Vertical, 8-inch Diameter Bore

- 9-inch Long Uniform Field Zone

- 0 to $9 T$ magnetic field capability

- Operating temperatures: 0C -> 1600C

200 KW dual frequency induction heating system with samplerotating, integrated $75 \mathrm{gpm}$ polymer quench capability

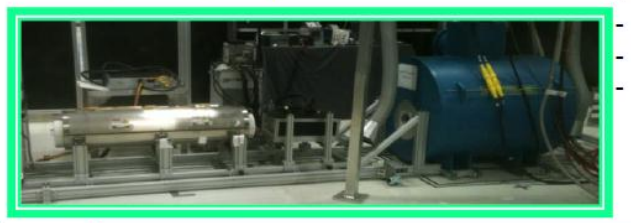

All systems have state-of-the-art cryogen recondensing coolers eliminating the need to replenish cryogens for the superconducting magnets.

Figure 55. ORNL's multiple HTMP/EMAT systems represent the world's most advanced systems for conducting high magnetic field experiments from small prototype to large scale commercial samples.

\subsubsection{Validation of commercial prototype to handle significant EMAT forces without quenching}

The initial EMAT testing (of the 9T-, $\sim 8$ inch bore vertical superconducting magnet HTMP/EMAT system) was conducted in December 2011 and stopped at 8T. With coil currents up to 1060 Amps, the rms sonic $\mathrm{JxB}$ radial pressure acting on the induction coil maxed out at just under $700 \mathrm{kPa}$, or 7 atmospheres, at a frequency near $29 \mathrm{kHz}$. During $20 \mathrm{sec}$ heat up testing of the HP-30, the coil current was significantly higher, more like 1500 amps. In addition, the frequency was reduced to about $23 \mathrm{kHz}$ in order to get enough power to heat the HP-30 in the $20 \mathrm{sec}$ time interval, without exceeding the voltage limit. So the highest EMAT coil pressure (also acting on HP-30) to date was conducted at 7T and 1520 amps, corresponding to a $\mathrm{JxB}_{\mathrm{X}}$ pressure of $850 \mathrm{kPa}$, at a frequency near $23 \mathrm{kHz}$. For 9T full field testing, this will increase to $1080 \mathrm{kPa}$ at 9T. No issues/problems are anticipated when those tests are completed at $9 \mathrm{~T}$ in the early part of CY2012 which is a credit to and direct result of the design considerations described in this section 3.4. 


\section{CONCLUSIONS AND RECCOMENDATIONS}

The HMFP/EMAT technology has been shown to be an enabling disruptive technology that can achieve significant improvements in microstructure and performance metrics unachievable through conventional processing avenues.

- Reduction of retained austenite in high carbon/high alloy content steels was demonstrated by an ambient temperature HTMP process replacing either a cryogenic or double tempering operations normally employed to accomplish this reduction. HMFP can be described as a "heat-free, heat treating technology". Lower residual stresses are anticipated since no thermal strains are involved in reducing the retained austenite content of the steel.

- Simultaneous increases of $12 \%$ in yield strength and $22 \%$ in impact energy were achieved in a bainitic alloy using HTMP processing. This is a major breakthrough in materials processing for the next generation of structural materials since normally strength and toughness change in opposite directions, and HTMP provides a new paradigm to beneficially increase both of these properties simultaneously.

- HTMP refines both the martensite lathe population and the carbide dispersion in the bainitic alloy during Gausstempering ${ }^{\mathrm{TM}}$ which is believed responsible for the simultaneous increase in strength and toughness. Hence, HTMP significantly impacts nucleation and growth phenomenon.

- HTMP develops comparable ultimate tensile strength and twice the impact energy in a lower cost, lower alloy content ( $\sim 8 \%$ in the bainitic steel) steel compared to the much higher cost, highly alloyed (31\% alloy elements involving $\mathrm{Ni}, \mathrm{Co}$, and $\mathrm{Mo}$ ) 250-grade maraging steel. Future low-cost HTMP alloys appear viable that will exceed the performance of much more highly alloyed materials processed conventionally, enabling U.S. industry to reduce cost and better compete globally while maintaining or exceeding current performance metrics.

- EMAT processed cast iron exhibits significantly higher hardness (by $51 \%$ for a 9T condition) than a no-field processed sample.

- EMAT microstructures in cast iron are very different in graphite nodule morphology, in pearlite content, and in the type of carbides that form during the solidification and solid-state cooling processes.

- EMAT processing of nanoparticle dispersions in magnesium results in a very fine, unagglomerated distribution of the nanoparticles in the matrix material. This provides a breakthrough technology to make the next generation of nanocomposite reinforced metal matrix composites which can be tailored to exhibit higher strength and ductility combinations not only at ambient temperature but also at elevated temperatures with enhanced creep performance. This technology can be extended to non-metallic systems as long as a conductive containment vessel is utilized that will convey the EMAT signal into the material of interest during processing.

- Facilitation of HTMP/EMAT technology commercialization occurred throughout the course of the project. Two technology limitations of the superconducting magnet and induction heating systems were identified, and new HTMP systems were designed that overcome those issues leading to the design of the first generation commercial prototype HTMP/EMAT capable systems which were installed at ORNL.

- The effort, downtime and expense of regularly replacing liquid cryogens were identified as a major barrier to commercialization. A recondensing cryocooler system for liquid helium was designed built and installed on an operating system. A second potential barrier to commercialization was identified relating to the EMAT effect. When lower frequency was employed at relatively modest ( $>2 \mathrm{KW}$ ) induction power levels, the EMAT effect cause the 
superconducting magnet to quench, lose cryogens and no longer be superconducting. Industrial partner AMI implemented several proprietary internal system design changes to make the superconducting magnet itself very robust against having any EMAT-induced quenches.

- During this project, a production-scale equipment design to enable commercialization of HMFP technology was conceptualized, designed, fabricated, and installed at ORNL as a commercial-scale prototype system. The commercial-scale prototype is comprised of a $\sim 8$ inch diameter, warm-bore superconducting magnet and a $220 \mathrm{KW}$, dual-frequency $(10 \mathrm{KHz}$ and $30 \mathrm{KHz}$ ) induction power supply with $75 \mathrm{gpm}$ polymer quenching capability. The system includes a sample handling system and is capable of an extraction force of 2,000 pounds and the integrated quench assembly can rotate a component at $30 \mathrm{~Hz}$ during the quenching operation to promote uniform heat transfer boundary conditions. Currently, negotiations are underway for the technology commercialization licensing of the HTMP/EMAT equipment.

Future R\&D projects should pursue these recommendations to expand the applications space for HTMP/EMAT technologies:

- For alloys with large commercial market applications that benefit from retained austenite conversion by ambient temperature magnetic field processing, evaluate their high cycle fatigue life for performance enhancement.

- Apply the Gausstemper ${ }^{\mathrm{TM}}$ process to plain carbon steels for the purpose of refining their martensite lathe size and inducing a finer and more copious carbide dispersion, with the goal of simultaneously increasing their yield strength and toughness, extending these low-cost alloys into higher performance applications normally requiring expensive alloys.

- Based on the success of simultaneously increasing the yield strength and toughness for a low alloy content bainitic steel, examine applying HTMP (Gausstemper ${ }^{\mathrm{TM}}$ process) to high-end, high alloy content steels such as the 350-grade maraging steel (the 350 grade has a $\sim 350 \mathrm{ksi}$ UTS) to see if yield strength and toughness can be increased significantly above the currently accepted upper limit values (e.g., move the UTS to $400 \mathrm{ksi}$ ).

- Expand EMAT studies of cast iron, Al-based, and Mg-based alloys to characterize improvements in strength and fatigue behavior.

- Continue investigations of EMAT processing for making the next generation of high performance (increases in yield strength, high cycle fatigue, creep, wear resistance, and conductivity) metal matrix composites for ambient and elevated temperature applications.

- Develop predictive models that will provide the required magnetic field energy term(s) for the Gibbs Free Energy equation to incorporate into predictive phase equilibria and kinetics codes such as ThermoCalc, Calphad, and Dictra.

- Develop appropriate microstructural evolution models (using phase field and/or molecular dynamics codes) to predict microstructures that develop under HTMP/EMAT conditions.

- Conduct in-situ microstructural evolution experiments using advanced neutron diffraction methods (at ORNL's Spallation Neutron Source) to validate the analytical tools developed in the future for predicting new phase equilibria and microstructure morphologies.

- Once the current HTMP/EMAT commercialization licensing negotiations are finalized, announce this agreement and commercial equipment availability in multiple material and processing trade journals. 


\section{REFERENCES}

1. "Magnetic Processing of Structural Components for Transportation Vehicles", Gail M. Ludtka, Gerard M. Ludtka, Sean Fleming, and Joaquin del Prado Villasana, Final CRADA Report for ORNL CRADA No. NFE -09-02418, September 30, 2011.

2. "An Attractive Materials Process: Exploring High Magnetic Field Processing for Developing Customized Microstructures with Enhanced Performance", Mackiewicz-Ludtka, et al., 2007, Symposium Proceedings of the 2007 ASM Heat Treat Society Conference \& Exposition, Detroit, MI, September 17-19-2007.

3. "Time-Resolved Analyses of Microstructure in Advanced Materials under High Magnetic Fields at Elevated Temperature Using Neutrons", Ludtka, et al, (invited paper) in Materials Processing Under the Influence of External Fields, Q. Han, G. Ludtka, and Q. Zhai, editors, Symposium Proceedings from the TMS 2007 Annual Meeting, Orlando, FL, February 25March 1, 2007, TMS Publishers, Warrendale, PA, 2007.

4. "Isothermal Phase Transformation Cycling in Steel by Application of a High Magnetic Field", Ludtka, et al, in Materials Processing Under the Influence of External Fields, Q. Han, G. Ludtka, and Q. Zhai, editors, Symposium Proceedings from the TMS 2007 Annual Meeting, Orlando, FL, February 25-March 1, 2007, TMS Publishers, Warrendale, PA, 2007.

5. "Retained Austenite in SAE 52100 Steel Post Magnetic Processing and Heat Treatment", Ludtka, et al, in Materials Processing Under the Influence of External Fields, Han, Ludtka, and Zhai, editors, Symposium Proceedings from the TMS 2007 Annual Meeting, Orlando, FL, February 25-March 1, 2007, TMS Publishers, Warrendale, PA, 2007.

6. "Exploring Ultrahigh Magnetic Field Processing of Materials for Developing Customized Microstructures and Enhanced Performance", Ludtka, et al, in Materials Processing in Magnetic Fields (Eds. Schneider-Muntau, H. J. and Wada, H.), World Scientific Publishing, New Jersey, pp 55-65 (2005).

7. "Texture Evolution in Fe-1\%Si As A Function of High Magnetic Field", T. A. Bennett, R. A. Jaramillo, D. E. Laughlin, J. B. Wilgen, R. Kisner, G. Mackiewicz-Ludtka, G. M. Ludtka, P. N. Kalu, and A. D. Rollett, Solid State Phenomena, (105), 2005, 151-156.

8. "In-situ Evidence of Enhanced Phase Transformation Kinetics Due to a High Magnetic Field in a Medium Carbon Steel", Ludtka, et al, Scripta Materialia, (51), 2004, 171-174.

9. "The Effect of High Magnetic Field Annealing on Enhanced Phase Stability in 85Fe-15Ni", Ludtka, et al, Journal of Applied Physics, (95) No. 11, June 2004, 6580-6582.

10. "Effect of 30 Tesla Magnetic Field on Phase Transformations in a Bainitic High-Strength Steel", R. A. Jaramillo, S. S. Babu, G. M. Ludtka, R. A. Kisner, J. B. Wilgen, G. MackiewiczLudtka, D. M. Nicholson, S. M. Kelly, M. Murugananth, and H. K. D. H. Bhadeshia, Scripta Materialia, (52), 2005, 461-466.

11. "Investigation of Austenite Decomposition in High-Carbon High Strength Fe-C-Si-Mn Steel under 30 Tesla Magnetic Field”, Jaramillo, R.A., Babu, S., Miller, M.K., Ludtka, G.M., Mackiewicz-Ludtka, G. Kisner, R.A., Wilgen, J.B. and Bhadeshia, H.K.D.H, Proceedings of Int'l Conf. on Solid-Solid Phase Transformations in Inorganic Materials 2005, May 29-June 3, 2005, Phoenix, Arizona.

12. "Investigation of Phase Transformation Kinetics and Microstructural Evolution in 1045 and 52100 Steel under Large Magnetic Fields", Jaramillo, R.A., Ludtka, G.M., Kisner, R.A., Nicholson, D.M., Wilgen, J.B., Mackiewicz-Ludtka, G., Bembridge, N. and Kalu, P.N., Proceedings of Int'l Conf. on Solid-Solid Phase Transformations in Inorganic Materials 2005, May 29-June 3, 2005, Phoenix, Arizona.

13. "Exploring Ultrahigh Magnetic Field Processing of Materials for Developing Customized Microstructures and Enhanced Performance”, Ludtka, G. M., Jaramillo, R. A., Kisner, R. A., 
Mackiewicz-Ludtka, G., Wilgen, J. B., ORNL Tech. memo, ORNL/TM-2005/79, March 2005.

14. "Annual Report", American Iron and Steel Institute, 2006, Washington, DC, http://www.steel.org/

15. "Characterization of Retained Austenite and Carbides in Stainless Steel by Combined EBSD, EDS, and XRD”. Parish, C.; Watkins, T.; Rios, O.; Mackiewicz-Ludtka, G.; Ludtka, G.; Cavin, O. Publication: Microscopy and Microanalysis, vol. 17, issue S2, pp. 410-411.

16. "Microstructural Modification of a Cast Iron by Magnetic Field Processing", E.A. Kenik, G. Mackiewicz-Ludtka , G.M. Ludtka, J.B. Wilgen and R.A. Kisner, Conference Proceedings Microscopy and Microanalysis 2010, Cambridge University Press.

17. "Electron Microscopy Study of Hypo-Stoichiometric Fe-Pd Nanocomposites Resulting from Combined Reaction Thermomechanical Processing", E. D. Cantando, G. M. Ludtka G. Mackiewicz-Ludtka, and W. A. Soffa, 2011, Solid State Phenomenon, v. 172-174, p.356-361. 